\section{RESEARCH ARTICLE \\ 10.1029/2018JE005706 \\ The Deposition and Alteration History of the Northeast Syrtis Major Layered Sulfates}

Key Points:

- The eroded stratigraphy at Northeast Syrtis Major includes meter-scale-layered, sulfate-enriched sedimentary basin deposits up to 600 m thick

- Layer dips $<10^{\circ}$ and topographic high embayment are consistent with deepwater deposition; volume loss fractures indicate diagenetic dewatering

- Strata also including Syrtis Major lavas and fluvio-deltaic phyllosilicates record three fluvio-lacustrine episodes into the early Amazonian

Supporting Information: - Supporting Information S1

Correspondence to:

D. P. Quinn,

davenquinn@caltech.edu

Citation:

Quinn, D. P., \& Ehlmann, B. L. (2019) The deposition and alteration history of the northeast Syrtis Major layered sulfates. Journal of Geophysical Research: Planets, 124, 1743-1782. https://doi.org/10.1029/2018JE005706

Received 13 JUN 2018 Accepted 9 JAN 2019 Accepted article online 10 APR 2019 Published online 10 JUL 2019

(C)2019. The Authors.

This is an open access article under the terms of the Creative Commons Attribution-NonCommercial-NoDerivs License, which permits use and distribution in any medium, provided the original work is properly cited, the use is non-commercial and no modifications or adaptations are made.

\author{
D. P. Quinn ${ }^{1}(\mathbb{D})$ and B. L. Ehlmann ${ }^{1,2}(\mathbb{D}$ \\ ${ }^{1}$ Division of Geological and Planetary Sciences, California Institute of Technology, Pasadena, CA, USA, ${ }^{2}$ Jet Propulsion \\ Laboratory, California Institute of Technology, Pasadena, CA, USA
}

\begin{abstract}
Ancient stratigraphy on Isidis Basin's western margin records the history of water on early Mars. Noachian units are overlain by layered, basaltic composition sedimentary rocks that are enriched in polyhydrated sulfates and capped by more resistant units. The layered sulfates- uniquely exposed at northeast Syrtis Major-comprise a sedimentary sequence up to $600 \mathrm{~m}$ thick that has undergone a multistage history of deposition, alteration, and erosion. Siliciclastic sediments enriched in polyhydrated sulfates are bedded at meter scale and were deposited on slopes up to $10^{\circ}$, embaying and thinning against preexisting Noachian highlands around the Isidis Basin rim. The layered sulfates were modified by volume loss fracturing during diagenesis. Resultant fractures hosted channelized flow and jarosite mineral precipitation to form resistant ridges upon erosion. The structural form of the layered sulfates is consistent with packages of sediment fallen from either atmospheric or aqueous suspension; coupling with substantial diagenetic volume loss may favor deepwater basin sedimentation. After formation, the layered sulfates were capped by a "smooth capping unit" and then eroded to form paleovalleys. Hesperian Syrtis Major lavas were channelized by this paleotopography, capping it in some places and filling it in others. Later fluvial features and phyllosilicate-bearing lacustrine deposits, sharing a regional base level of $\sim-2,300 \mathrm{~m}$, were superimposed on the sulfate-lava stratigraphy. The layered sulfates suggest surface bodies of water and active groundwater upwelling during the Noachian-Hesperian transition. The northeast Syrtis Major stratigraphy records at least four distinct phases of surface and subsurface aqueous activity spanning from late Noachian to early Amazonian time.
\end{abstract}

\section{Introduction}

A major focus of Mars science is deciphering the nature and drivers of changing environmental conditions during the planet's early history. Orbital observations of late Noachian fluvial and alluvial systems (e.g., Andrews-Hanna \& Lewis, 2011; Fassett \& Head, 2005; Irwin et al., 2005; Howard et al., 2005; Schon et al., 2012) and phyllosilicate and carbonate alteration of igneous bedrock by surface and subsurface waters (e.g., Bibring et al., 2006; Ehlmann et al., 2008a, 2011; Mustard et al., 2009; Murchie et al., 2009), as well as in situ examination of lacustrine deposits and groundwater diagenesis by the Opportunity and Curiosity rovers (Grotzinger et al., 2013; Squyres et al., 2004), present powerful evidence of the active role of liquid water on early Mars. From this initial active hydrosphere, the Martian climate underwent a secular drying through the Hesperian period to arrive at the cold, arid environment that prevailed through most of the Amazonian period. However, the timing and character of this global shift are unclear.

The character of environmental change during the Noachian and Hesperian is best constrained by analyses of stratigraphic sections that span portions of this time interval. Stratified sedimentary deposits with hydrated minerals stand out as key environmental records (Ehlmann \& Mustard, 2012; Grotzinger et al., 2012; Gendrin et al., 2005; Milliken et al., 2010; Niles \& Michalski, 2009). The stratigraphy exposed at the northeast margin of the Syrtis Major lavas (Figure 1; NE Syrtis) presents an opportunity to examine environmental change from approximately the early Noachian to the Hesperian, and possibly Amazonian, in a sequence of geologic units whose timing is well constrained. The lower units were emplaced after the Isidis Basin-forming impact around $3.9 \mathrm{Ga}$ (Mangold et al., 2007; Mustard et al., 2007, 2009) and are capped by Hesperian Syrtis Major lavas (Hiesinger \& Head, 2004). The units record a characteristic change in Martian igneous materials, including a transition from low-Ca pyroxene bearing units to high-Ca pyroxene bearing units as well as a high Fo\#, olivine-enriched deposit whose formation is related to the Isidis impact 


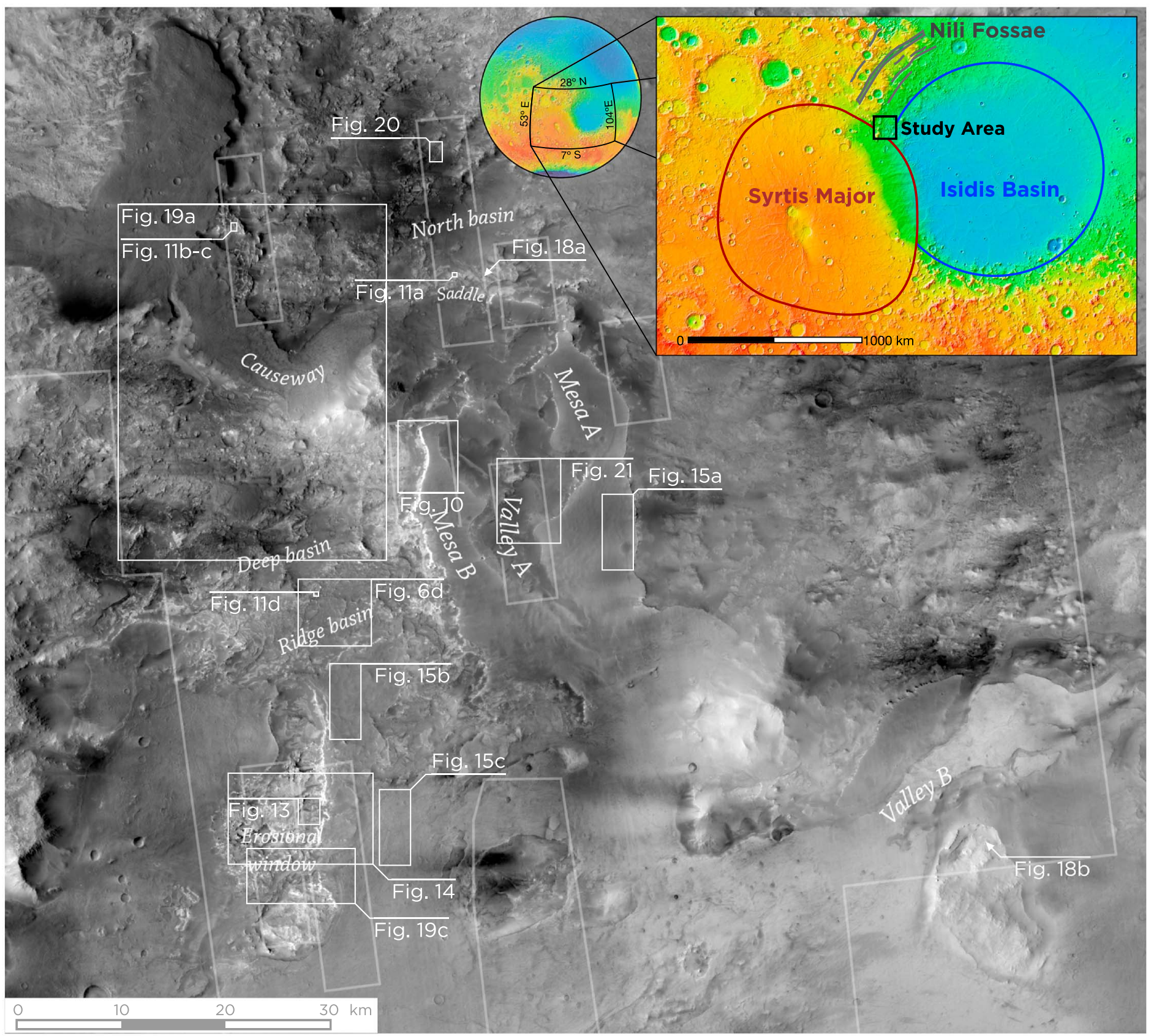

Figure 1. CTX mosaic of the study area showing the location of elevation models and figures referred to in text. The unofficial names used to refer to physiographic features in this study are shown.

(Baratoux et al., 2013; Koeppen \& Hamilton, 2008; Mustard et al., 2005, 2007, 2009). Importantly, the NE Syrtis stratigraphy contains most of the hydrated mineral diversity recognized on Mars in an organized stratigraphic sequence. Layered sulfates with jarosite ridges are superposed over carbonate-bearing units, which are superposed over clay-bearing units (Ehlmann \& Mustard, 2012). This stratigraphic sequence records a transition from neutral-alkaline (clay forming and carbonate forming) to acidic (iron sulfate forming) aqueous environments that corresponds to a global pattern indicating increasing aridity (Bibring et al., 2006). Thus, the mesas of NE Syrtis stratigraphy represent a rare temporally constrained and in-place record of changing hydrological conditions during the Noachian-Hesperian transition.

The thick-layered sedimentary sulfates represent a major change in formation style from the impact and volcanically emplaced units dominating the rest of the stratigraphy (Bramble et al., 2017; Ehlmann \& 


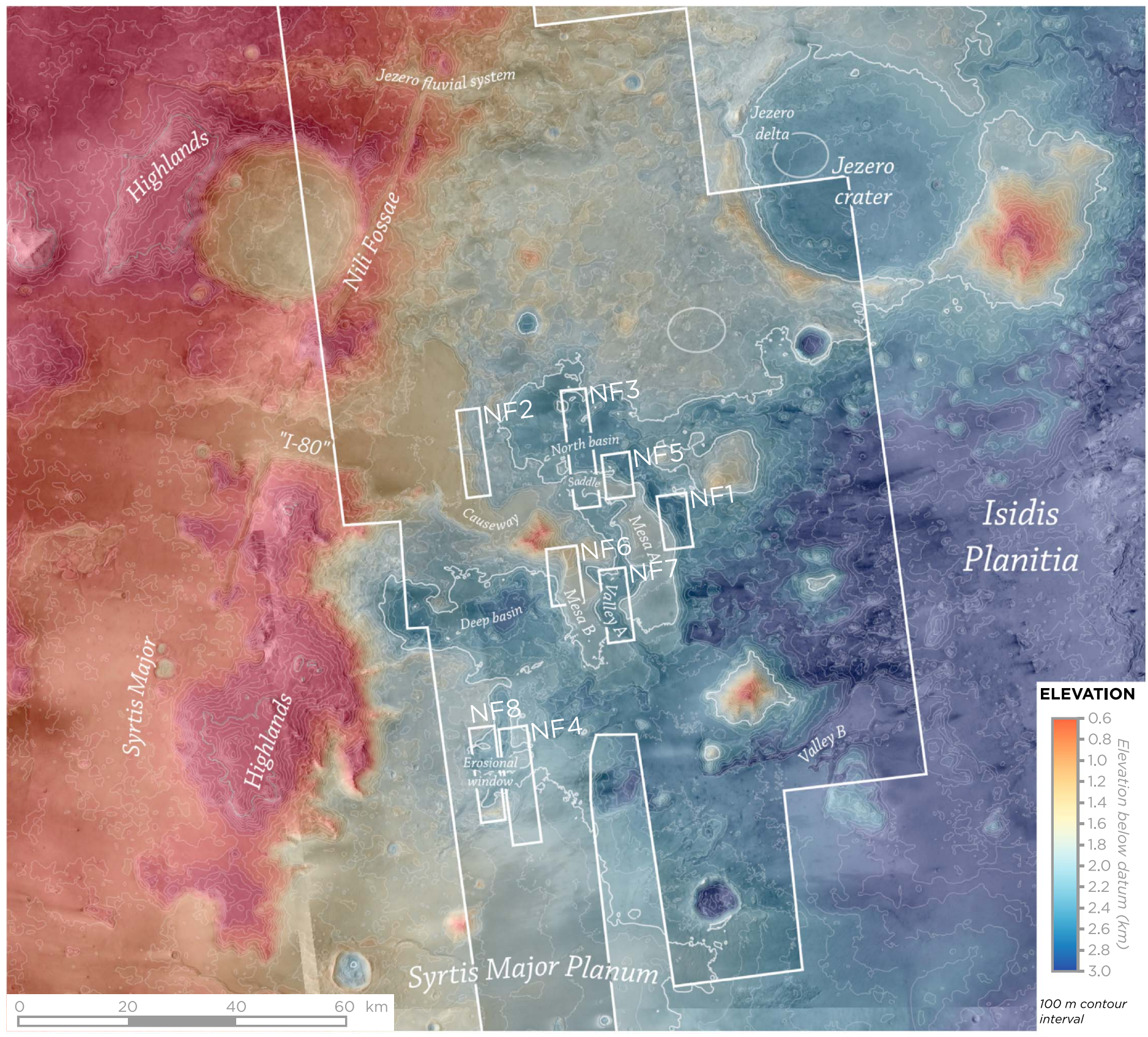

Figure 2. Context map of the NE Syrtis region. The white outlines nf $1-n f 8$ and the larger regional outline show the nine elevation data sets prepared for the study using HiRISE and CTX stereo images, respectively (Table 1). A CTX mosaic basemap is color shaded by elevation to show the broad topographic context of NE Syrtis. For elevation shading, our study-created elevation models are supplemented by High Resolution Stereo Camera (HRSC) elevation models outside the study area. The names of major physiographic features, including unofficial names assigned in this study, are shown. The working landing ellipses for the Jezero and NE Syrtis landing sites (as of late 2017) are also shown.

Mustard, 2012). The lower Noachian clay and carbonate units, exposed regionally to the north over an area spanning hundreds of thousands of square kilometers, have been well studied by prior workers (e.g., Ehlmann et al., 2009; Ehlmann \& Edwards, 2014; Mangold et al., 2007; Mustard et al., 2009; Michalski et al., 2010; Viviano-Beck et al., 2014). However, only the basics of sulfate mineralogy (polyhydrated sulfates and jarosite), texture (ridged and layered), and stratigraphic position have been previously reported (Ehlmann \& Mustard, 2012). What is the extent of this sulfate unit? How did it form? What controls the layering, ridges, and specific sulfate mineralogy? These questions hold particular significance because at the time of this 
Table 1

HiRISE and CTX Scenes Used in Elevation Models

\begin{tabular}{|c|c|c|c|c|}
\hline ID & Nadir & Oblique & $\mathrm{CA}^{\mathrm{a}}\left({ }^{\circ}\right)$ & $\mathrm{EP}^{\mathrm{b}}(\mathrm{m})$ \\
\hline \multicolumn{5}{|c|}{ HiRISE } \\
\hline NF1 & PSP_009217_1975 & ESP_027625_1975 & 18.4 & 0.15 \\
\hline NF2 & ESP_018065_1975 & ESP_019133_1975 & 22.5 & 0.12 \\
\hline NF3 & ESP_026280_1975 & ESP_027902_1975 & 13.0 & 0.21 \\
\hline NF4 & PSP_002809_1965 & PSP_006000_1965 & 24.9 & 0.11 \\
\hline NF5 & ESP_013041_1975 & ESP_030025_1975 & 17.3 & 0.16 \\
\hline NF6 & ESP_021612_1975 & ESP_021757_1975 & 11.8 & 0.24 \\
\hline NF7 & ESP_027269_1970 & ESP_042671_1970 & 21.3 & 0.13 \\
\hline NF8 & ESP_047194_1965 & ESP_046983_1965 & 12.9 & 0.22 \\
\hline \multicolumn{5}{|c|}{ CTX (single multistrip elevation model) } \\
\hline \multirow{10}{*}{-} & G21_026280_1976 & D02_027902_1975 & 13.2 & 5.1 \\
\hline & B01_010206_1975 & B03_010628_1974 & 15.7 & 4.3 \\
\hline & Same as above & G02_019133_1977 & 13.5 & 5.0 \\
\hline & G09_021612_1972 & G09_021757_1972 & 11.9 & 5.7 \\
\hline & B18_016720_1978 & B18_016786_1978 & 22.0 & 3.0 \\
\hline & B19_016931_1975 & B19_017076_1975 & 14.0 & 4.8 \\
\hline & D14_032504_1996 & D14_032649_1996 & 14.8 & 4.5 \\
\hline & P15_006778_2002 & D17_033849_2002 & 22.9 & 2.8 \\
\hline & D14_032715_1995 & D15_033137_1996 & 20.2 & 3.3 \\
\hline & G11_022680_1976 & G12_022746_1976 & 23.2 & 2.8 \\
\hline- & P05_002809_1975 & P13_006000_1974 & 24.8 & 2.6 \\
\hline
\end{tabular}

writing, the NE Syrtis landing site is under consideration by the Mars 2020 rover mission, and the sulfates and Syrtis Major lavas are the key extended mission target.

In this paper, we examine the structural geology of the layered sulfates at NE Syrtis to determine their emplacement mechanism. We comprehensively map the sulfate unit's extent, thickness, bedding characteristics, ridge characteristics, and mineralogy. We further examine the contact relationships with units above and below, evaluate the capping materials, and determine the temporal relationship with regional fluvial features. We then evaluate these observations of the NE Syrtis Major layered sulfates critically against the range of possible formation mechanisms and propose a multistage formation and modification history that implies a significant role for water on the surface of Mars over a long period of time.

\section{Geologic Context}

\subsection{Physiography}

The study area is situated on the western rim of Isidis Basin, about $40 \mathrm{~km}$ southwest of Jezero crater and along the northeastern margin of the Syrtis Major volcanic province (Figures 1 and 2). The layered sulfates are exposed just inside the sharp topographic inflection that marks the 1,100-km diameter inner ring of Isidis Basin, as defined by Mustard et al. (2007), based on the concentric tectonic expressions of post-Isidis faulting that comprise the Nili Fossae (Ritzer \& Hauck, 2009; Wichman \& Schultz, 1989).

Broadly, both the Syrtis Major lavas south of the study area and the bedrock peneplain of Noachian units extending north of the study area gently slope into Isidis Basin. East of the study area, elevations decline into the knobby plains of Isidis Basin and the Vastitas Borealis formation (Ivanov \& Head, 2003; Ivanov et al., 2012).

In contrast, the study area itself contains a relatively abrupt topographic step from highland units at -0.5 to $0 \mathrm{~km}$, which define the inner ring of Isidis Basin, to flat-bottomed valleys with floors at less than $-2.5 \mathrm{~km}$ 


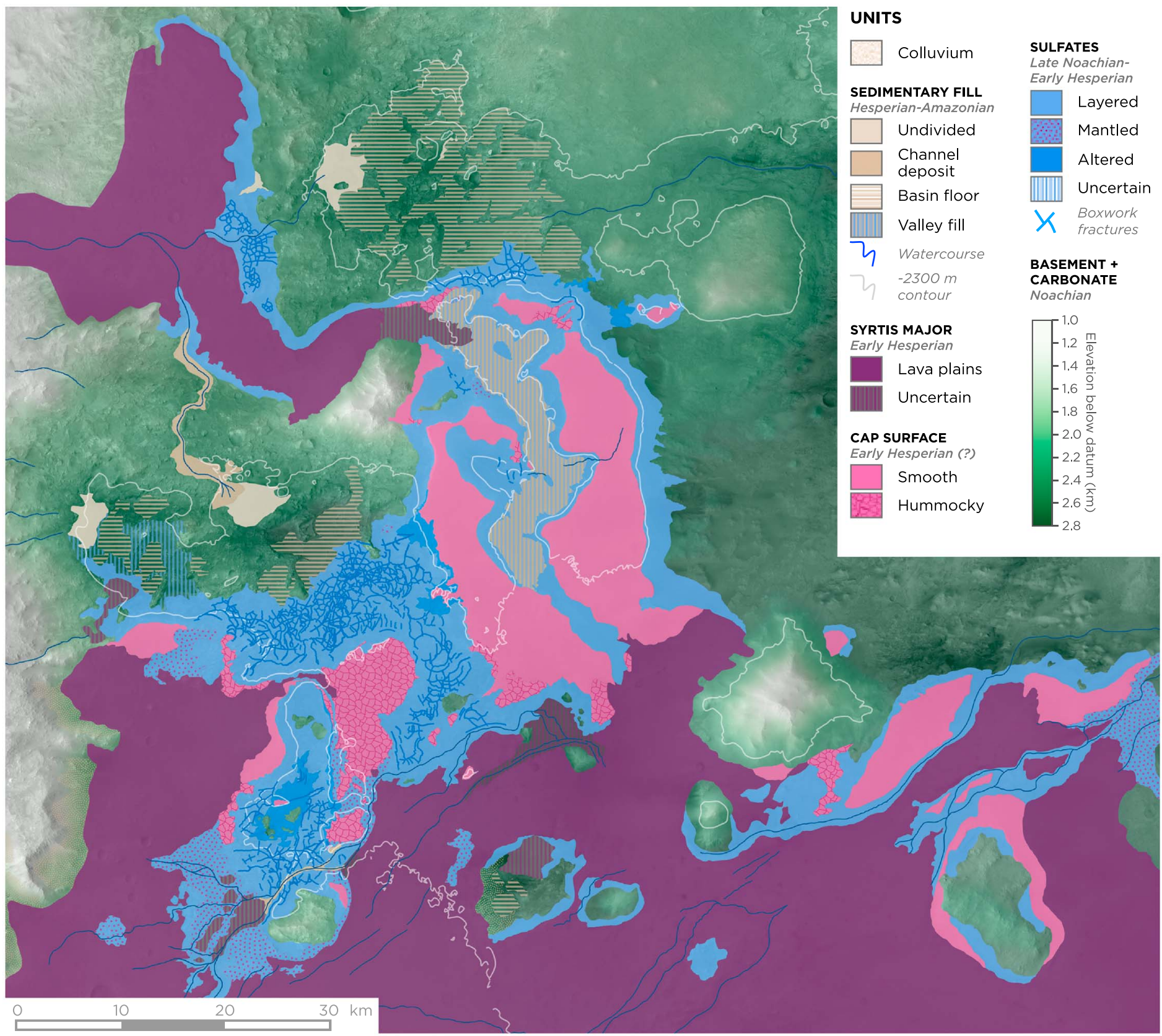

Figure 3. Geologic map of the layered sulfates, Syrtis Major lavas, and capping and sedimentary units discussed in this study. This map compliments that of Bramble et al. (2017), which focuses on basement morphologic units in the Northeast Syrtis plains, just to the north of this map area. Here the basement and olivine-carbonate unit of the northeast Syrtis regional stratigraphy are undivided, while sulfates, capping materials, and Hesperian/Amazonian sedimentary deposits are detailed.

on the Mars Orbiter Laser Altimeter (MOLA) datum (North Basin and Deep Basin in Figure 2). The valleys are bounded by exposures of highland crust that form mountains up to $1.5 \mathrm{~km}$ higher than the surrounding terrain. The degree of east-west topographic variation within the study area contrasts with smooth east-west slopes into the Isidis Basin to the north and south. The steep basin rim in our study area could be inherited from basin formation or modified by valley erosion. A major valley cutting across the innermost Nili Fossae graben and Isidis Basin rim (Figure 2; nicknamed "I-80" in Harvey \& Griswold, 2010) channelizes distal Syrtis Major lavas in the northwest portion of the study area. Southeast of the study area, a topographic scarp at $\sim-3.5 \mathrm{~km}$ is cut into the outer edge of the Syrtis Major lavas. This scarp continues southward and 


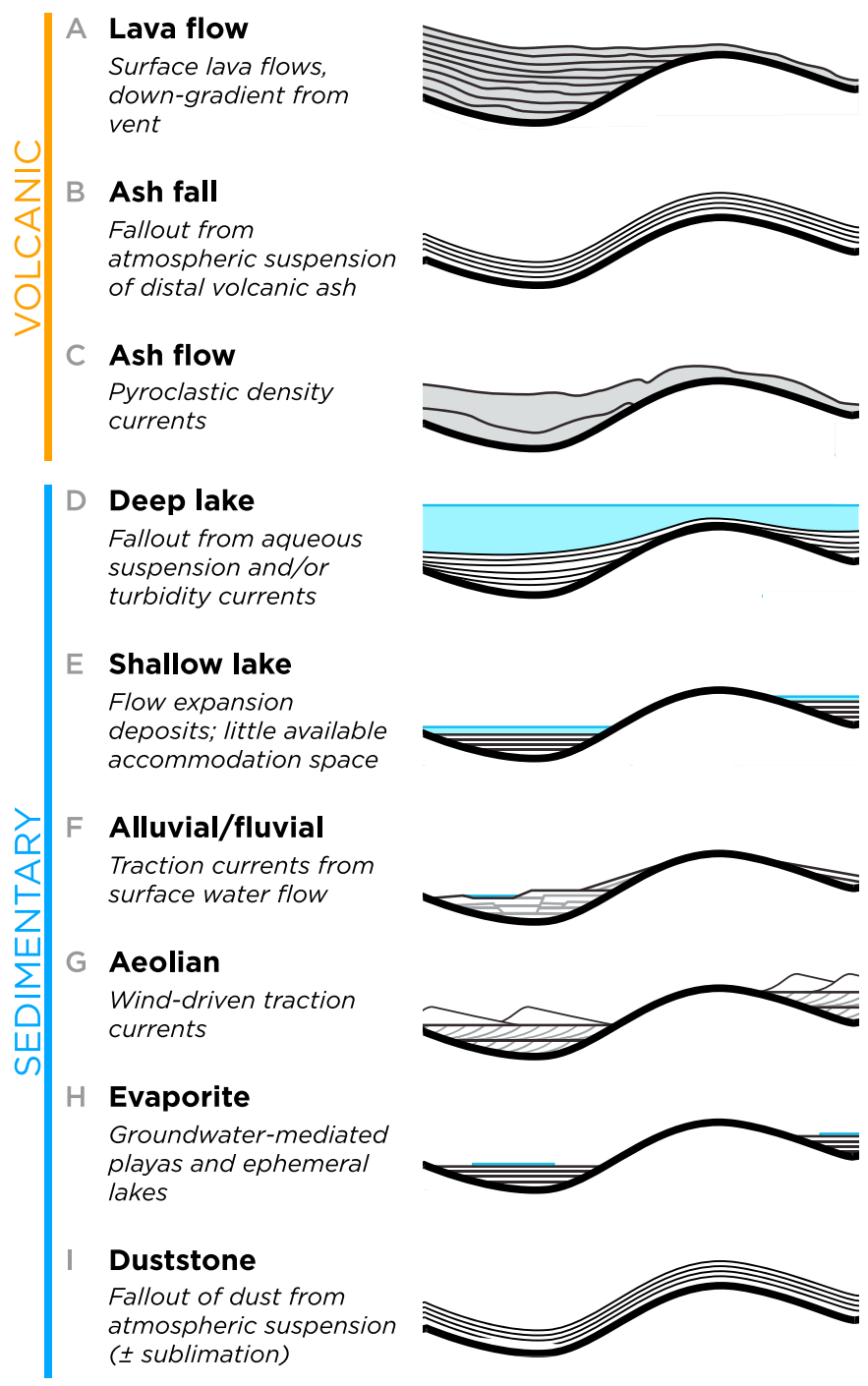

Figure 4. A graphical summary of depositional settings proposed for layered deposits on Mars, with applicability to the layered sulfates. Each potential mechanism varies in the structure and style of bedding predicted, which can be diagnostic of the unit's original form. represents erosional modification of the basinward edge of the Syrtis Major volcanic province (Ivanov \& Head, 2003).

\subsection{The Northeast Syrtis Noachian Plains}

We will refer to the bedrock peneplain of Noachian units within the study area as the NE Syrtis plains. The NE Syrtis plains are the lowest exposed stratigraphic units and consist of two lithologic units. A low calcium pyroxene and Fe/Mg phyllosilicate-enriched bedrock (the "basement") comprises the lowermost unit. The phyllosilicate-bearing hydrated basement contains exposures of megabreccia that were formed and/or modified by the Isidis Basin-forming impact (Mustard et al., 2009), which occurred in the Early to Middle Noachian (Frey, 2008; Werner, 2008). The basement is unconformably overlain by a later-emplaced, olivine-enriched unit partially altered to carbonate (Ehlmann et al., 2008a, 2009; Hoefen et al., 2003; Hamilton \& Christensen, 2005; Koeppen \& Hamilton, 2008; Mangold et al., 2007; Mustard et al., 2007, 2009). Both of these units are determined to be Noachian in age because they are disrupted by tectonics associated with the opening of the Nili Fossae graben (shortly after Isidis; Wichman \& Schultz, 1989) and are dissected by Noachian-aged valley networks, including the Jezero valley system (Ehlmann et al., 2008b, Fassett \& Head, 2005, 2008; Goudge et al., 2015; Mangold et al., 2007; Schon et al., 2012). These Noachian units extend over more than $100,000 \mathrm{~km}^{2}$ in the northwest part of Isidis Basin.

Bramble et al. (2017) completed a geomorphic mapping study of the beveled NE Syrtis plains directly to the north of the study area (in the area of interest for the candidate Mars 2020 landing site), focusing on relationships between the Nili Fossae basement, olivine-carbonate unit, and overlying capping mesas. Though these two units in the NE Syrtis plains are clearly distinct and well resolved from orbital mapping, this study treats them collectively as "Noachian Plains" units stratigraphically below the sulfates.

\subsection{Layered Sulfates}

The geologic features targeted by this study are layered basaltic composition materials enriched in polyhydrated sulfates relative to other materials. These sulfate-bearing layered deposits are referred to as the "layered sulfates." The unit is preserved and exposed only within this study area, at the NE margin of the Syrtis Major lava flows; it unconformably overlies the Noachian plains units (Ehlmann \& Mustard, 2012). The sulfates are layered at meter scale, thick ( $>300 \mathrm{~m}$ in several places), and exposed recessively beneath a cliff-forming capping unit(s), previously interpreted to be the Syrtis Major lavas. These layered domains have mineral signatures of polyhydrated sulfates. In parts of the region, the sulfates are cut by a boxwork of polygonal raised ridges, which show near-infrared spectral signatures of jarosite, signifying acidic $(\mathrm{pH}<4)$ aqueous conditions and a distinctive change relative to the clay and carbonate minerals formed earlier in the NE Syrtis plains (Ehlmann \& Mustard, 2012). The sulfates are exposed at the southeast margin of the area mapped by Bramble et al. (2017; their feature-bearing slope and raised boxwork ridges). The formation of these layered sulfates and their modification by subsequent events are the focus of this work (Figure 3).

\subsection{The Syrtis Major Lavas}

To the south, the Isidis rim is covered by the Syrtis Major volcanic province, a $\sim 1,100 \mathrm{~km}(\mathrm{E}-\mathrm{W})$ region of effusive lava flows averaging $~ 500 \mathrm{~m}$ thick (Hiesinger \& Head, 2004) which extends eastward into Isidis Basin. Syrtis Major lava flows are sourced in the vicinity of Nili Patera and Meroe Patera near $8^{\circ} \mathrm{N}, 67^{\circ} \mathrm{E}$ (Fawdon et al., 2015) and descend westward into Isidis Basin, extensively blanketing its rim to the south of the study area (Ivanov et al., 2012). The Syrtis Major edifice has been dated to the early Hesperian by crater counting, with model ages ranging from $3.4 \mathrm{Ga}$ (Skok et al., 2010) to 3.6 Ga (Hiesinger \& Head, 2004). The 
Syrtis Major lava flows are enriched in high-Ca pyroxene and distinct from the low-Ca pyroxene basement (Baratoux et al., 2007; Clenet et al., 2013; Skok et al., 2010), but in contrast to the Noachian plains to the north, no crystalline hydrous minerals are seen in orbital infrared imagery of the Syrtis Major lavas.

The Syrtis Major lavas are the stratigraphically highest unit in portions of our study area, and their relatively unaltered character suggests that they postdate pervasive aqueous alteration in the region. Nevertheless, the margin is eroded by numerous fluvial channels and valleys that point to Hesperian and/or Amazonian surface waters, at least episodically after lava emplacement. Mangold et al. (2008a) identified outflow channels inscribed on the surface of the Syrtis Major lava flows near the southern margin of the study area, where canyons and channels are cut into the edge of the Syrtis Major lava plains. These form an outflow system originating west of the study area and flowing south and east toward Isidis Basin, demonstrating hydrologic systems postdating the emplacement of the Syrtis Major sequence.

\section{Methods}

\subsection{Conceptual Approach: Formation Mechanisms for the Layered Sulfates}

The polyhydrated sulfates within the layered sulfate unit are not indicative of specific aqueous geochemical conditions (Ehlmann \& Mustard, 2012), and jarosite within the ridges indicates only precipitation from acidic waters (Ehlmann \& Mustard, 2012; Papike et al., 2006). Precipitation of sulfate minerals can occur both subaerially during evaporitic deposition (e.g., Hurowitz et al., 2010) and during "alteration" by circulating groundwater, either by bulk reaction or pore-occluding cementation (e.g., Siebach \& Grotzinger, 2014). Consequently, both polyhydrated sulfates and jarosite-bearing ridges may record an alteration signature and do not uniquely define the original depositional environment for these sulfate-bearing sediments.

Examination of physical characteristics of the layered sulfates provides a separate set of metrics for use to understand the formation and evolution of the unit. A wide range of potential mechanisms has been invoked for the deposition of layered rocks on Mars (Grotzinger \& Milliken, 2012), each of which possesses distinctive structural characteristics that are potentially observable at orbital scale (Figure 4).

Volcanic origin scenarios such as lava flows, ash flows, and ash falls have been proposed for layered deposits elsewhere on Mars (e.g., Kerber et al., 2012; McCollom et al., 2013). These emplacement mechanisms do not require abundant surface water; their potential alteration to sulfates could be enhanced by the circulation of volcanic hydrothermal fluids (e.g., Kaasalainen \& Stefánsson, 2011). Lava and ash deposits are typically thick and internally jointed (Bondre et al., 2004), and lavas are usually erosionally resistant.

Layered sedimentary sulfate deposits can form by the primary precipitation of evaporites, such as in playa environments. Alternatively, layered sediments can arise from a variety of physical sediment transport mechanisms, implying a wide range of depositional settings. Processes such as fluvial, shallow lacustrine, and aeolian sedimentation are dominated by sediment traction; in arid environments, their deposits are often found together and along with evaporites (Al-Masrahy \& Mountney, 2015). On Mars, rover (e.g., Grotzinger et al., 2015; McLennan et al., 2005) and orbital (Milliken et al., 2014) studies indicate the presence of sulfates in lacustrine, evaporite playa, and eolian deposits. The fallout of sediment from suspension forms a distinct set of deposits. Loess sedimentation implies the fallout of particles from aerial suspension, similar to distal ash fall (e.g., Smalley, 1966); "duststones" formed by this process are found on Mars (Bridges \& Muhs, 2012; Lewis et al., 2008). Alternatively, icy particles deposited from aerial suspension could form sublimation residues (Michalski \& Niles, 2012). Deep lacustrine sedimentation is dominated by sediment density currents and fallout from aqueous suspension (e.g., Stow \& Piper, 1984). The different geological processes that could form the layered sulfates imply radically different surface environments and water budgets at the time of emplacement.

Contact relationships and bedding orientations are key measures of the internal geometry of sedimentary sequences that distinguish depositional processes and their timing. Certain types of sedimentary sequences have characteristic limitations on the distribution of bedding orientations (i.e., strike and dip) imposed by their depositional process. Other important criteria include the assessment of sedimentary onlap and downlap onto preexisting surfaces versus bedding entirely concordant or draping topographic highs. Traction-current sediments typically form near-flat layers and onlap preexisting topography as they aggrade, while fallout of suspended sediment (e.g., ash falls, duststones, and deep lacustrine sediments) form draping, concordant layers. Subaqueous basin margin sedimentation occupies an intermediate case, where dipping sediments are emplaced by both density currents and fallout from suspension; these sedi- 
ments are sometimes base concordant but often thin over,onlap, and in some cases embay basement highs (Mitchum et al., 1977).

In this work, we attempt to determine the formation mechanism and postdepositional history of the layered sulfate unit primarily from its structural characteristics.

\subsection{Digital Elevation Models and Data Set Registration}

Images from the HiRISE instrument on the Mars Reconnaissance Orbiter (McEwen et al., 2007) were acquired covering key parts of the study area. Overlapping pairs of images were acquired with one near nadir and one oblique image for stereo convergence angles of $15-30^{\circ}$ (Table 1 ). These stereo pairs were processed using standard pipelines, and digital elevation models (DEMs) were created in the SOCET SET software using the techniques described in Kirk et al. (2008). In this pipeline, the stereo images are individually photometrically corrected and horizontally and vertically controlled to the MOLA datum. MOLA shot data are used to correct the elevation of ground control points, and the gridded MOLA DEM is used to anchor the DEM solution. In total, eight HiRISE stereo models were constructed, typically covering $5 \times 10$ - to 20 -km areas of the surface in overlapping HiRISE scenes at a ground sample spacing of $1 \mathrm{~m} /$ pixel. Relative vertical accuracy is $\sim 0.25 \mathrm{~m}$ in textured areas of the scenes (based on the "expected precision" metric of Kirk et al., 2003, and their estimate of 0.2 pixel typical image registration accuracy within SOCET Set). The resulting elevation models were used to create $0.25 \mathrm{~m} /$ pixel orthorectified images aligned exactly to the DEM.

In addition to the HiRISE DEMs, a single CTX DEM covering the entire study area was constructed using 21 images from 11 overlapping stereo pairs. The data set was prepared in SOCET SET using methods that closely followed the procedures used for HiRISE. The resulting DEM has a $10 \mathrm{~m} /$ pixel horizontal scale and 5-20 m vertical fidelity, varying based on the specific stereo pair.

The scale gap between HiRISE and MOLA can produce systematic bias when MOLA data are sparsely sampled, especially in the presence of N-S (along-track) sloping topography. Our CTX DEM is not susceptible to such bias due to its much larger coverage area, allowing its use as an external check on the whole image tilt of the HiRISE DEMs. Elevation models $n f 1, n f 2$, and $n f 4$ had negligible slope, but $n f 3$ and $n f 5$ at the northern margin of the study area had artificial southward slopes of $\sim 0.25^{\circ}$ and $0.38^{\circ}$, respectively, corresponding to elevation differences of 30-100 m within North Basin relative to CTX. HiRISE elevation models $n f 6-n f 8$ were explicitly controlled to the CTX DEM during creation, removing this source of error. These small tilts do not significantly impact the dip magnitudes measured in this study, but they do limit the precision with which true horizontality can be recovered.

The internal quality of stereo DEMs varies based on the stereo convergence angle between scenes. Also, image-matching algorithms perform better on areas with fine-scale surface features. In general, DEM quality is much higher in areas with significant slopes and high local contrast. DEM errors are summarized by the "Figure of Merit" data set produced by SOCET SET. Errors can additionally be visually inspected using contour lines (following procedures described by Kirk et al., 2003). Areas with errors were avoided for our quantitative analyses, but all areas have sufficient data quality for 3-D visualization. The CTX DEM suffers from noise for images with low contrast or poor stereo separation. This manifests as noisy, discontinuous contours and uneven topography in 3-D model views. The poorer results of this registration are propagated through our elevation models, yielding large error ellipses on some CTX-derived bedding poles (see, e.g., section 3.4).

Each topographic data set (consisting of a DEM, quality metrics, and aligned orthoimages) is warped to a transverse mercator projection centered on $76.5^{\circ}$ to retain angular conformality and approximate true scale over the study area. The data sets were coregistered using significant shared landmarks to build a unified geodetic framework tied to regional CTX imagery. The result is a network of aligned images forming a regionally consistent basemap of the study areas. Other imagery data sets, such as thermal inertia, imaging spectrometer, and nonstereo HiRISE images, were aligned to this framework.

The DEM and imagery basemap was integrated into a 3-D computer vision system with a NVIDIA 3-D Vision system used for stereo display. HiRISE and CTX stereo pairs were examined in their original viewing geometry using SOCET Set photogrammetry software, and synthetic stereo reconstructions (e.g., Figure 6a) were created using the OSGEarth 3-D toolkit to examine the region from arbitrary oblique viewpoints. 


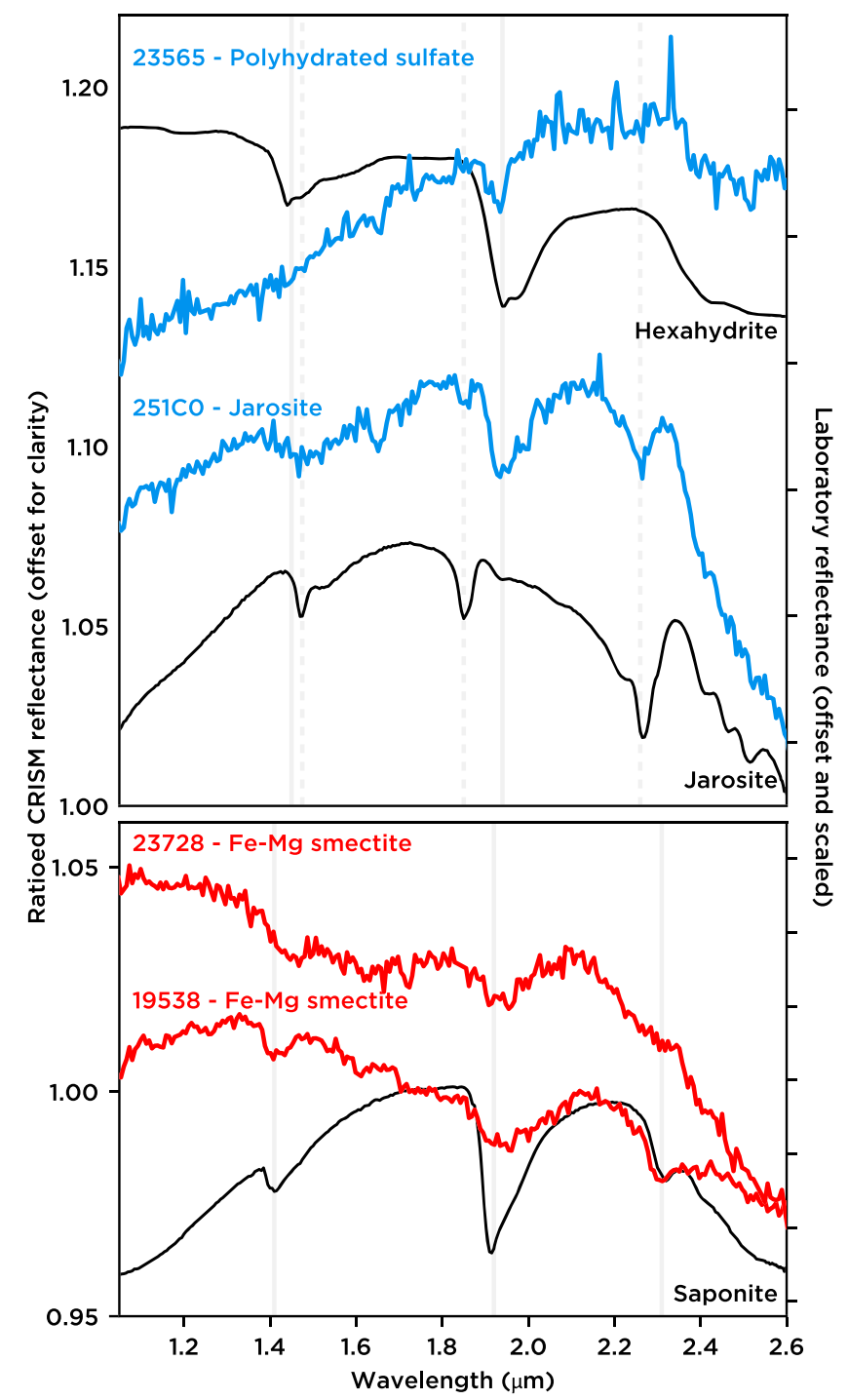

Figure 5. Examples of Compact Reconnaissance Imaging Spectrometer for Mars spectra used to verify new mapping of the layered sulfates and surrounding units at several locations within the study area. Compact Reconnaissance Imaging Spectrometer for Mars scenes are identified by five-digit ID, and mineral identification is shown. Laboratory reflectance spectra shown for comparison are from Brown RELAB, available at http:// psf.uwinnipeg.ca/Sample_Database/. The top panel shows sulfate identifications and characteristic absorptions for polyhydrated sulfates (solid) and jarosite (dotted) that are shown as vertical lines. The lower panel shows smectite clay identifications in late sedimentary deposits (section 4.5.3), with characteristic absorptions for smectite clay shown as vertical lines.

\subsection{Regional Mapping}

The morphological character of the layered sulfates and surrounding units was evaluated in detail within the eight HiRISE stereo pairs used in the project, and their local character was correlated with larger-scale features visible in CTX orthoimages. Regional mapping across all images focused primarily on the internal character of the layered sulfates and on the nature of capping units. Map units were identified based on their morphological characteristics, and small-scale features from HiRISE scenes were extrapolated into CTX data. Morphological identification of map units is augmented by Compact Reconnaissance Imaging Spectrometer for Mars (CRISM) hyperspectral data (Murchie et al., 2007). In areas with available CRISM coverage, morphological mapping was cross-correlated with spectral data for verification. Spectra were ratioed to relatively featureless terrains to accentuate the compositional differences in the area of interest. These ratioed spectra were classified broadly into spectral types. The sulfate units have characteristic absorptions for jarosite and polyhydrated sulfates (Figure 5).

Contacts between map units, morphological features indicative of channels, and over $850 \mathrm{~km}$ of boxwork fractures were mapped. Within the layered sulfates, surface traces of bedding were captured for the structural interpretation of the layered sulfates. Polygonal swatches of surficial units were captured to estimate the orientation of unit surfaces. Mapped contacts were correlated with the topographic data set to create elevation constraints on the top and bottom of the layered sulfates, which can be interpolated throughout the study area to form a 3-D structural model of the layered sulfates before large-scale erosion of the unit.

\subsection{Orientation Measurements}

To understand stratal relationships, bedding orientations are typically evaluated alongside outcrop-scale observations of angular relationships along a contact. However, where the contact is obscured (as is often the case in remote sensing), the local nature of the contact between sedimentary packages must be assessed using bedding orientation differences observed in portions of units in isolation. This approach has been employed since the advent of seismic stratigraphy (Mitchum et al., 1977), including on Mars. For instance, angular relationships and approximate unit bounding surfaces have led to the identification of downlap surfaces associated with prograding sedimentation in the nearby Jezero Crater deltaic system (Goudge et al., 2017; Schon et al., 2012) and other deltas on Mars (DiBiase et al., 2013; Lewis \& Aharonson, 2006).

In order to compare structural data collected from differently oriented hillslopes and DEMs with different levels of inherent accuracy in the NE Syrtis sulfates and capping units, we have developed a new statistical approach and software pipeline for making orientation measurements in the presence of errors. This technique is described in detail in Quinn and Ehlmann (2019). In brief, we use principal components regression to fit planes to DEM data points, form error distributions for planar estimates, and convert these errors to major axis and minor axis error bounds in spherical coordinates. These errors are hyperbolic error bounds on a nominal plane or ellipsoidal error bounds around the normal vector to the plane. This new technique allows us to build a regional database of comparable bedding orientation measurements of geologic units with statistically rigorous error bars to assess the quality of calculated strikes and dips. Uncertainties are higher for CTX than HiRISE, reflecting high levels of noise in low-relief areas and between poorly registered image pairs in the CTX DEM.

Within individual images, several techniques were used to find the local orientations of geologic units at high resolution. In several cases, beds could be traced and evaluated individually. In other cases, individual bed- 


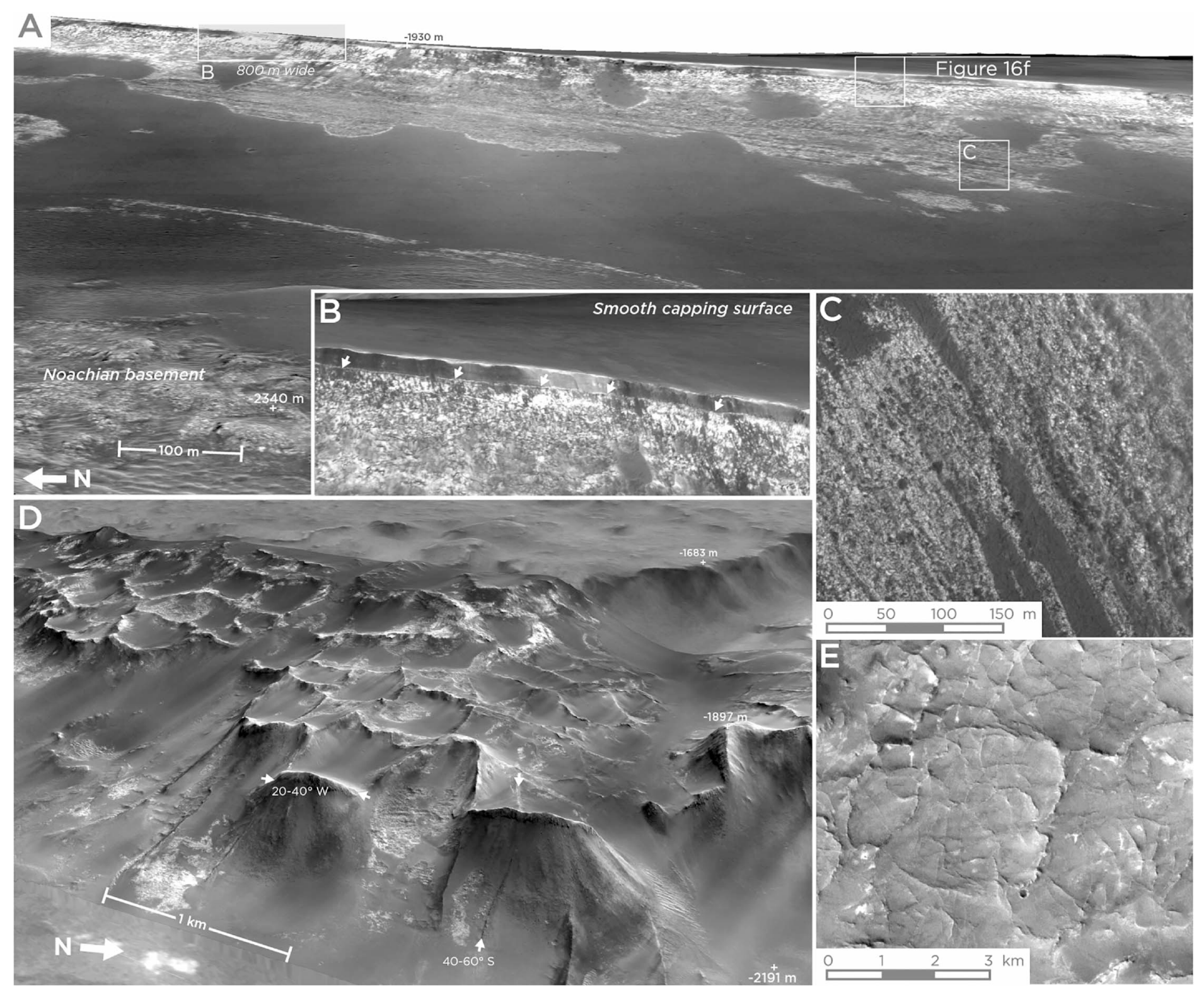

Figure 6. Examples of key morphologies of the layered sulfates. (a) HiRISE stereo (nf6) perspective image of a 2.7-km segment of the west face of Mesa B (no vertical exaggeration), showing a 400-m-thick stratigraphy of layered sulfates beneath the "smooth capping surface." The beds in this stratigraphy dip consistently at $\sim 7^{\circ}$ to the southwest (Figure 11). (b) Oblique view (two times vertical exaggeration) of an 800-m segment of the bright top contact of the layered sulfates beneath the darker smooth capping surface. Arrows show truncations of bedding by the contact. (c) Plan view image of typical bedding features in the layered sulfates. (d) HiRISE stereo (nf2) perspective image of boxwork polygons, which cover large parts of the study area and have a characteristic scale of $\sim 500 \mathrm{~m}$ on a side. The approximate dips (within error) of several relatively planar boxwork fracture segments are shown. (e) CTX map view of boxwork ridge network in the Ridge Basin area of the unit.

ding traces do not form a 3-D exposure adequate to capture a unique bedding orientation. To mitigate this, closely spaced individual measurements were grouped under the assumption of parallel bedding within the same stratigraphy. The resulting jointly fitted orientation was tested against the residuals of each measured plane. Groupings with low out-of-plane variation are accepted as likely representative of the true dips of a consistent package of beds. An additional method used for several resistant units primarily exposed at the surface is the measurement of slopes of the current topographic surface. Absent differential erosion, which would impart tilt, surface orientations, can be examined alongside outcrop-traced bedding measurements. 


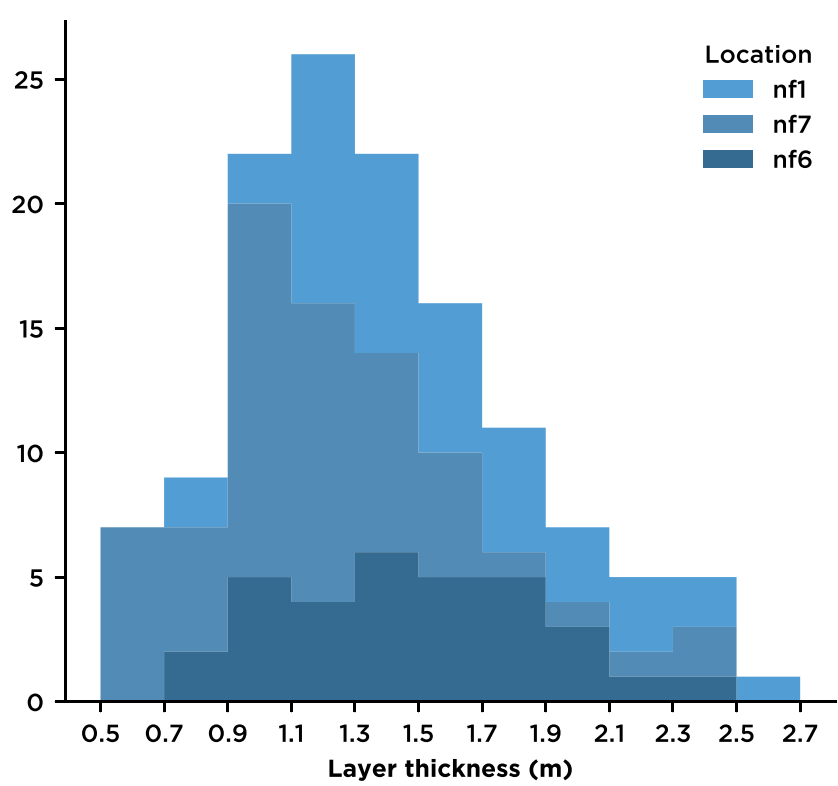

Figure 7. Histogram of layer thicknesses measured for the layered sulfates in three HiRISE scenes with well-exposed, consistently dipping beds, with a mean of $1.38 \mathrm{~m}$ and a standard deviation of $0.44 \mathrm{~m}$ for 131 layer thicknesses. A single sequence of beds was measured within each image using the method shown in Lewis et al. (2008); dip corrections of $4.0^{\circ}$ for $\mathrm{nf} 1,6.9^{\circ}$ for $\mathrm{nf} 6$, and $3.5^{\circ}$ for $\mathrm{nf} 7$ were applied. Locations of measured beds in $\mathrm{nf} 6$ are shown in Figure 11.

\section{Results}

4.1. The Layered Sulfates

4.1.1. Basic Morphological and Mineralogical Characteristics

The general character of the layered sulfates has been reported in previous investigations (Ehlmann \& Mustard, 2012) and was used along with CRISM to map their full extent in the CTX and HiRISE basemaps. The sulfates are light-toned where exposed, exhibiting a polyhydrated sulfate infrared spectral properties and continuous, meter thick bedding. Layers can be followed for several kilometers in a few cases (Figure 6a) but are often obscured by dark debris. Layers identified in HiRISE are tightly distributed around a mean thickness of $1.4 \mathrm{~m}$ (range: 0.5 to 2.7 $\mathrm{m}$; Figure 7); these layers may package finer-scale lamination at below HiRISE scale.

The layered sulfates have been eroded to their present form by fluvial activity (section 4.5), and capping units and postdepositional alteration appear essential for their preservation. The layered sulfates are recessive in general and are only preserved where beneath more resistant caprock or buttressed by polygonal ridges, forming slopes otherwise. Locally, ridged (Figure 6c) regions of the layered sulfates show strong signatures of jarosite mineralogy (as previously reported for selected locations in Ehlmann \& Mustard, 2012) and are more resistant to erosion. We have also found jarosite in a horizon with localized pervasively altered sulfate that appears texturally distinct (section 4.3). Craters are not generally preserved in the sulfate unit, potentially because the surface of the unit is continuously refreshed by scarp retreat.

\subsubsection{Extent}

The layered sulfates are exposed over $\sim 100 \mathrm{~km}$ east-west along the transition zone between the Syrtis Major lava flows and the Noachian Plains. They extend from $\sim 74^{\circ} \mathrm{E}$ to $76^{\circ} \mathrm{E}$ and $\sim 14^{\circ} \mathrm{N}$ to $16^{\circ} \mathrm{N}$. Their northern boundary can be mapped, but the southern boundary is not fully characterized, as it lies beneath the Syrtis Major lava flows. The southernmost well-characterized exposure is within an Erosional Window at $74^{\circ} \mathrm{E}, 14^{\circ} \mathrm{N}$. The layered sulfates range in elevation from $-1,600$ to $-2,800 \mathrm{~m}$ at their southeastern eroded margin. The highest exposures of the layered sulfates broadly coincide with the elevation of the regional topographic step that defines the inner ring of Isidis Basin.

We construct a 3-D model of the layered sulfates using simple structural rules constrained by mapping data. First, observed contacts between the layered sulfates and other map units provide direct elevation constraints on the top and bottom boundaries of the layered sulfates (Figure 8a). Contacts with the Syrtis Major lavas and other capping units represent the top surface of the sulfates, and contacts with the NE Syrtis plains units form its base. In select locations, both contacts are exposed in close proximity, allowing a direct measurement of thickness. Unconformities where a capping surface instead directly meets the NE Syrtis plains constrain both the top and bottom surfaces of the sulfates, that is, indicating places where they are absent. Additional constraints on the bottom surface of the sulfates are imposed in some covered areas to improve the smoothness of the overall result and mitigate the shallowing bias on the sulfates imparted by contacts on localized Noachian basement highs.

Second, the interpolated surfaces are constructed using kriging, a statistical procedure commonly used for interpolating geological surfaces (e.g., Caumon et al., 2009; Oliver \& Webster, 1990). The kriging model is implemented on a 200-m grid using the Python program PyKrige. Separate kriged surfaces for the top and bottom of the layered sulfate are interpolated beneath present topography and projected into space to model the extent of the layered sulfates in areas they likely occupied in the past but were since eroded. The uncertainty of each surface is calculated based on the RMS distance to the nearest control point.

The interpolated structural surfaces provide key limits on the regional form and thickness of the layered sulfates. The sulfates form a thick regional package that has been partially eroded in some areas. Cross sections extracted along arbitrary axes through the structural model provide a means to assess the performance of the 


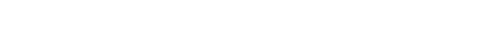

Figure 8. Maps of parameters derived from structural modeling of the top and bottom surfaces of the layered sulfate.

(a) Point constraints used for the kriging model underlying the structural model (filled symbols also shown in Figure 9). These points are at the edges of the surface exposure of the layered sulfate and constrain the 3-D volume of the unit relative to present topography. Additional constraints (open symbols) are imposed on the top and bottom surface of the layered sulfates to maintain consistent thickness in areas without exposures. (b) Modeled thickness of the layered sulfate prior to erosion of NE Syrtis mesas, showing the tapering of the deposit away from the center of the study area. Locations with known thicknesses (measured from the top to bottom of sulfate exposures) are shown numerically atop the kriged surface. Section lines for Figure 9 are shown.
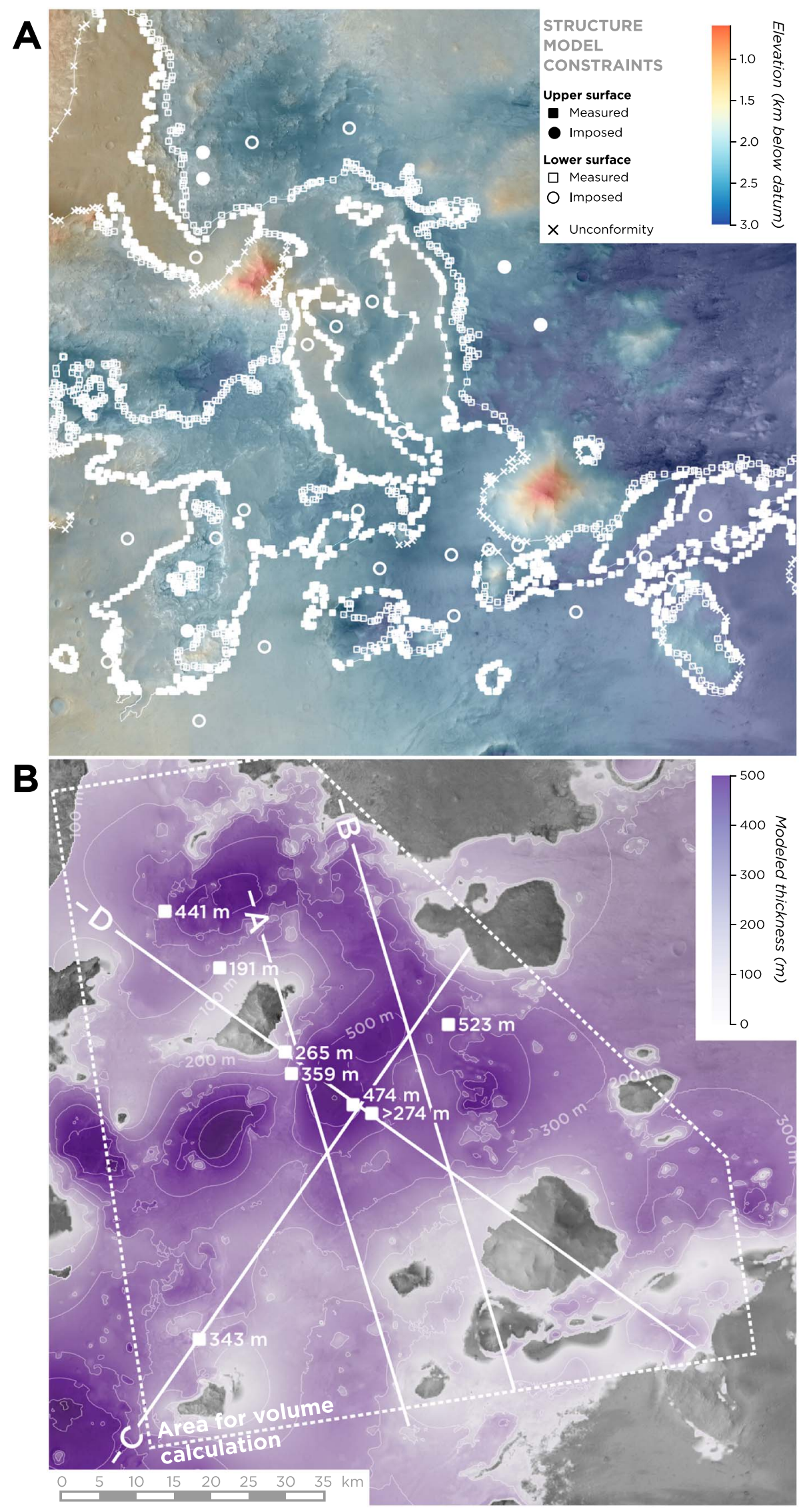

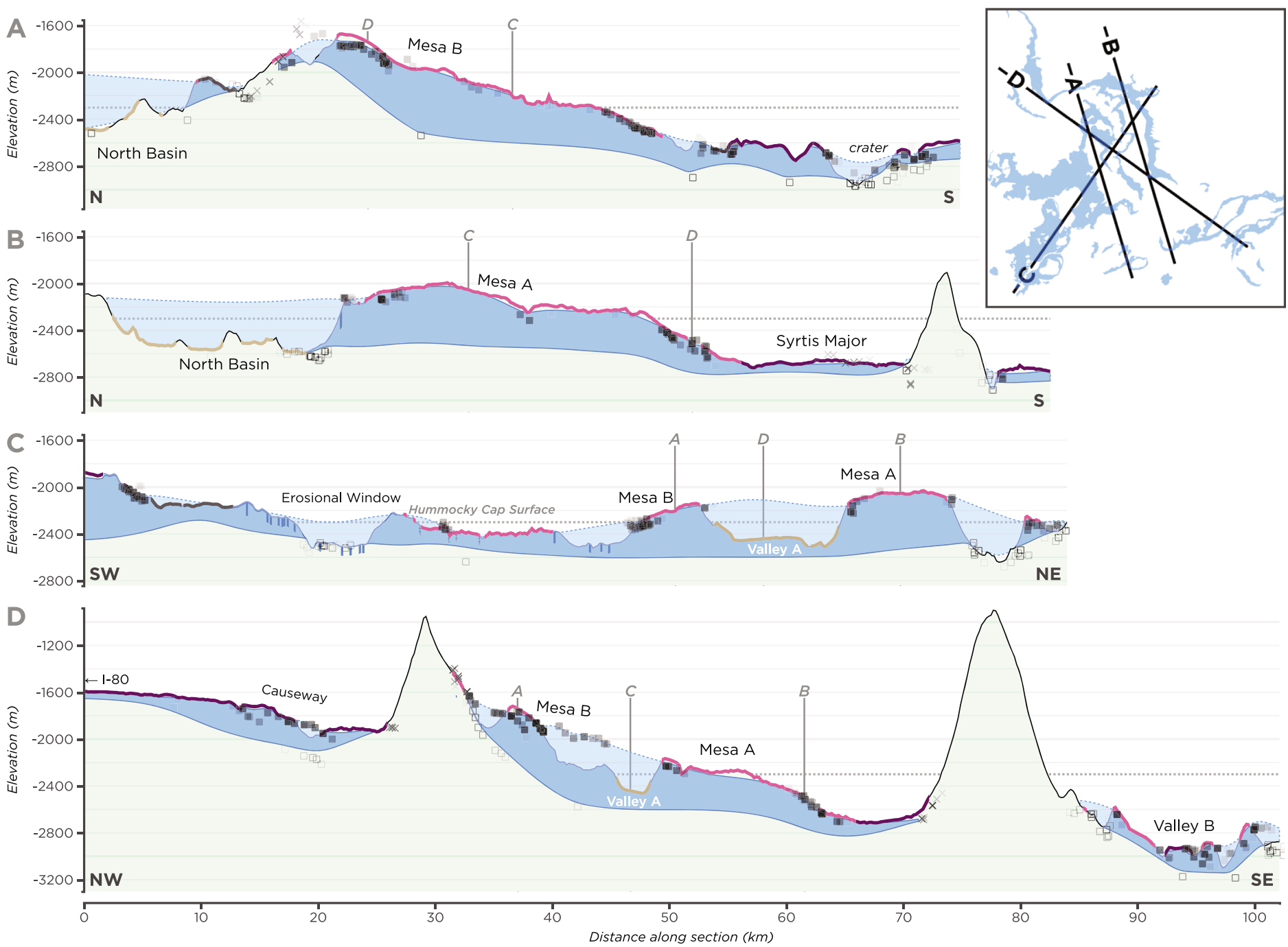

Figure 9. Cross sections of the study area showing profiles through the layered sulfates created using the structural model (Figure 8). Model constraints are shown on the section using the symbology of Figure 8, faded with distance from the section line, with constraints up to $2 \mathrm{~km}$ away shown. All sections are at the same scale, with 10 times vertical exaggeration. (a) A north-south transect through Mesa B showing the draping of the sulfates atop basement topography. (b) A north-south transect across Mesa A and the adjacent low-elevation North Basin and Syrtis Major lava flow surface. (c) A southwest-northeast transect showing the Erosional Window at the southwest of the study area and Mesas A and B. (d) A northwest-southeast transect including both of the basement buttes and paleovalley relationships shown in Figure 19.

modeling approach and evaluate the deposit-scale character of the layered sulfates (Figure 9). The layered sulfates have a variable thickness throughout the study area and embay and thin to zero against inherited highs of Noachian highlands topography. The sulfates have a mean thickness of $197 \mathrm{~m}$, varying from 0 to a maximum of over $600 \mathrm{~m}$ over the topographic depression we term Deep Basin (Figure 8b). Our structural model suggests a prior total volume of layered sulfates of $1,245 \mathrm{~km}^{3}$ within the $\sim 5,800 \mathrm{~km}^{2}$, polygonal area with high-quality mapping constraints, with a volume of $460 \mathrm{~km}^{3}(37 \%)$ still buried. These volume estimates constitute a minimum constraint on the original volume of the layered sulfates.

\subsubsection{Bedding Orientations}

Resolvable bedding traces in the layered sulfates were challenging to assess as they are only exposed in some areas, where broad hillslopes or the interiors of boxwork domains are stripped of debris cover. In many cases, instead of surface-exposed bedding planes that are ideal for measurement, the strikes and dips of sulfates were constructed from the trace of linear features on hillslopes. The quality of local bedding exposures provides varying levels of confidence in bedding between areas (section 3.4). A regional set of representative bedding orientations for sulfates and surface orientations for capping units was determined 


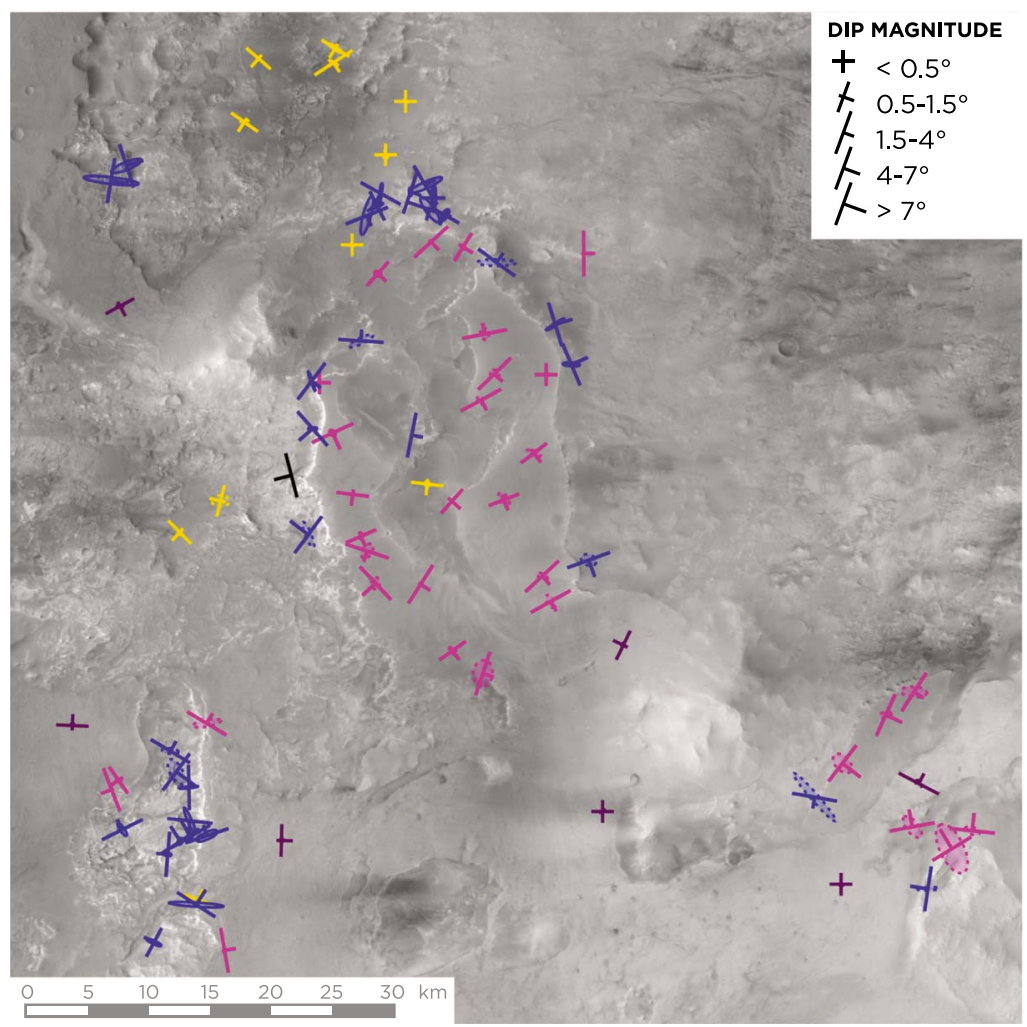

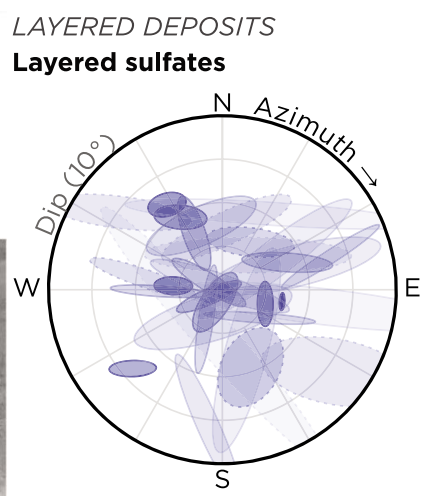

CAPPING SURFACES Smooth capping surface

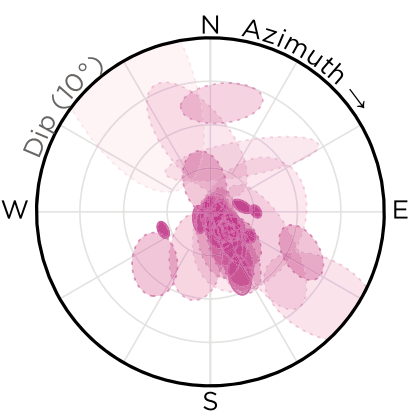

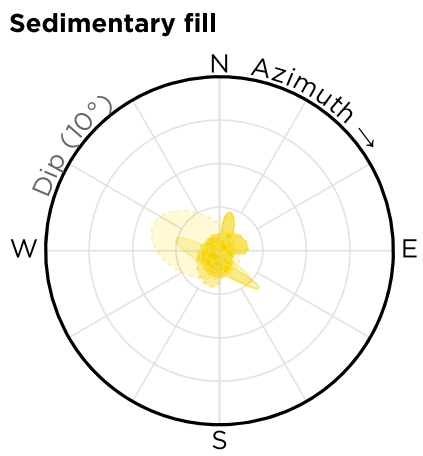

Syrtis Major lavas

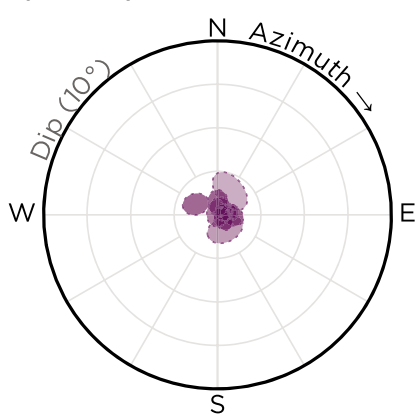

Figure 10. Representative bedding orientations for the study area showing the variation of dips within each class of units. On the map (left panel), nominal bedding orientations are underlain by error ellipses showing the direction of errors. Measurements derived from lower-resolution CTX data have a dotted error ellipse. These ellipses correspond to the data plotted to the right as poles to bedding on upper-hemisphere stereonets. Measured bedding orientations for sulfates and later layered deposits (e.g., late fluvial features) are shown along with surface orientations of the Syrtis Major lava flows and the smooth capping surface.

using measurements along outcrops that had low errors and agreed with surrounding measurements (Figure 10).

Bedding within the layered sulfates always dips at low angles $\left(<10^{\circ}\right.$ and usually $\left.<7^{\circ}\right)$ in a variety of directions. There is no systematic trend in dips that might suggest that the orientation of the sulfate unit was modified by large-scale tilting or regional folding. Instead, the relatively wide range of dips measured within the layered sulfates suggests that the unit was not deposited as an originally flat surface. Some areas of the layered sulfates are nearly flat, such as near the northern boundary of the unit in $\mathrm{nf} 3$ and nf5. Despite this, truly flat deposition is well outside of the confidence bounds for many individual measurements. Both CTX and HiRISE produce orientations with low-angle nonzero dips with a magnitude greater than measurement errors.

The layered sulfates onlap basement topography at both deposit scale and bed scale. The unit thins over and embays basement highs (Figure 9), and bedding often dips away from high topography as well. Bed-scale contact relationships are not directly resolvable from remote sensing but can be inferred from dip relationships; while individual beds may thin somewhat over localized highs, bedding dips shallower than and projecting into adjacent basement topography imply an onlapping relationship.

Relatively steep dips of $5-10^{\circ}$ are persistent over large areas of the layered sulfates. For example, the $\sim 7$ $\mathrm{km}$ west facing hillslope in $\mathrm{n} f 6$ exposes a stratigraphy dipping $5-7^{\circ}$ to the southwest (Figure 11). Grouping bedding traces across the entire hillslope yields a maximum orientation error of $<1^{\circ}$, consistent with a planar, dipping stratigraphy. Dips slightly steeper than the underlying basement surface suggest that the sulfate package may downlap at its base. The shallower slope of the capping surface above the sulfates (section 4.4), which dips to the south instead of southwest, implies a low-angle unconformity between the two. Bedding truncations at the base of the cap are visible in HiRISE imagery (Figure 6b). 


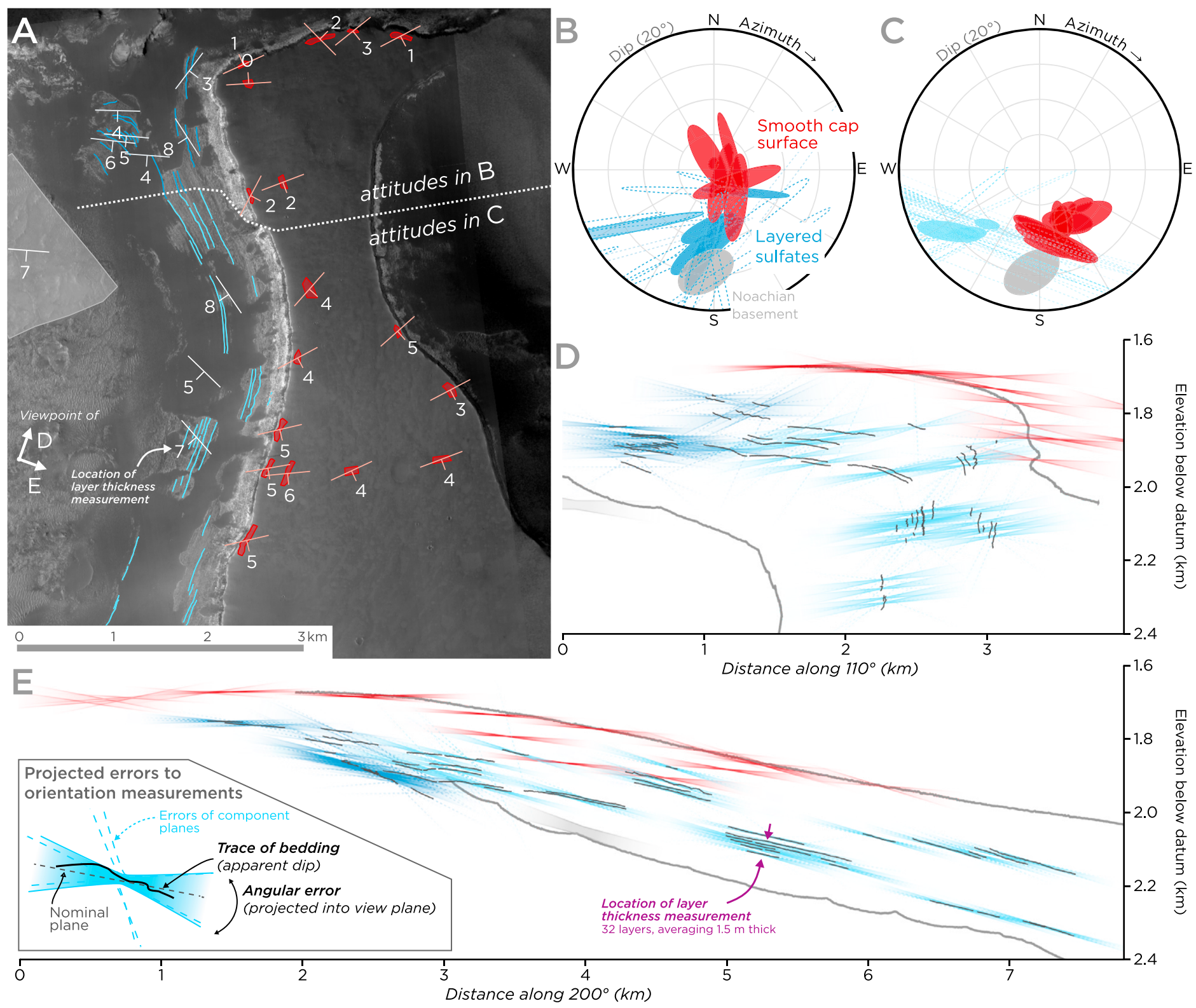

Figure 11. Bedding orientations collected for the top and west face of Mesa B in HiRISE orthomosaic nf 6, showing the surface slope of the smooth capping surface in red and the layered sulfates in blue. (a) Map view of bedding orientations. (b, c) Upper-hemisphere stereonets showing poles to bedding with error ellipses for the north and south parts of (a), respectively. Dotted, unfilled ellipses represent components of grouped measurements. (d, e) Projections of the entire stratigraphy along orthogonal axes as shown in (a), with apparent dips of bedding traces and hyperbolic error bounds to planar fits. The difference in orientation of the capping surface and layered sulfates suggests a low-angle unconformity at the top of the layered sulfates. The difference in dips between the northern and southern section corresponds to a "kink" in projected bedding traces in (d).

Although layers within $\sim 5$-km packages are often consistently oriented, these exposures differ substantially in orientation across the study area. In $n f 7,5 \mathrm{~km}$ to the west of $n f 6$, dips are consistently $\sim 2-3^{\circ}$ to the east. In $\mathrm{n} f 1$, still further west, layers dip $\sim 5^{\circ}$ northeast. Orientations may change gradually within a single stratigraphic package or at unconformities between relatively planar packages, but this cannot be further addressed with current data.

Some exposures of the layered sulfates are less internally consistent, with variable bedding orientations at subkilometer lateral scale. In the northern part of $\mathrm{nf} 6$, dips shallow from $\sim 7^{\circ}$ (southwest-directed) to $\sim 4^{\circ}$ (south directed; Figure 11). In the northern part of the Erosional Window (covered only by CTX topography), 

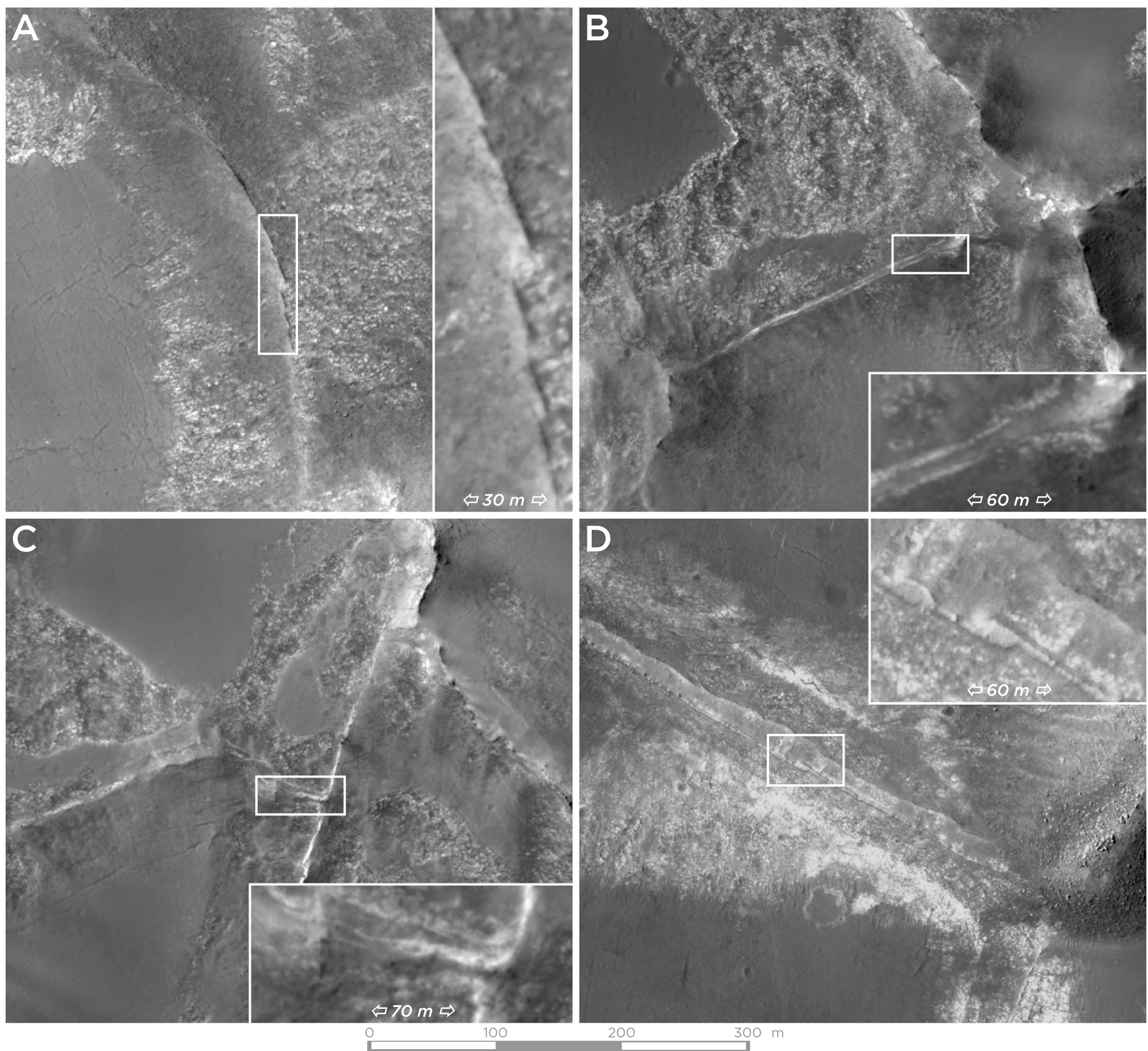

Figure 12. Examples of boxwork fractures from HiRISE images within the study area. (a) A minimally altered fracture $<1 \mathrm{~m}$ thick (nf3). (b) A slightly thicker fracture showing a characteristic double-walled morphology of channelized fluid along the fracture (nf2). (c) A fracture junction showing a dark-toned halo around the fracture $(\mathrm{nf} 2)$. (d) A wide fracture zone showing a light-toned fracture surrounded by a halo, with the entire alteration zone $>100 \mathrm{~m}$ wide (HiRISE ESP_026069_1970).

east dipping exposures contain bedding traces that are kinked relative to their best fitting plane, signifying localized variation. Discordant layer orientations at hundred meters to 1-km scale are particularly evident in areas with abundant boxwork polygonal fractures, which we discuss further in section 4.2.3.

\subsection{Boxwork Polygons}

Boxwork polygonal ridges are a striking feature of parts of the layered sulfates. They occur in many areas including the central Ridge Basin, along the northern erosional margin of the unit, and in the southern Erosional Window. While geographically widespread in occurrence, they are found only patchily throughout 


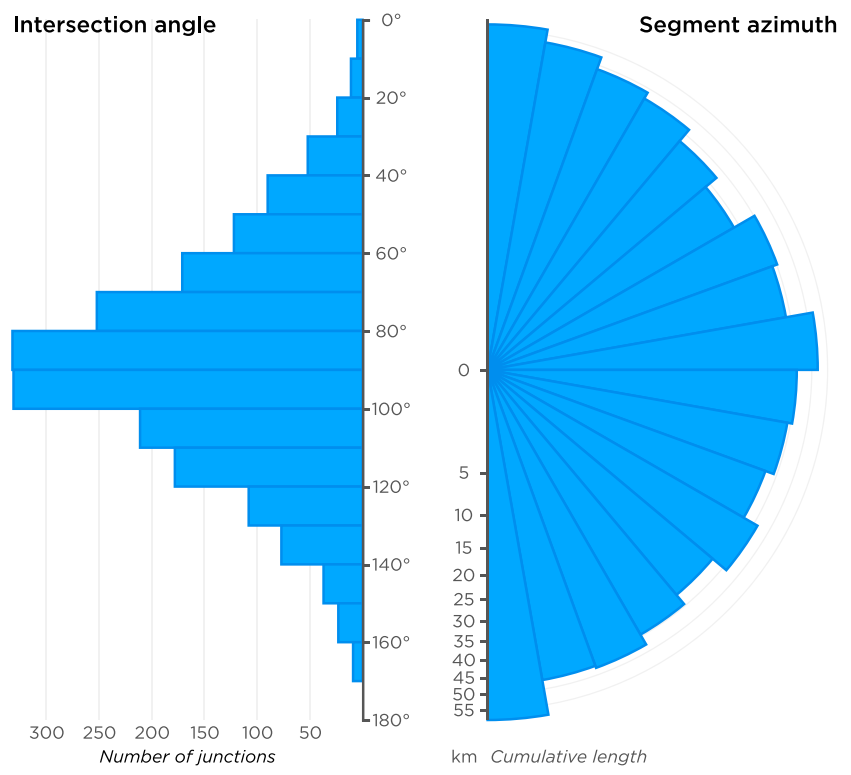

Figure 13. Summary parameters for boxwork fractures measured across the study area (Figure 3). (a) Frequency distribution of boxwork fracture intersection angles. The largest angle is redundant and is excluded (all angles must sum to $360^{\circ}$ ). Thus, “T junctions" between fractures are plotted as two $\sim 90^{\circ}$ angles with an implicit $180^{\circ}$ angle between parallel segments. (b) Frequency diagram of boxwork fracture azimuth, demonstrating a lack of preferred orientation for the fractures. the unit. For simplicity, we will discuss these ridge-forming features as fractures while we discuss the data supporting this classification.

\subsubsection{Fracture Morphology}

The boxwork polygons have a characteristic length scale of $\sim 500 \mathrm{~m}$ and have strong positive relief with exposures defining ridges standing as much as $30 \mathrm{~m}$ above polygon interiors. The features have a significant vertical dimension within the layered sulfates: some single ridges continue through an elevation range of greater than $200 \mathrm{~m}$ (Figure 14). In $\mathrm{nf} 2$ and $\mathrm{nf5}$, the boxwork features penetrate the entire 400 -m thickness of the unit (Figure 6d). The different examples of polygonal fractures vary markedly in thickness. Some ridges are thin and have little topographic expression, while others are thick, prominent, and shed boulders (Figure 12).

Morphological features of the polygonal ridges suggest that they may be filled fractures instead of single-origin injective features. Many boxwork ridges show light-toned bands parallel to and on either side of the fracture centerline (Figures 12b-12d). This parallel-sided geometry varies from $\sim 5 \mathrm{~m}$ (Figured $12 \mathrm{~b}$ and $12 \mathrm{c}$ ) to up to $20 \mathrm{~m}$ in width (Figure $12 \mathrm{~d}$ ). Several examples show additional features such as a light-toned central zone ranging from $\sim 1$ to $\sim 30 \mathrm{~m}$ across (Figure 12d) or a diffuse bright-toned halo $\sim 2-20 \mathrm{~m}$ on each side of the fracture itself (Figures $12 \mathrm{c}$ and 12d). No cross-cutting relationships are observed at fracture intersections, suggesting that the fractures were filled separately from their propagation.

Parallel-sided fills are indicative of channelization of fluid along preexisting fractures. Relatively narrow, zoned fractures surrounded by wide zones of light-toned material texturally continuous with the groundmass of the unit (e.g., Figure 12d) suggest the formation of a zone of alteration around a relatively narrow original fracture. The considerable width range of altered zones along fractures suggests that the intensity of fluid channelization along boxwork fractures varied significantly within the sulfate unit.

\subsubsection{Fracture Orientations}

Over 850-km of boxwork ridges exposed within the layered sulfates were digitized as lines atop regional CTX imagery (Figure 3). Ridge orientations were measured across the data set, and intersection angles were calculated for any point where three or more digitized fracture segments met. Angles were calculated at 10-m radius buffers around each intersection, which corrects for digitization noise and changes in orientation within this radius.

Boxwork ridges commonly intersect at right angles, both crossing and forming "T junctions" (Figure 13). They do not have $120^{\circ}$ orientations characteristic of progressively annealed drying polygons and permafrost patterned ground (El-Maarry et al., 2010) or cooling polygons where rock tensile strength exceeds fracture propagation stresses (Shorlin et al., 2000). Individual ridges can run for several kilometers, over which they range from relatively straight to curvilinear. In some areas (particularly the Ridge Basin) ridges follow gentle arcs with radii of $\sim 8-10 \mathrm{~km}$. However, these circular trends are commonly disrupted by cross-cutting fractures. The dominant map pattern of the boxwork ridges is of a coarsely grid like, sometimes weakly concentric, network.

The summary of fracture orientations suggests a complete lack of preferred orientation for the fractures (Figure 13b). This suggests that the features were not formed by injection or in a regionally consistent stress field. The curvilinear nature of individual fractures makes it difficult to assess their dip in many cases, and most appear to be near vertical. However, some apparently planar fractures have steep $\left(40-60^{\circ}\right)$ nonvertical dips (Figure 6d).

\subsubsection{Dip Changes at Small Spatial Scale}

Changes in local bedding orientations of $2-3^{\circ}$ are resolvable in many areas of the layered sulfates with boxwork fractures. $\mathrm{nf} 3$ and $\mathrm{nf} 5$ contain a 200-m-thick exposure of sulfates cut by boxwork fractures which range from near flat to $\sim 2^{\circ}$ south dipping or northeast dipping. nf 7 contains planar-dipping boxwork 

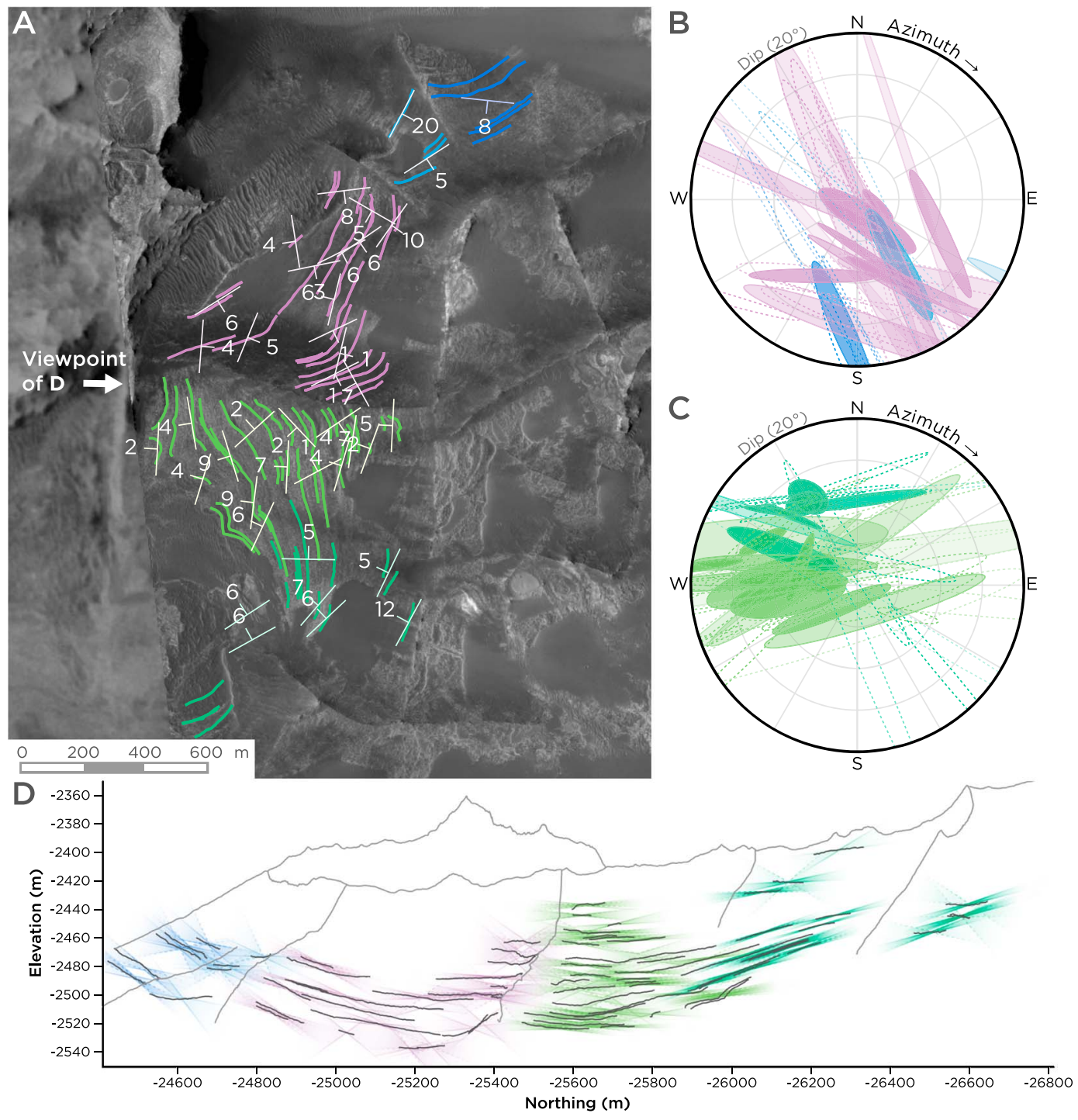

Figure 14. Attitude measurements of layered sulfates in boxwork fracture domains within HiRISE scene $\mathrm{nf} 4$ in the southern Erosional Window. The measurements show a change in bedding dips from dominantly south to north dipping over $\sim 2$-km north to south. (a) Map view of bedding orientation measurements. (b, c) Upper-hemisphere stereonets showing poles to bedding for the north and south parts of (a). Measurements are color coded by boxwork domain and shaded by confidence. Dotted, unfilled ellipses represent components of grouped measurements. (d) A N-S cross section within the measurement domain, showing the apparent dip of bedding traces and hyperbolic error bounds to planar fits. The poles to bedding and projected cross section show a change in apparent dip from north to south along the cross section and sudden small-scale dip changes across boxwork fractures.

domains with southeast dips steepening from $\sim 1^{\circ}$ to $3^{\circ}$ over a few hundred meters in successive fracture polygons. The best exposed example of localized bedding variation associated with boxwork contains more dramatic changes of bedding orientation (up to $10^{\circ}$ over a kilometer) on a west facing slope in $\mathrm{n} f$, within the southern part of the Erosional Window (Figure 14). The slope contains sulfate material layered at meter scale and buttressed by resistant polygonal ridges. In the northern part of this exposure, dips are variable but generally southward. Scatter to the northwest represents high uncertainties aligned with the local hillslope. The southern part of this exposure contains dips that are generally northwestward. The opposing dips occur within a 2-km section over several boxwork domains. A projected cross section (Figure 14d) shows dip changes both gradually within boxwork domains and abruptly between them. Many of the individual measured bedding traces are curved relative to their best fitting plane, suggesting that individual layers are not planar and leading to large error magnitudes for orientation data. 

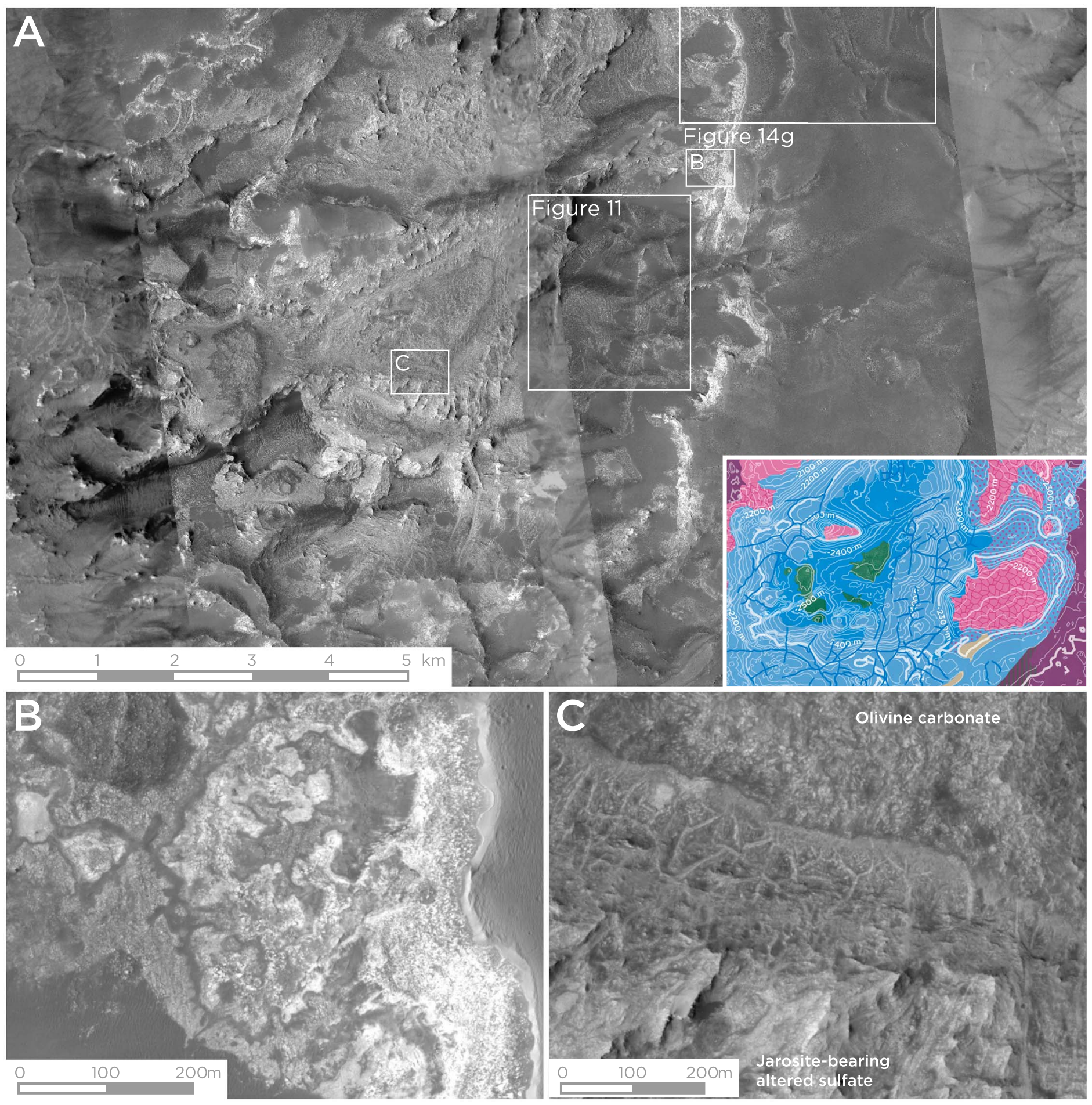

Figure 15. (a) The Erosional Window at the southwest margin of the study area, showing parts of HiRISE scenes nf 4 and $n f 8$, where the layered sulfates are erosionally resistant and carry strong jarosite signatures. The inset geologic map (from Figure 3) covers the same area. (b) Mottled light-toned altered domains associated with the contact between the "hummocky capping surface" and unaltered exposures of layered sulfate. Light-toned material is partially channelized along boxwork fractures, suggesting that the two features are linked. (c) Jarosite-bearing, erosionally resistant altered sulfates adjacent to and stratigraphically above an exposure of olivine-carbonate, with dense fractures indicative of fluid flux at the interface. 


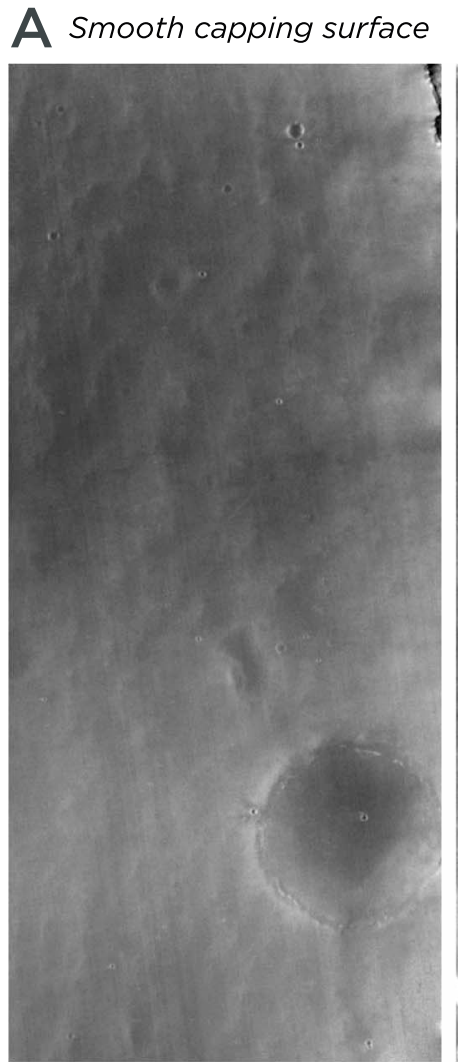

Center

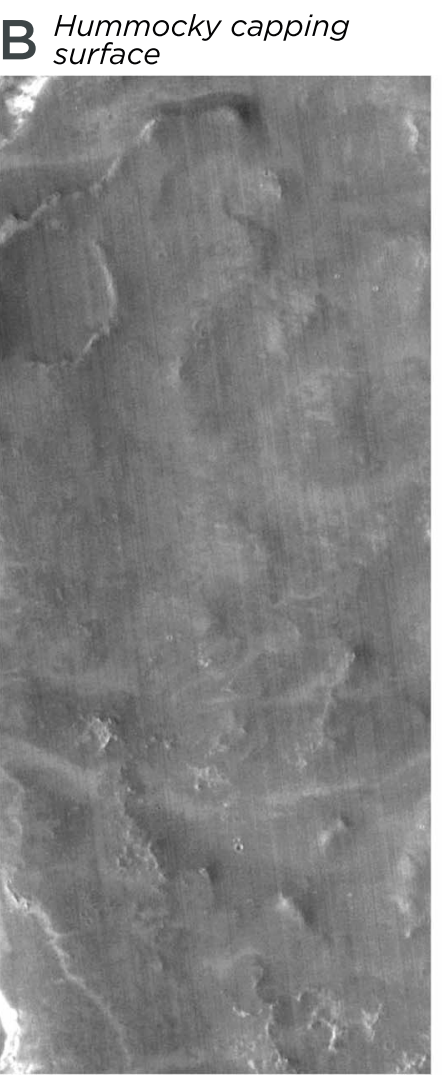

$16.75^{\circ} \mathrm{N}, 76.59^{\circ} \mathrm{E}$
C Syrtis Major lava
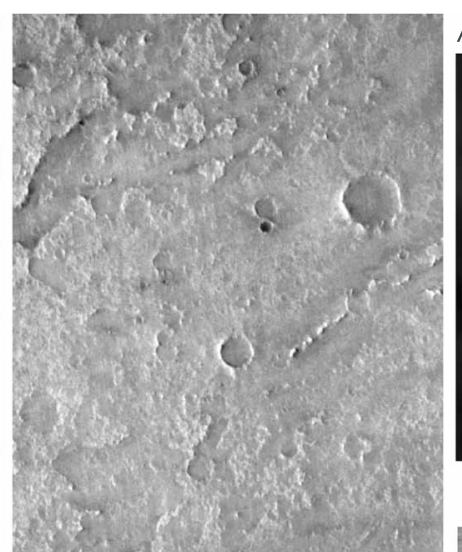

Themis nighttime IR
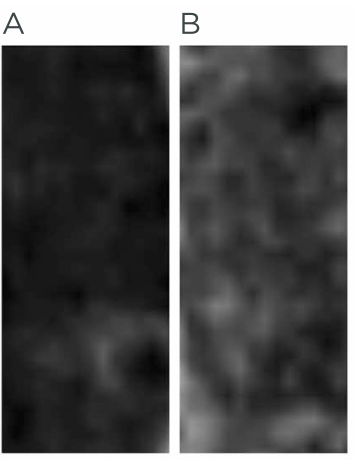

E Ad acent surfaces at Valley $B$

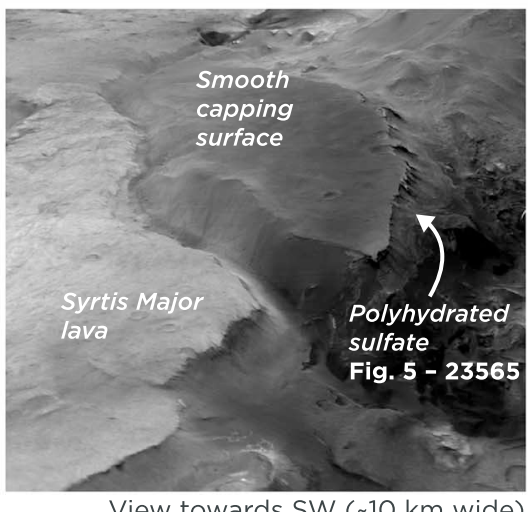

$\begin{array}{lllllll}0 & 0.5 & 1 & 1.5 & 2 & 2.5 & \mathrm{~km}\end{array}$

Figure 16. Same-scale views atop a CTX orthomosaic of morphological characteristics of (a) the smooth capping surface, (b) the hummocky capping surface, and (c) the Syrtis Major lavas. (d) Thermal Emission Imaging System (THEMIS) nighttime temperature corresponding to panels (a-c). (e) An example of the smooth capping surface and the Syrtis Major lavas in contact.

The association of bedding orientation changes at small spatial scale with the boxwork ridges suggests that the formation of the ridges may have modified dips of the nearby beds. The proposed mechanism for creating these boxwork fractures can lead to localized bed orientation changes at subkilometer scale (section 5.2.1).

\subsubsection{Fracture Mineralogy}

Some of the boxwork polygons, particularly in $\mathrm{nf2}$, are within a CRISM scene and wide enough to be covered by a single pixel. Ehlmann and Mustard (2012) presented measurements showing spectral signatures of jarosite family minerals $\left(\left(\mathrm{K}_{\mathrm{N}^{a} \mathrm{H} 3} \mathrm{O}\right) \mathrm{Fe}_{3}^{3+}(\mathrm{OH})_{6}\left(\mathrm{SO}_{4}\right)_{2}\right)$ in the boxwork polygonal ridges. Applying the same methods to other ridged areas within the layered sulfates, we have found several other examples of polygonal ridges enriched in jarosite (Figure 5). Given the similar morphology and erosional resistance of ridges across the study area, jarosite is likely a key feature of the boxwork fractures across the entire study area.

\subsection{Penetrative Alteration}

Some areas of the layered sulfates are characterized by pervasive mineralization not channelized along boxwork fractures. In all cases with CRISM coverage, the "altered sulfate" shows spectral signatures of jarosite. This light-toned, erosionally resistant altered sulfate is notably present in the north part of nf1, the Erosional Window ( $\mathrm{nf} 4$ and $\mathrm{nf8}$ ), and the central part of $\mathrm{nf} 6$ (Figure 3). In the Erosional Window, several subkilometer scale flat-topped outcrops of the olivine-carbonate unit (Ehlmann \& Mustard, 2012) are surrounded by erosionally resistant, massive and light-toned altered sulfates (Figure 15). The valley containing these materials is ringed by eroded layered sulfates with raised boxwork ridges. The margins of the altered sulfates show finely patterned fractures at the boundary and wider, linear fractures extending $200 \mathrm{~m}$ into the sulfates (Figure 15b). This pattern of fracturing is much denser than the boxwork domains, suggesting a localized and intense fluid interaction at the basal contact of the sulfates in this location. 

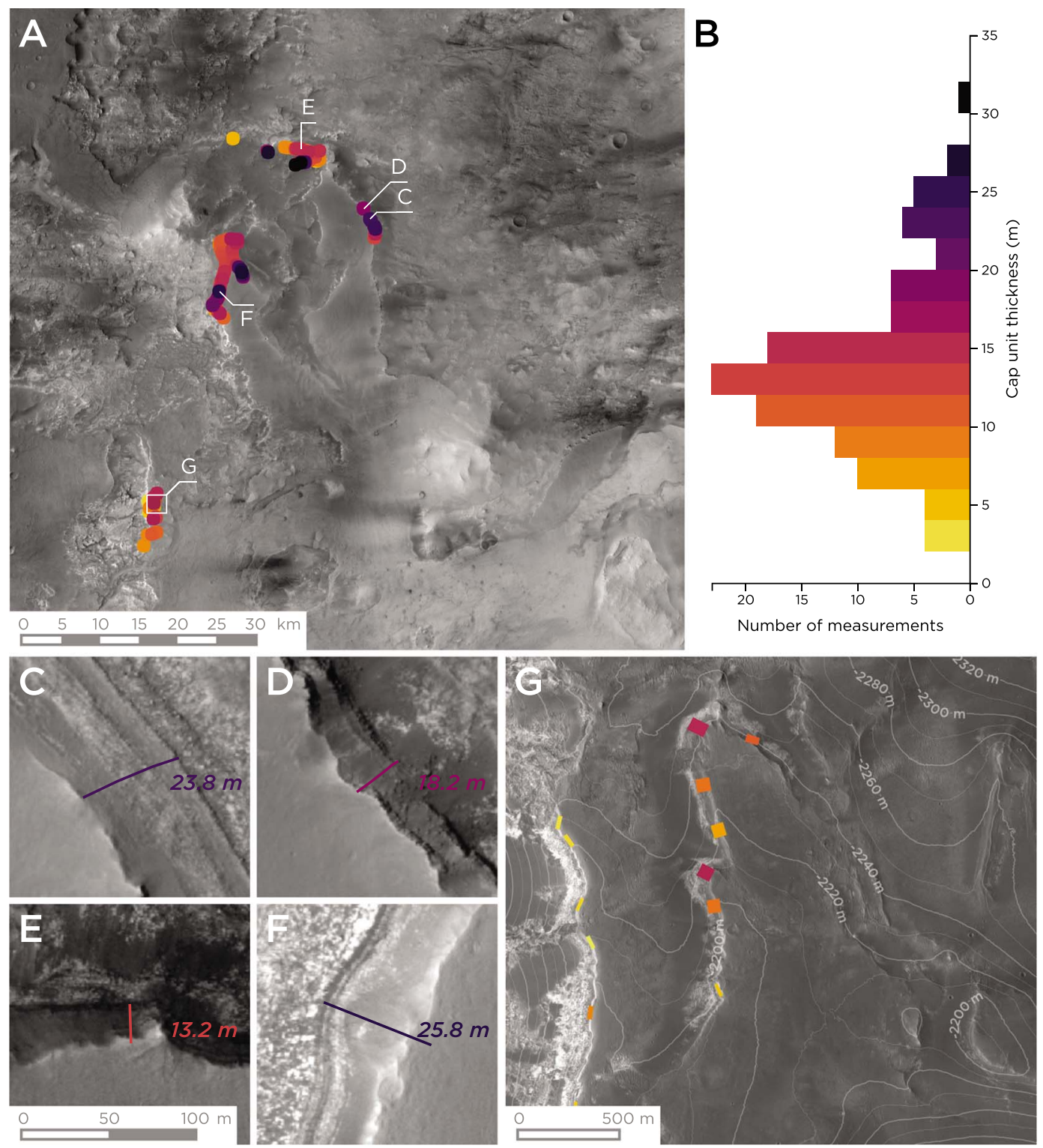

Figure 17. Thickness and morphology of the smooth capping surface in HiRISE scenes within the study area. (a) A summary of sampling, with measured locations color coded by thickness. (b) Histogram of thicknesses sampled throughout the study area. The coloration of histogram bands corresponds to the points on (a). Thickness ranges from 5 to $25 \mathrm{~m}$ across the sampled HiRISE scenes. (c-f) Close-ups of capping unit margin showing thickness and morphology at a single location: (c) coarse internal layers within the capping surface, (d) poorly resolved layers and shedding of boulders downslope, (e) poorly resolved internal structure, and (f) downwarping of the basal contact by cratering. (g) The "hummocky cap surface" at the eastern edge of the Erosional Window. This area hosts the thinnest recorded examples of the capping unit and two parallel curved scarps (left side of image) doubling the edge of the capping surface.

Light-toned, mineralized zones are also associated with the upper surface of layered sulfates, just below the smooth capping surface (e.g., Figure 6c). Unlike the more intense fluid alteration overprint described above, these zones show no contrast in erosional resistance relative to the groundmass of the sulfates. However, they do have jarosite spectral signatures (251C0-Jarosite in Figure 5). In the Erosional Window, this light-toned material includes a collection of coarsely patterned, rounded alteration domains, with a $\sim 10$-m characteristic scale (Figure 15c). The patterned material grades laterally eastward into boxwork ridges which cut visibly layered material, and the light-toned material in these domains appears to be channelized along boxwork ridges. The mineralogical parallels between massive, altered domains and the boxwork ridges suggests that these features were formed in the same or a similar episode of fluid interaction. 

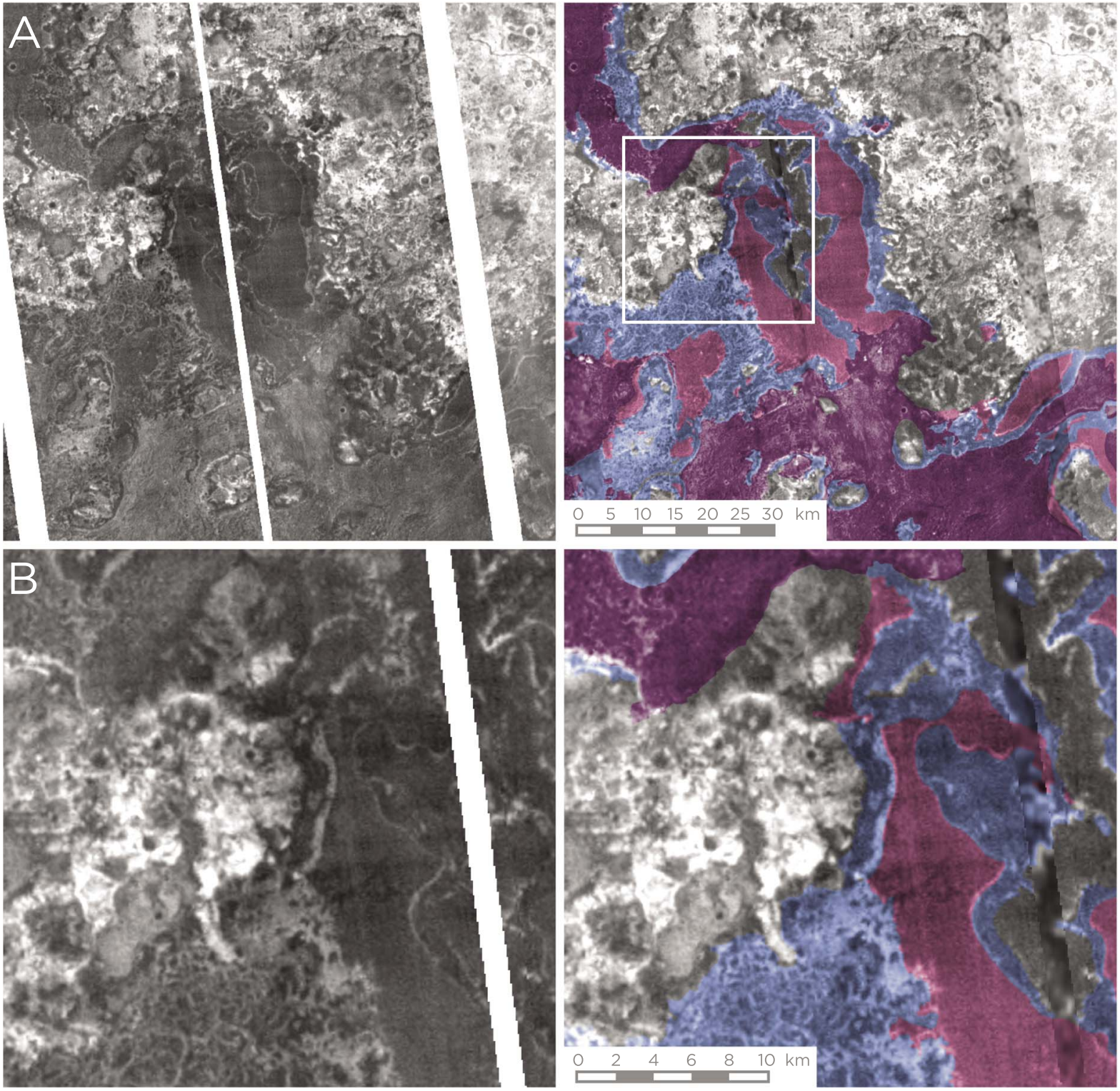

C

Noachian

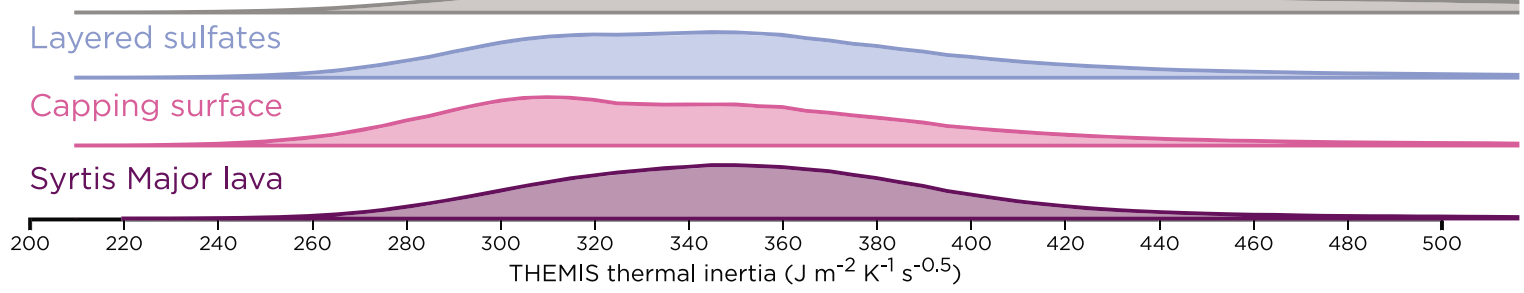

Figure 18. (a) THEMIS quantitative thermal inertia images, selected for capture during the same season (autumn) for consistency based on the guidelines established in Fergason et al. (2006); in the right panel, gaps are filled with mosaicked Thermal Emission Imaging System nighttime IR, and unit boundaries are overlaid. This data set shows the low thermal retentivity of the smooth capping surface. (b) Zoom highlighting the central part of the study area. (c) A histogram of thermal inertia subset by unit over the study area, showing that the capping surface has the lowest average thermal inertia of all mapped units. 

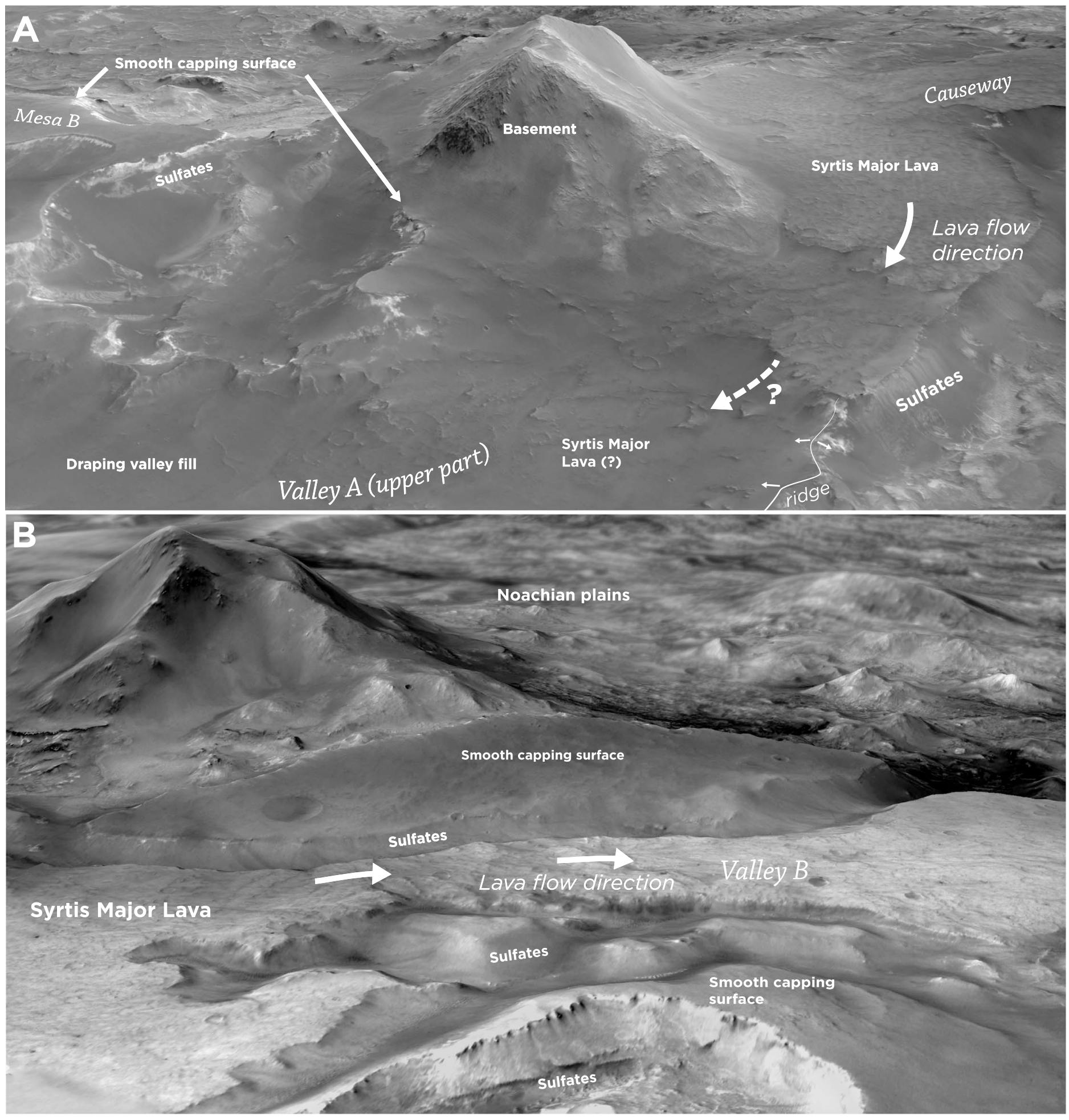

Figure 19. Key examples of the relationship between the smooth capping surface and the Syrtis Major Lavas, with orthoimagery atop CTX and HiRISE elevation models. (a) View southwestward toward Mesa B. The Syrtis Major lava flow lobe of the Causeway ends in the foreground, embaying the basement exposures and flowing down a gradient toward Valley $A$. The smooth capping surface crops out $\sim 200 \mathrm{~m}$ higher on the south flank of this basement exposure. (b) View of Valley $B$ with the smooth capping surface mantling layered sulfates on the flanks of the valley. The Syrtis Major lavas flows are channelized between these elevated exposures, and secondary channels have eroded the edge of the lava flow. 

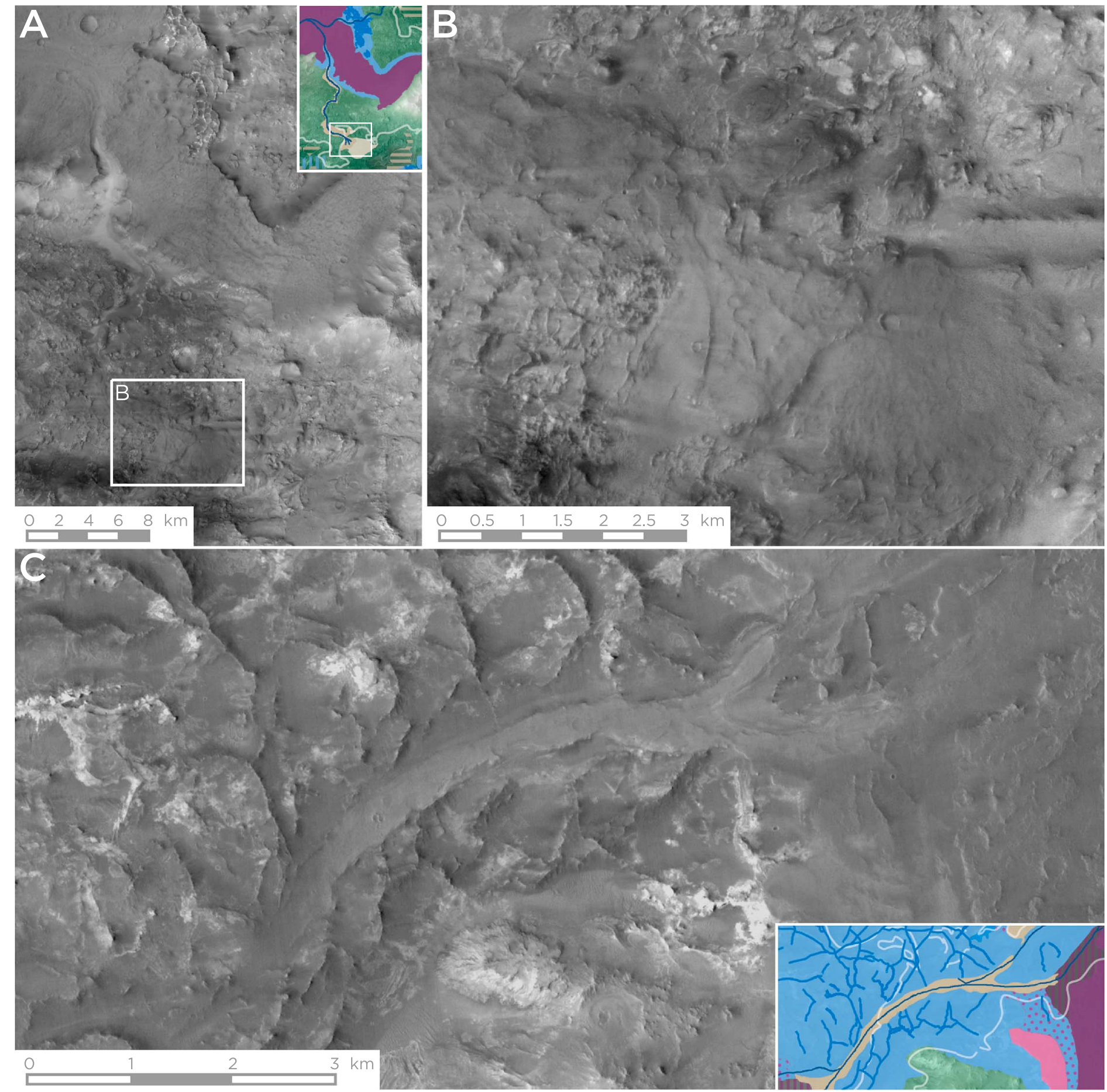

Figure 20. (a) Canyons cut into the edge of the Syrtis Major lava flows in the northwest of the study area, with a preserved downstream channel system and a 1.5-km-wide delta deposit at roughly $-2,300-\mathrm{m}$ elevation at its terminus. Inset geologic map covers the same area. (b) Close-up of the delta deposit, with basement megabreccia in the upper right. (c) An inverted fluvial deposit 10-20 m thick in the Erosional Window in the southwestern part of the study area. The fluvial deposit is sourced from atop the Syrtis Major lavas. Inset geologic map is of the same area. 


\subsection{Capping Units}

The layered sulfates are exposed at the boundary of the Syrtis Major volcanic province, and studies to date have identified its capping surface as the Syrtis Major lava throughout the region (Bramble et al., 2017; Ehlmann \& Mustard, 2012). We find that the capping surface in the central part of the study area is distinct from the Syrtis Major lavas, and we interpret this "smooth capping surface" to have formed by a fundamentally different process.

\subsubsection{Morphology}

Two distinct types of unit locally overlie the layered sulfates within the study area (Figure 16). The smooth capping surface is uniformly dark and relatively featureless. Preserved craters are small and fresh, with a relative lack of intermediate-sized craters; larger craters that are preserved appear as poorly defined "ghost" features (Figure 16a). The hummocky capping surface, a subtype of the smooth capping surface, has increased apparent roughness at 100-m lateral scale (Figure 16b), created by localized topographic variations of $\sim 10-50 \mathrm{~m}$ in elevation (Figure $17 \mathrm{~g}$ ). The smooth and hummocky capping surfaces are predominantly found in the central and southeast parts of the study area.

The Syrtis Major lavas mapped within the study area are continuous with a regionally eastward sloping surface of the Syrtis Major volcanic province (Hiesinger \& Head, 2004; Ivanov \& Head, 2003). This surface has a notably different character than the other capping units: it preserves small-scale features (e.g., low-relief benches and scarps), retains craters well (Figure 16c), and preserves evidence of fluvial incision on its surface and edges (Figure 19b; see also section 4.5).

\subsubsection{Structural Characteristics}

The range of surface orientations of the smooth capping surface is more restricted than the range of bedding dips within the layered sulfates (Figure 10). The smooth capping surface dominantly slopes southeast, with surface slopes of up to $5^{\circ}$. The difference in orientation distributions of the smooth cap and the underlying layered sulfates suggests a low-angle unconformity, with the smooth capping surface emplaced atop the layered sulfates after a period of erosion.

The surfaces of the smooth capping surface are likely to have formed in situ atop dipping exposures of the layered sulfates. In contrast, the Syrtis Major lavas are low dipping and generally sloped to the east with dips of less than $2^{\circ}$ (Figure 10). Broadly, the lavas form surfaces with regionally consistent dips at 10 - to $20-\mathrm{km}$ scale, oriented with the topographic gradient into Isidis Basin.

\subsubsection{Spectral and Thermophysical Characteristics}

Both the Syrtis Major lavas and smooth capping surface have an indistinctly mafic mineralogy with olivine and pyroxene absorptions in CRISM data. The smooth capping unit has generally lower thermal inertia than the Syrtis Major lava flow (Figure 18). Low thermal inertia is typically the result of lesser induration, higher porosity, or mantling fine-grained debris.

\subsubsection{Thickness of the Smooth Capping Surface}

The low thermal-inertia character of the smooth capping surface is coupled with a resistant erosional style. The measured thicknesses of the cap unit (Figure 17b) are largely between 10 and $20 \mathrm{~m}$ with several outliers in $\mathrm{nf} 3$ and $\mathrm{nf} 4$. Close-up views of the internal structure of this interval show coarse internal layering and boulder-shedding scarps (Figures 17c-17f). Figure 17f shows warping of the lower contact by an impact and continuous dark bands within the light-toned material at the base of the cap surface.

The hummocky capping surface subtype of the smooth capping surface is topographically rough and may be affected by dislocations in the underlying layered sulfates. Figure $17 \mathrm{~g}$ shows 10 - to $20-\mathrm{m}$ elevation steps separating differently-dipping "plates" of capping material at subkilometer scale. In the center, the capping surface is resolved into two distinct surfaces, the lower of which is thinner $(\sim 5 \mathrm{~m})$ and slopes eastward and slightly away from the scarp defining the edge of the window. The two scarps are at nearly the same elevation and may be the result of small-offset $(\sim 10 \mathrm{~m})$ normal faulting within the underlying layered sulfates, propagated upward to cause dislocations in the hummocky capping surface.

\subsubsection{Relationship With the Syrtis Major Lavas}

The local relationships between the smooth capping surface and the Syrtis Major lavas are key to separating the two units. In the central portion of the study area, the distal Syrtis Major lavas flow eastward from the outlet of the $I-80$ valley, capping a mesa of the layered sulfates (the Causeway) and embaying a major basement peak (Figure 19a). The lava flow terminates at an indistinct point in the upper part of Valley A, with morphologically similar surfaces forming "steps" at progressively lower elevation. Below this transi- 


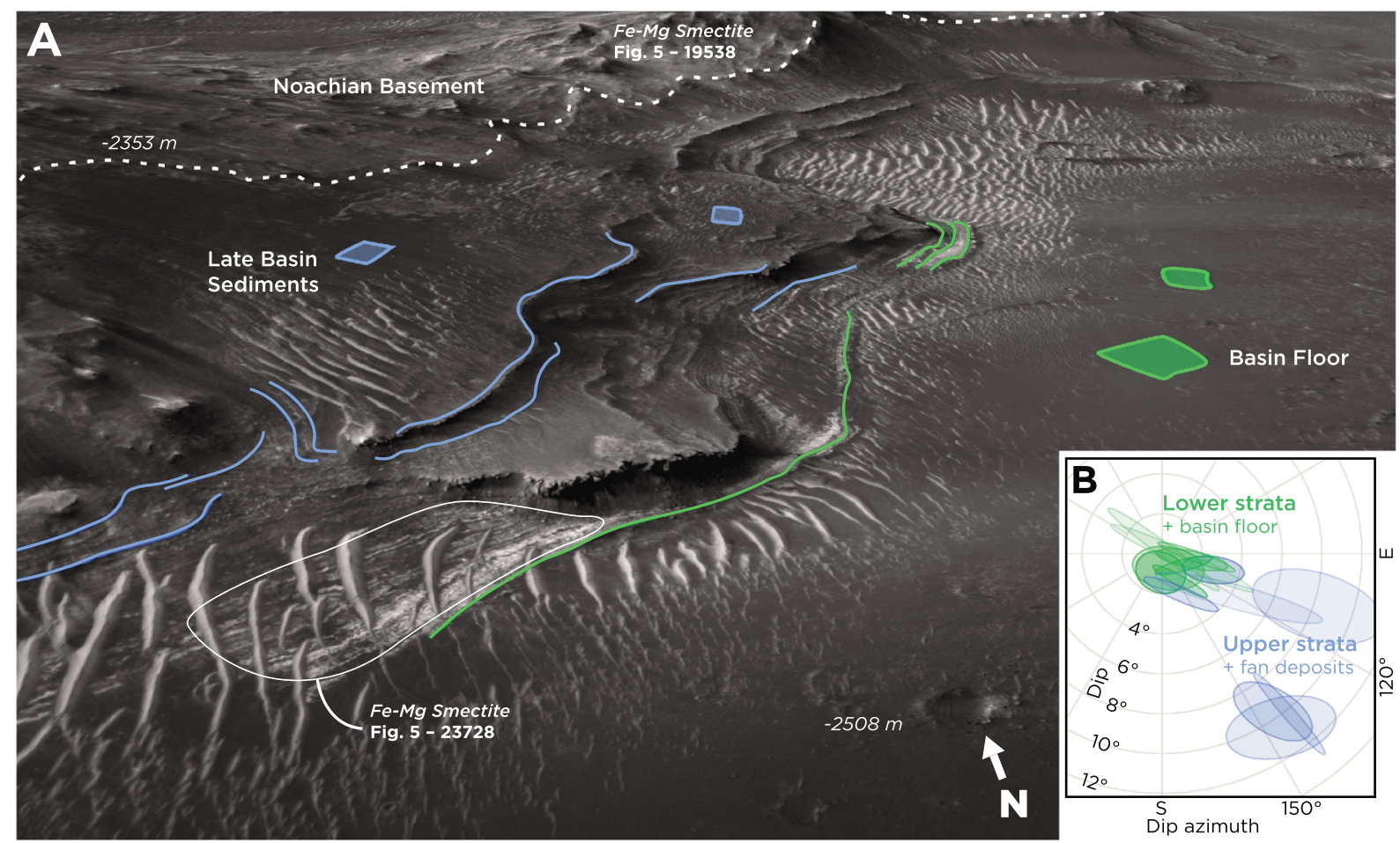

Figure 21. N-looking oblique view in $\mathrm{nf} 3$ (no vertical exaggeration) showing the Basin Floor units and layered scarps and fans of the Sedimentary Fill deposits. Measured bedding traces (green for the lower scarp and basin floor and blue for the upper fan) are shown. Calculated orientations for these traces (bottom right) show upper fan deposits dipping up to $10^{\circ}$ into the basin. Approximate locations for CRISM spectra (Figure 5) showing smectite clay signatures within the basement and detrital sediment are shown. View is $\sim 1 \mathrm{~km}$ wide.

tion zone, Valley A is mantled by the "draping valley fill" (section 4.5.4) in its lower reaches. On the valley's southwest flank, the layered sulfates form the bulk of Mesa B, which is capped by the smooth capping surface at $\sim-1,600 \mathrm{~m}$. The smooth capping unit is $\sim 200 \mathrm{~m}$ higher than adjacent Syrtis Major flows. This elevation relationship suggests that the smooth capping surface was formed atop the sulfates prior to and at significantly higher elevations than the Syrtis Major lavas. The Syrtis Major lavas appear to have flowed down a valley that was eroded through the layered sulfates and cap and into the upper reaches of Valley A. The topography is now inverted to form the Causeway, capped by lavas. The presence of an erosional unconformity at the sulfate-smooth capping surface contact implies significant erosion before the formation of the capping surface. The mesas flanking Valley A were formed by another episode of fluvial erosion that postdates the formation of the smooth capping unit.

Valley $B$ at the southeastern margin of the study area contains a similar relationship (Figure 19b). The northwest flank of the valley slopes inward at $\sim 5^{\circ}$ and is composed of CRISM-verified layered sulfates capped by the smooth capping surface; the southwest side does not have CRISM coverage but is morphologically similar. The floor of the valley contains a lobe of Syrtis Major lava, which has a rougher surface with an indurated, crater-retentive character. On both sides of the valley, the contact between the lavas and smooth capping surface is erosionally modified with channels cut into the boundary (discussed in section 4.5.1). This relationship demonstrates that the Syrtis Major lavas flowed through significant preexisting relief of paleovalleys formed in capped layered sulfates.

\subsection{Late Fluvial History}

\subsubsection{Channels Atop the Lava Flows}

Fluvial activity continued after sulfate and smooth cap unit erosion and Syrtis Major lava emplacement, substantially eroding parts of the Syrtis Major lava flows. The Syrtis Major lavas are modified by inscribed channels across the surface and at the edges of the lava throughout the study area, in agreement with the outflow channels reported to the south of the study area by Mangold et al. (2008a). The down gradient and incised nature of the inscribed channels distinguishes them from lava channel features. 

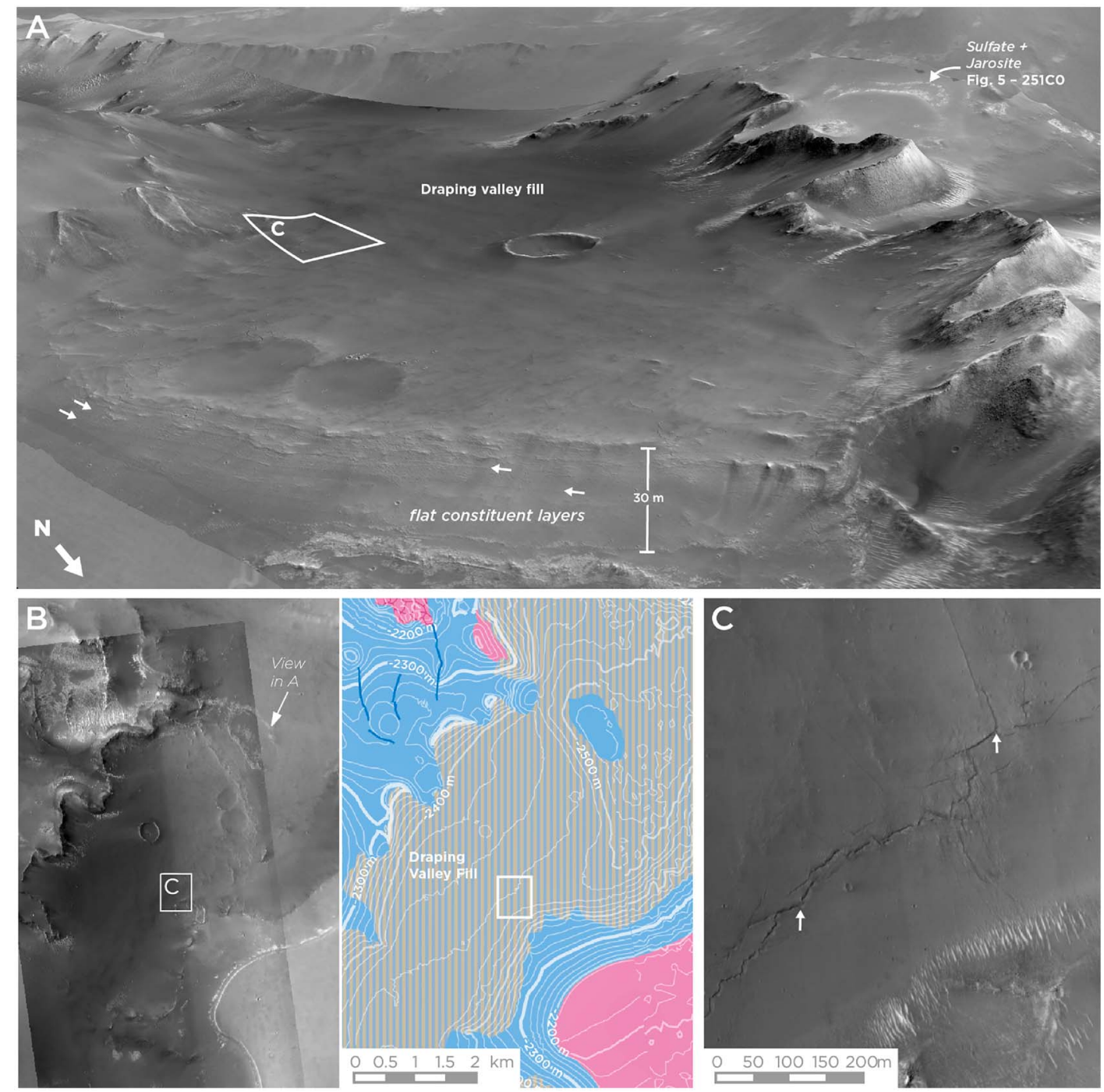

Figure 22. The draping valley fill in Valley A. (a) Southwest looking HiRISE (nf 7) oblique view of the unit, showing its nearly flat base and a rim that extends up the side of the valley to roughly the $-2,300 \mathrm{~m}$ contour. The raised edges of the unit appear thin and buttress the material beneath them, and the inconsistent erosion creates a sinuous map pattern on the edge. (b) Paired map views corresponding to (a), showing imagery data sets and elevation overlaid on geology. (c) Cracks in the unit located just inside the slope break at the edge of the valley floor.

The inscribed fluvial features are paired with deeper ( $100 \mathrm{~m})$ canyons cut into the surface of the lava flow. In Figure 9b, these features separate parts of the lava flow at discrete elevation steps, suggesting that different flow bodies formed at different times, during progressive erosion of the layered sulfates.

These channels and canyons cut into the lava flow surface postdate the sulfate-hosted paleovalleys described in section 4.4.5. After Valley B in the southern part of the study area was filled with a lobe of the Syrtis Major lava flows, smaller canyons were inscribed at the contact between the lavas and the capping surface forming the slopes of the valley (Figures 9a and 19b). Valley A did not experience similar reoccupation, which we discuss in section 4.5.4.

\subsubsection{Fluvial and Lacustrine Deposits}

The north margin of Deep Basin contains an integrated fluvial system, with an ampitheatre-shaped canyon incised into the edge of the Syrtis Major lavas connected by a preserved channel to a small delta (elevation $-2,320 \mathrm{~m}$; Figures 20a and 20b). This channel formed atop Noachian basement, layered sulfates, and the Syrtis Major lavas. Distal to this delta, a flat-lying surface of presumably lacustrine origin is preserved at $-2,340 \mathrm{~m}$. These features are perched $\sim 500 \mathrm{~m}$ above the floor of Deep Basin, which has its deepest point at $-2,800 \mathrm{~m}$ only $3.5 \mathrm{~km}$ to the southwest. The canyon cut into the Syrtis Major lavas is tied to lightly incised 
channels on the flow surface and to the similar canyon at the flow scarp in nf 4 (Figure 6c), which feeds into North Basin.

An inverted channel cuts fractured exposures of the layered sulfates within the Erosional Window at the southern part of the study area (Figure 20c). Layers within this channel body are nearly flat, dipping at most $1^{\circ}$ to the east. The channel flows north of a Noachian basement peak, overtops and cuts boxwork ridges with in the layered sulfates, and is confined to a narrow belt roughly $300 \mathrm{~m}$ wide. The channel deposit aligns with valleys cut into the edge of the Syrtis Major lavas to the west (Figure 3) and a valley at the northern edge of the Syrtis Major lavas that results from focused erosion of the layered sulfates along this boundary.

\subsubsection{Basin-Floor Deposits}

Parts of North Basin and Deep Basin are floored with flat, smooth surfaces that suggest fluvial or lacustrine deposition. These low-elevation exposures form nearly flat surfaces $\left(<1^{\circ}\right.$ east dips $)$ within an interconnected network of basins; dipping sediments suggestive of alluvial fans are sometimes found at the margin of these surfaces (Figure 21). In North Basin, the fluvial system discussed above feeds into these basins, and an outlet channel is preserved to the east (Figure 3). The sourcing of associated channels atop the Syrtis Major lavas suggests Hesperian or later deposition, and crater counting of North Basin surfaces (Skok \& Mustard, 2014) yields an Amazonian age of $1.29 \mathrm{Ga}$. These surfaces were mapped as "capping unit" by Bramble et al. (2017) but appear to be fundamentally different than the exposures of the same morphological unit at higher elevations atop the NE Syrtis Plains. Bramble et al. (2017) grouped these units based primarily on their crater retentive character, but they are likely much younger than these cratered plains. We reinterpret these surfaces as fluvial/lacustrine sediment sheets and suggest that they are late deposits, based on their association with clearly postsulfate fluvial systems. We map these deposits as "basin floor" in Figure 3.

Low-relief layered scarps in HiRISE scenes $n f 1, n f 3$, and $n f 5$ in North Basin are mapped as undifferentiated sedimentary fill, closely associated with the Basin Floor deposits. These features are associated with topographic scarps $\sim 10$ to $20 \mathrm{~m}$ high and are flat lying to $\sim 2^{\circ}$ east-dipping, similar to the adjacent basin floor surfaces. In $\mathrm{nf3}$, they increase in dip to $\sim 10^{\circ}$ over $\sim 100 \mathrm{~m}$ of elevation, grading into thin fan deposits mantling the Noachian basement (Figure 21). In $n f 2$ and $n f 4$, similar layered scarps at somewhat higher elevation are associated with the "Channel Fill" deposits discussed above.

In $n f 2$ and $n f 3$, these scarps contain planar, bright-toned layers with CRISM signatures indicative of phyllosilicates. In Bramble et al. (2017), these exposures are mapped as "undifferentiated" and are typically adjacent and slightly above exposures of the capping unit. The thin packaging of beds, confinement to deep basins in present-day topographic lows, and formation of crater-retaining flat floors contrast with the thickly packaged layered sulfates. We interpret these features as representing late fluvial and lacustrine deposits, and map them as "late basin sediments" (Figure 3).

4.5.4. Draping Valley Fill

Valley A does not contain a clear channel system, despite the significant erosion of Mesas $A$ and $B$ on its flanks and its overall southward slope. It is instead floored by the draping valley fill, a unit unique to the interior of Valley A (Figure 22). Within the footprint of $n f 7$, this unit is characterized by a flat surface with $<2^{\circ}$ slopes to the southeast (truncated at a 40-m layered scarp in the foreground of Figure 22a). Continuous with the surface capping the valley floor, resistant thin surfaces dip steeply (15-20 $)$ into the valley, mantling the layered sulfates below and forming distinctive, sinuous hogback ridges up to $40 \mathrm{~m}$ high at its erosional boundary (Figure 22b). The valley floor surface hosts fine cracks near its edge, just inside of the eastern slope of the valley (Figure 22c). We interpret these as tension cracks caused by differential deflation of the unit after emplacement. The draping valley fill has low thermal inertia and shows indistinct mafic infrared signatures. The restricted elevation range and draping sedimentary style of this unit suggests that it was formed during partial inundation of a previously existing valley.

The draping valley fill mantles the entire bottom of Valley A and extends north to an uncertain boundary with a lobe of the Syrtis Major lava flows that extends southeast toward the head of the valley. This zone (the foreground of Figure 19a) suggests that the lava flow terminates at the northwestern margin of the draping valley fill. It is also possible that the Syrtis Major flows continue downgradient into Valley A beneath a thin veneer of draping valley fill; however, lavas are not exposed at the surface anywhere further down the valley. 4.5.5. Elevation Alignment of Fluvial Features

With the exception of the inscribed channels, the late fluvial-lacustrine features discussed above occur at or below $-2,300 \mathrm{~m}$ across the entire study area. This elevation (highlighted in Figures 2, 3, and 9) is an open 


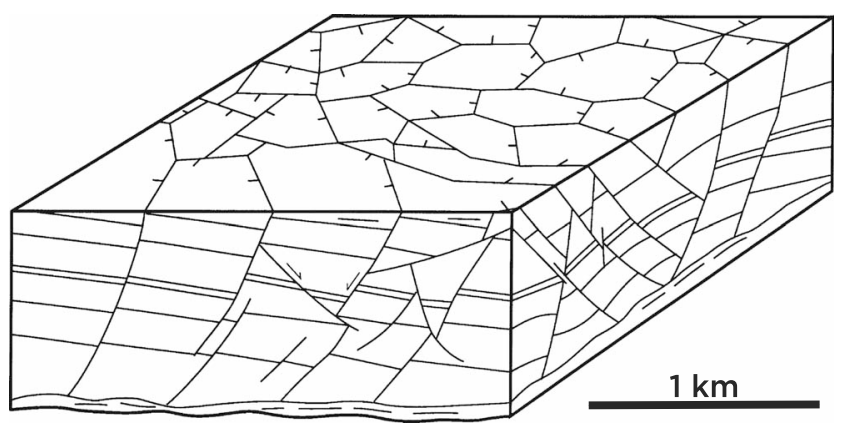

Figure 23. Schematic view of boxwork fracturing compiled from seismic well logs in the North Sea after Cartwright and Lonergan (1996). The polygonal geometry forms in the subsurface due to compaction during diagenesis and is found at similar scales in offshore basins on Earth as the exposures in Syrtis Major. contour connecting all the major valleys in the study area, including the closed Deep Basin and Erosional Window. The delta shown in Figure 20 has topsets just below an elevation of $-2,300 \mathrm{~m}$, and the basin floor surfaces and associated draping sedimentary deposits within North Basin and Deep Basin (Figure 21) are at or below this level (as low as $-2,800$ $m$ in Deep Basin). In North Basin, flat basin-floor surfaces cover most of the area within this contour. The Draping Valley Fill is also consistently associated with this contour, draping the interior of Valley A to an elevation of $-2,300 \mathrm{~m}$ over the entire length of the valley; $-2,300 \mathrm{~m}$ is also the transition elevation between the Syrtis Major lavas and the draping valley fill (Figure 19a); this transition zone at the upstream end of Valley A is separated from North Basin by the narrow Saddle Ridge, which has elevations just over $-2,300 \mathrm{~m}$. The alignment of postsulfate fluvial and lacustrine deposits at a single elevation suggests that this stage of deposition involved inundation of the entire study area to a single base level. The level is similar to the $-2,320 \mathrm{~m}$ preincision elevation of Jezero crater's eastern outflow channel (Fassett \& Head, 2005).

\section{Discussion}

\subsection{Deposition of the Layered Sulfates}

The sulfates have five key characteristics: (1) parallel, closely spaced bedding, which indicates sedimentary accumulation, (2) poor induration and susceptibility to erosion, (3) dips always $<10^{\circ}$ and mostly $<7^{\circ}$ with regionally variable orientations, (4) variable unit thickness, ranging up to $600 \mathrm{~m}$, and (5) unconformable emplacement on and thinning up to basin highs. Gentle structural folding can be excluded as a cause for dipping layers in the layered sulfates. The generation of folds requires basement-involved tectonic shortening that is not evident in the NE Syrtis region. Additionally, dip directions within the sulfates do not conform to a consistent fold pattern, and no tectonic stresses were present during diagenetic fracturing of the layered sulfates (section 4.2.2). Consequently, shallow but nonzero dips within the layered sulfates are best explained as depositional dips; we seek a sedimentary mechanism that can form thickly packaged, regionally extensive, shallowly dipping strata.

Depositional mechanisms that operate by sediment traction (Figure 4) are a poor fit for the layered sulfates. Shallow lake, evaporite playa, or eolian sedimentation could form the observed laterally continuous, meter-scale layering, but these mechanisms typically form deposits that onlap preexisting topography and fill localized, low-lying basins, with near-zero depositional dips (the basin floor unit is interpreted to represent this type of environment) rather than thinning against preexisting topographic highs. Deposits formed by fluvial networks would additionally be limited in extent and associated with clear erosive and constructional features such as valley networks and inverted channel casts (DiBiase et al., 2013; Fassett \& Head, 2008). The sulfates extend at least $50 \mathrm{~km}$ east of the Isidis inner rim, too far to have been formed from proximal alluvial sediments shed from local topographic highs, as has been proposed for some layered deposits in Valles Marineris (Fueten et al., 2011). Thick eolian sedimentary deposits generally have cross bedding, which is observable at orbital HiRISE scale in Gale Crater (Milliken et al., 2014) but not at Meridiani Planum (e.g., Grotzinger et al., 2005; Hayes et al., 2011); eolian deposits also tend to form horizontal bedsets due to water table-driven cementation (Kocurek, 1981), which are not observed. We consider three sedimentation mechanisms viable, all of which entail fallout from suspension: distal ash fall, dust deposition from ices, and deposition in a deep lake (or lakes).

There is significant global evidence of explosive volcanism on Mars (e.g., Broz \& Hauber, 2012), and ash falls have been suggested as a likely depositional mechanism for other layered deposits on Mars (Kerber et al., 2011, 2012), including in the eastern Medusae Fossae Formation, which hosts polygonal ridges interpreted as filled fractures (Kerber et al., 2017) that have similarities to those within the NE Syrtis layered sulfates. While Syrtis Major is mostly an effusive basaltic province (Hiesinger \& Head, 2004), there is significant evidence that Nili Patera in its center hosted major pyroclastic eruptions (e.g., Fawdon et al., 2015). Ghent et al. (2012) find signatures of devolatilization of a substantial amount of pyroclastic material within Isidis Planitia, but these postdate the Syrtis Major lava flows. 
The layered sulfates show no structures associated with chaotic pyroclastic emplacement or devolatilization that would be expected for large-volume ash flow deposits (e.g., Ghent et al., 2012). Instead, the dozens of similarly thick $(0.5-2.5 \mathrm{~m})$ beds with no evidence of unconformities internal to the deposit would require airfall ash emplacement from consistently small or distant eruptions, regularly paced and close in time. While ash fall cannot be excluded based on the structural form of the layered sulfates, the regularly spaced bedding lacking internal unconformities does not easily match a stochastic process such as pyroclastic volcanism.

Loess deposition, in which obliquity-mediated climate cycles drive the accumulation of airfall dust, likely explains some Martian layered sedimentary rocks (Bridges \& Muhs, 2012; Lewis et al., 2008; Lewis \& Aharonson, 2014). Niles and Michalski (2009) suggested that layered sulfates might occur as sublimation residues of ice-rich sediments. Crudely layered dust mounds left over from progressive sublimation of these deposits could exhibit shallow dips and drape prior topography (Michalski \& Niles, 2012; Michalski et al., 2013). Again, the number of layers, their regularity in size, and most importantly the lack of internal unconformities are difficult to explain by any obliquity-driven sedimentation process. Additionally, sediment volume loss under airfall accumulation would entail gradual dehydration, dewatering, or sublimation rather than the single-stage, throughgoing episode of volume loss that impacted the layered sulfates [see Section 4.2).

If the layered sulfates were formed by airfall or ice deposition, correlative deposits should be found elsewhere in the study area, including at higher elevations; none are evident at NE Syrtis. Like airfall mechanisms, deep lacustrine sedimentation operates by fallout from suspension; it additionally forms deposits with regional architecture similar to the NE Syrtis layered sulfates. Terrestrial deepwater sedimentation occurs at large scale along passive continental margins, environments with both a steady supply of sediment, and steep underwater topography (,Stuart \& Caughey, 1977). Deepwater sedimentary packages can dip relatively steeply ( $\sim 5^{\circ}$ depositional dips are common) while maintaining internally parallel geometries; bedding both onlaps and dips concordantly with preexisting topography. Depositional sequences are limited in thickness by available accommodation space (i.e., the water depth). Prograding sediment accumulates outward from the basin margin and deposits thin and decreases in elevation into the basin (Mitchum et al., 1977). The geometry of preexisting topography, along with relationships between individual stratal sequences, leads to a diversity of bedding orientations with dominantly but not exclusively basinward dips (Mitchum et al., 1977). Deepwater sedimentation operated on Mars in crater lakes (Grotzinger et al., 2015), and deepwater deposition without regional topographic confinement has been proposed to explain large-scale sedimentary features observed from orbit in Valles Marineris (e.g., Dromart et al., 2007) and in the Northern Plains (Oehler \& Allen, 2012).

Major bedding features of the NE Syrtis layered sulfates, such as variable bedding dips (up to 7-10 ${ }^{\circ}$ ) and parallel-bedded stratal packages, are typical of deepwater sediments. Regionally, the extent, lack of confinement to localized basins, and onlapping and embayment of preexisting highs also suggest this type of sedimentation. Both the preserved thickness and overall elevation of the layered sulfates decrease eastward into Isidis Basin (Figure 9d), although the original thickness may be masked by erosion. Collectively, the structural characteristics of the layered sulfates are typical of deposits at the margin of a deep, water-filled basin. However, deposits formed by fallout from atmospheric suspension cannot be fully excluded based on layer orientations and deposit thickness alone.

\subsection{Postdepositional Alteration of the Layered Sulfates}

If the layered sulfates formed by deepwater sedimentation or any nonevaporative process, their sulfate mineral signature must arise from interaction withgroundwater after deposition; ample morphologic evidence of such groundwater activity exists.

\subsubsection{Interpretation of Boxwork Fractures}

The large scale and continuity, throughgoing nature, and positive relief of boxwork polygonal ridges are typical of injective dikes; however, the detailed morphology, mineralogy, and structural form of these ridges (section 4.2) instead clearly indicate a two-stage formation history: fracturing of the layered sulfates in a polygonal pattern followed by later mineralization channelized along fracture surfaces.

Tectonically controlled ridges are pervasive in the phyllosilicate-bearing Noachian basement of the NE Syrtis region. These features, classified as "Nili-type" ridges by Kerber et al. (2017), follow the NE-SW regional trend of the Nili Fossae circum-Isidis ring graben (Saper \& Mustard, 2013). The filled fractures in the overlying layered sulfates demonstrate a fundamentally different structural form: the absence of directional bias 
in ridge-orientation measurements implies that they were not tectonically controlled. Instead, fracturing occurred in an isotropic regional stress field, under volume loss and internal contraction.

Several mechanisms are known to generate polygonal fractures through volume loss in sedimentary material. Melting is a common process forming polygonal "patterned ground" on Earth (e.g., Kocurek \& Hunter, 1986) and on Mars (El-Maarry et al., 2010). However, it generally occurs at near the free surface and involves sagging and large volumetric reductions that can disrupt or destroy internal layering (Soare et al., 2017). Typical dessication polygons such as mud cracks are generally vertical and tied to the free surface; they tend to form hexagonal patterns due to progressive annealing. By contrast, fractures in the sulfate unit (1) have $90^{\circ}$ preferred intersection angles and $\mathrm{T}$ junctions, (2) are both straight and curvilinear, (3) penetrate the full exposed thickness of the layered sulfates, and (4) are steeply dipping and vertical (Figure 14). These characteristics show that the fractures resulted from a single stage of volume loss (Goehring et al., 2010) and were not formed at the free surface.

One type of fracture that matches these characteristics is three-dimensional "polygonal faulting" (Goulty, 2008), which forms during diagenesis and dewatering of cohesive, clay-rich, or chalk-rich sediments. These features are often found in shallow offshore sedimentary basins on Earth (Cartwright \& Lonergan, 1996). Most examples of polygonal faulting on Earth are at similar scales to that examined in this study with 500-m polygon domains typical (Figure 23). The scale of boxwork domains is controlled by the strength and cohesion of sediments undergoing diagenesis (Cartwright \& Lonergan, 1996; Goulty, 2008). Most examples of polygonal fractures occur a few hundred meters below the seafloor in continental-margin sedimentary basins; these have been investigated solely with seismic imaging (e.g., Gay et al., 2004). Tewksbury et al. (2014) document a rare surface-exposed polygonal fault network in Egypt.

Key to polygonal faulting is that during compaction-driven dewatering and diagenesis, volume loss creates localized extensional stresses. The exact mechanism causing the initiation of polygonal faults is unclear, but synaresis (e.g., Siebach et al., 2014), overburden, and density inversion are several possibilities. The depth of burial required for faulting to initiate is unclear, but depths of $100 \mathrm{~m}$ or more are typical in submarine settings (Cartwright, 2011; Goulty, 2008). Once faults are initiated, the numerous T junction and right-angle crossing fractures characteristic of this mechanism are due to a preference for linear defect propagation as dewatering progresses. Three-dimensional material shrinkage is converted to one-dimensional compaction by small-magnitude slip along fault surfaces. This suggests small bedding offsets and dip changes between boxwork domains, matching the character of boxwork in the layered sulfates.

On Mars, Oehler and Allen (2012) proposed polygonal faulting as a mechanism to explain $\sim 2$ - to 10-km polygons expressed on the surface of Acidalia and Utopia Planitia, using this to argue for their formation in a subaqueous setting. Similar features have also been attributed to periglacial processes (e.g., Haltigin et al., 2014). Unlike these examples, the northeast Syrtis layered sulfates show the full 3-D geometry of the fault network, which allows a much clearer identification of polygonal faulting, since the ridge characteristics match the scale, morphology, and penetrative nature of the fractures.

\subsubsection{Implications for Sediment Size and Amount of Burial}

Based on the character of Earth analogs, polygonal faulting has a particular set of implications for sediment characteristics and diagenetic environment. Polygonal faults dependably involve dewatering of fine grained (silt/clay), water-rich sediments under three-dimensional compaction in the subsurface. Dewatering solely by compaction might require a few hundred meters of sediment above presently exposed ridges in the layered sulfates. However, dewatering may require less overburden in cases where drying conditions are favored by thermal/climatic factors (e.g., arid, evaporative conditions). Boxwork fracturing is chiefly found in the western part of the study area, and most areas of boxwork cluster in basin lows, which are predicted to be sufficiently buried based on projection of current exposures (Figure 9). A clear exception is the boxwork fractures in $n f 4$, which occur within some of the highest-elevation exposures of the sulfates in the study area (Figure 6c). The presence of boxwork at these high elevations requires either substantial overburden at levels above the currently preserved sulfates or volume loss without significant burial, possibly by changes in the hydration state of water-bearing minerals.

The chief factor permitting polygonal faulting for fine-grained sediments is the internal friction angle, which sets the stress threshold to initiate fracturing. For silt- and mud-sized sediment, low internal friction allows defects to form and propagate under small, localized stresses (Cartwright \& Lonergan, 1996; Goulty, 2008). Polyhydrated sulfates often have $>10 \mathrm{wt}$. \% water, and fine-grained polyhydrated sulfate sediments 
would have characteristics conducive to polygonal faulting. Fracture mineralization is also indicative of fine-grained sediments: channelization of altering fluids along fractures suggests that the bulk of the unit has low permeability. In contrast, sand-sized sediments have open pore spaces and easily permit fluid migration.

The formation of boxwork polygonal ridges by the mechanism outlined above requires thick, initially water-saturated, fine-grained sediments that undergo single-phase volume loss after deposition of the entire package. As such, boxwork fractures align with the unit's structural geometry and layer orientations to suggest a deep lacustrine sedimentary origin for the layered sulfates.

\subsubsection{Mineralization of Fractures and Implications for Water Volume}

The parallel-sided, or isopachous, geometry of boxwork fractures, their current existence as resistant ridges, and a mineralogy distinct from the rest of the unit indicate the mineralization of preexisting fractures. The diffuse "halo" around some fractures (Figure 12) represents an interaction between fracture-filling material and a relatively impermeable groundmass. These morphologies can be formed by either fracture-filling cements that close an open fracture inward or an outward-propagating zone of alteration around a channel carrying reactive fluid (e.g., Nelson et al., 1999). Such a fluid would either chemically alter the groundmass of the unit or fill pores with light-toned cement.

The margin of Isidis Basin is modeled as an area of groundwater upwelling (Andrews-Hanna \& Lewis, 2011), and the deep basins in NE Syrtis would have the strongest topographic gradient in the region. This may suggest the focusing of abundant groundwater into the base of the layered sulfates to drive fracture mineralization. The presence of jarosite mineral detections on the ridges indicates infiltration of pH<4 fluids (e.g., Ehlmann \& Mustard, 2012; McCollom et al., 2013). Fluid leaching combined with induration has been proposed as a mechanism to develop haloed fractures in Candor Chasma (Okubo \& McEwen, 2007). Double-walled fractures similar to those seen here have been identified from orbit in smaller (decameter-scale) boxwork fractures in the upper Gale Crater mound (Siebach \& Grotzinger, 2014). For the Gale Crater system, a mass balance given plausible limits on pore water volume suggested that the formation of $1.75 \mathrm{e} 6 \mathrm{~m}^{3}$ of cemented fractures required the evaporation of at least $\sim 0.4 \mathrm{~km}^{3}$ of water (Siebach \& Grotzinger, 2014). Using the same $30 \%$ porosity and mineral precipitation assumptions and a fracture volume of $0.86 \mathrm{~km}^{3}$ ( $860 \mathrm{~km}$ of fractures mapped, an average vertical penetration of $200 \mathrm{~m}$, and a fracture width of $5 \mathrm{~m}$ ), we estimate that the evaporation of $\sim 515 \mathrm{~km}^{3}$ of water was required to mineralize the fractures within the layered sulfates.

In a few locations, localized, pervasive jarosite mineralization within the groundmass of the sulfate unit is unchannelized and at the high end of alteration intensity observed (Figure 15). Intricately patterned exposures in the Erosional Window could be driven by surface water as well as groundwater with mineralization occurring in a transient, evaporitive lake fed by periodic outflow-channel inundation (Mangold et al., 2008a).

\subsection{Comparison With Other Martian Layered Deposits}

The layered sulfates at NE Syrtis share some features with other layered deposits in the martian midlatitudes, many of which show sulfate mineral signatures but range in local characteristics and structural context.

Many thick layered deposits on Mars have been attributed to deepwater sedimentation. The sulfate-bearing interior layered deposits (ILDs) in Valles Marineris occur in steep-walled, connected basins that could host deepwater deposition (e.g., Lucchitta et al., 1994; Warner et al., 2013); sedimentary structures typical of deepwater, prograding sediments have been identified in the walls of Melas Chasma (Dromart et al., 2007) at elevations of $\sim-1,700 \mathrm{~m}$. In other areas, warped, folded, and locally dislocated strata suggest dipping sedimentation and soft-sediment slumping typical of deepwater environments (Metz et al., 2010; Okubo et al., 2008; Roach et al., 2009).

Evaporite or evaporite-mediated eolian sedimentation has also been suggested to form some Valles Marineris ILDs (Flahaut et al., 2010; Murchie et al., 2009; Roach et al., 2009). Possibly related sulfate-bearing layered deposits on the adjacent highland plains (Fueten et al., 2011) could not have formed in any conceivable deepwater basin. The deposits on the highland plains co-occur with preserved channel networks (Mangold et al., 2008b) and were likely formed by fluvial or lacustrine processes, although ash fall and aeolian deposition with later weathering are not excluded (Weitz et al., 2008).

Sulfate-bearing sedimentary rocks are widespread at Meridiani Planum; those investigated by the Opportunity rover contain aeolian sediments reworked by fluvial processes (Grotzinger et al., 2005; McLennan et al., 2005). These deposits may be related to layered, sulfate-bearing deposits that mantle the adjacent high- 
lands at Arabia Terra. These deposits are relatively thick (up to $200 \mathrm{~m}$ ), internally layered and capped by a thin, resistant unit (Fassett \& Head, 2007). Like the Valles Marineris rim deposits, sulfate-bearing sediments at Arabia Terra are perched on the highlands and cannot be related to deepwater deposition. Instead, hydrological modeling suggests formation due to a perched water table mediating detrital sedimentation and groundwater upwelling and evaporation in the highlands during the Noachian-Hesperian transition (Andrews-Hanna et al., 2007, 2010; Zabrusky et al., 2012).

At Sinus Meridiani, thick, enigmatic sulfate-bearing "etched terrain" units are stratigraphically beneath the units investigated by the Opportunity rover (Michalski et al., 2013; Wiseman et al., 2010). Layered deposits of uncertain origin form a thick, partially incised bedrock sequence at Aeolis Dorsa (Kite et al., 2015). Thick layered deposits also form the substrate for valley networks and paleolake deposits within Melas Chasma (Quantin et al., 2005). These sulfate-bearing layered deposits are unconfined by topography but otherwise similar to sequences that occur in bounded crater basins, such as Aram Chaos (Lichtenberg et al., 2010).

The construction of thick sedimentary sequences, including the NE Syrtis sulfates, in either sediment filled or open lacustrine basins, could straightforwardly relate to the global groundwater system modeled to drive aggradation of the perched Arabia Terra deposits (Andrews-Hanna et al., 2007, 2010). These models imply that low-elevation basins would contain either thick evaporite sequences supported by high water tables or open-basin bodies of water fed at least partially by upwelling groundwater.

Understanding of formation mechanisms of thick, low-elevation layered deposits and their potential links with NE Syrtis sulfates is inhibited by poorly-known layer orientations. The Meridiani deposits have low $\operatorname{dips}\left(<1^{\circ}\right)$ based on regionally traced layers (Hynek \& Phillips, 2008), but no localized bedding information is captured. Many deposits have rigorously described mineralogy but more ambiguous internal structure (Roach et al., 2009; Wiseman et al., 2010). Future work on these deposits using the structural approach taken by this study will illuminate any structural similarities to the NE Syrtis sulfates and allow our proposed deepwater sedimentation mechanism to be tested in more places. Alternative hypotheses of airfall or ice-mediated deposition can also be evaluated.

\subsection{Containing Basin for the Layered Sulfates}

A key question for the deep subaqueous sedimentation hypothesis is the geometry and confinement of the containing basin. Deposition of the sulfates in a deep subaqueous setting would require a basin filled to about $-1,600 \mathrm{~m}$, the maximum elevation of the layered sulfates in the region (Figure 9d). Given the location at the edge of Isidis Basin, the basin is not confined by current topography. Two possible mechanisms to inundate the NE Syrtis region deeply enough to deposit the layered sulfates include a global ocean or an ice-dammed lake marginal to an ice sheet within Isidis Basin.

A basin at the margin of a global ocean would provide a straightforward analog to Earth. However, evidence for a global ocean is uncertain (e.g., Ghatan \& Zimbelman, 2006), and the required topographic level is hundreds of meters higher than putative ocean deposits (DiBiase et al., 2013; Perron et al., 2007). An alternative is confinement of a large lake by a basin-filling ice sheet, which could provide the regional topographic confinement and be a source of abundant meltwater. Ivanov and Head (2003) and Ivanov et al. (2012) suggested that ice sheets covered parts of the Isidis Basin rings and floor during the early to late Hesperian ( 3.5-3.1 $\mathrm{Ga}$ ) and eroded previously existing layered sediments, based on morphologic similarities of sinuous ridges to terrestrial, subglacially formed eskers. Soucek et al. (2015) modeled the potential extent of a crater-filling ice sheet given expected precipitation and climate, finding that an ice sheet would preferentially mantle the NE Syrtis region relative to other parts of the Isidis rim. Such an ice sheet could dam a regional lake including NE Syrtis, creating the conditions for deposition of the layered sulfates.

A crucial question associated with both the ice-dammed regional lake and hemispheric ocean hypotheses is whether the climatic state supporting either of these phenomena would support a lake for a sufficient cumulative lifetime to produce the observed sedimentation. If its meter-thick beds were laid in uninterrupted annual cycles, the layered sulfates could have formed in as little as $~ 1,000$ years. However, with reasonable constraints on sediment supply and intermittency, deposition rates would likely be orders of magnitude slower. On Earth, lakes and small basinal seas commonly show sedimentation rates of 0.1 to $10 \mathrm{~m} / \mathrm{kyr}$ (Sadler, 1981), corresponding to 100 to 10 Myr to accumulate the thickness of the layered sulfates. Abundant glacially eroded sediment at the margin of wet-based ice sheets can drive aggradation of $\sim 60 \mathrm{~m} / \mathrm{ka}$ 


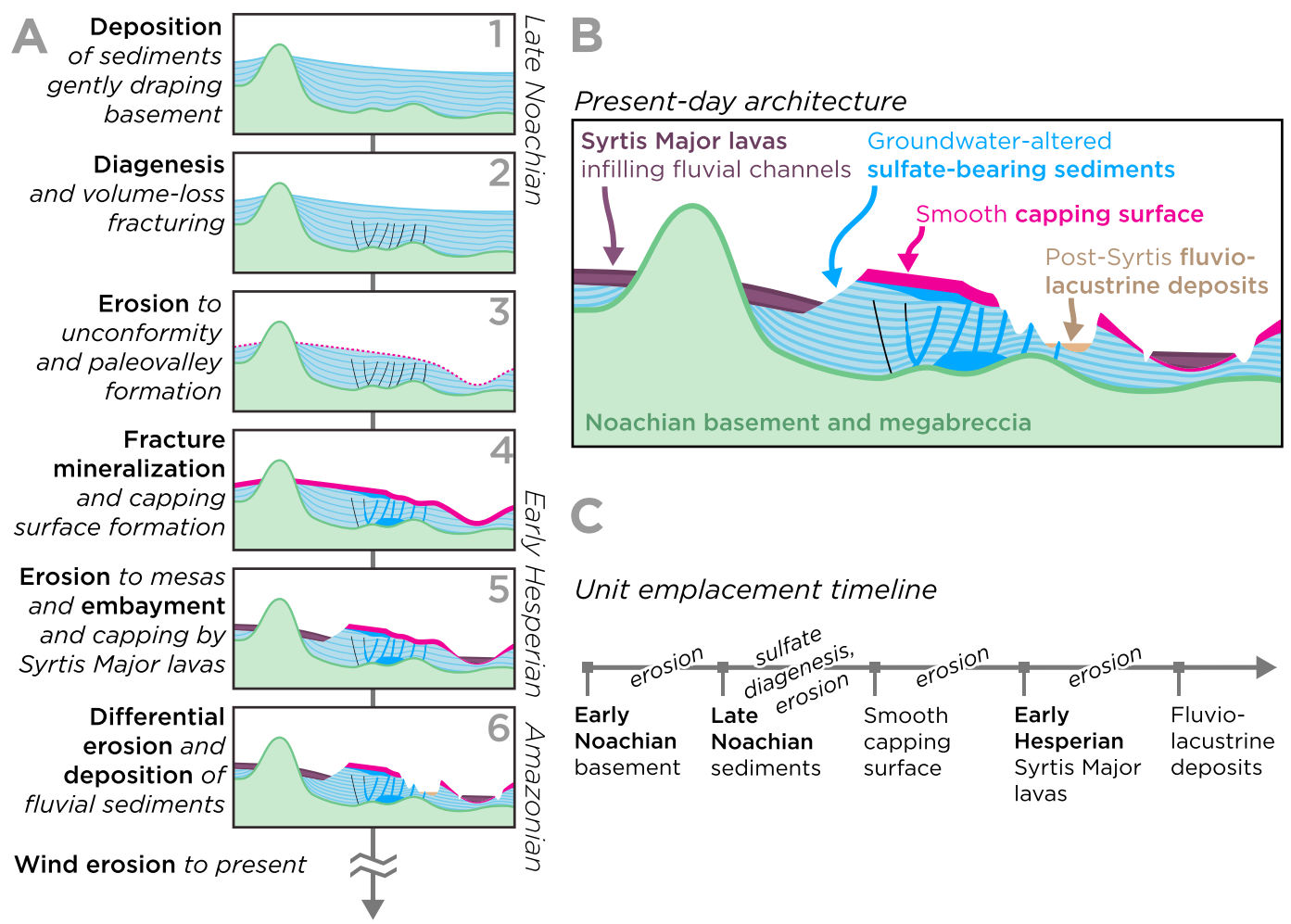

Figure 24. (a) Model emplacement and alteration history of the NE Syrtis layered sulfates. The relative timing of steps 3 and 4 is uncertain, and the genesis of the smooth capping surface is unknown. (b) Schematic cross section, equivalent to panel 6 of (a), showing the present-day stratigraphic architecture of NE Syrtis Major. (c) Simplified timeline showing the age of the units in (b) and the diagenetic and erosional phases that separated these depositional events.

(Dowdeswell \& Siegert, 1999). However, extrapolation from terrestrial sediment fluxes and environments is of limited value for forecasting cyclical sedimentation rates in an unknown Martian surface aqueous system.

The regional scale of proposed basin confinement, by either an Isidis-filling ice sheet or a hemispheric ocean, also raises a key question of preservation: why are the layered sulfates only found at NE Syrtis? No comparable deposits have been found elsewhere on the rim of Isidis Basin, though the Libya Montes to the south are otherwise similar (Bishop et al., 2013). Erosion clearly played a major role: the layered sulfates are only preserved in association with more durable units such as the Syrtis Major lavas and mineralized boxwork fractures. In the absence of the fortuitous capping or groundwater interaction seen at NE Syrtis, any sulfates deposited elsewhere could easily be stripped away by wind erosion or later fluvial incision.

\subsection{Modification by Fluvial Erosion, Lavas, and Late Lake Deposits}

Another major finding of this study is continued erosion and fluvial activity postdating the layered sulfates. The long sedimentary history after layered sulfate deposition includes several phases of erosion, cap unit emplacement, further fluvial erosion, lava emplacement, and then still-later fluvial-lacustrine erosion and deposition. No matter how the layered sulfates formed, the smooth capping unit, Syrtis Major lavas, and late fluvial features formed significantly afterward. This history implies substantial episodic interaction with surface water significantly postdating the formation of the layered sulfates.

Angular differences between the smooth capping surfaces and the underlying sulfates indicate erosional truncation of the sulfates (Figures 6-19). This unconformity suggests the erosion of a significant volume of sulfates prior to cap unit formation. The observed smooth, featureless surface, low thermal inertia, and low crater retentivity are at odds with the observed resistant nature of the cap surface. A partly cemented sandstone, welded or later-indurated ash fall, highly degraded lava flow, or capping "duststone" (Bridges \& Muhs, 2012; Malin \& Edgett, 2000) could potentially generate the characteristics of the deposit. The jarosite-containing, light-toned "halo" extending up to $30 \mathrm{~m}$ beneath the capping unit (Figure 6a) could indicate interaction with the underlying sulfates during cementation of the capping surface or simply a weathered surface covered by the capping material. 
Valley A in the center of the study area is cut between Mesas $A$ and $B$, which are both topped by the smooth capping surface. Valley A and its upstream extension may be remnants of a major fluvial system that flowed from the northern margins of the Syrtis Major volcanic province (Figure 2b). Beginning in the early Hesperian, effusive Syrtis Major lava flows flowed through these preexisting fluvial channels and embayed the partially eroded layered sulfates at their southern margin in multiple locations, notably Valleys $A$ and $B$ (Figure 19b). Cap unit formation, paleovalley erosion, and embayment by lava flows did not occur as a single event, and these processes may have been interleaved and closely spaced in time during a geologically active late Noachian to Hesperian transition.

The latest fluvial systems within the study area start atop the Hesperian Syrtis Major flows and erode the capped sulfates and Noachian basement, forming deltas and inverted channels. The preserved fluvial and lacustrine deposits are relatively small, with sedimentary deposits at most $\sim 20 \mathrm{~m}$ thick atop the basement and layered sulfates, and ampitheater canyons cut back at most $1 \mathrm{~km}$ into the Syrtis Major lavas. The basin-fill and associated layered scarps in North Basin and Deep Basin show lacustrine deposition and phyllosilicate-bearing sediments; they indicate inundation of substantial portions of the study area after erosion of the layered sulfates.

The deltas, basin-filling deposits, and draping valley fill described above occur at similar topographic levels within the study area. This open-contour alignment of late sedimentary deposits suggests that they were deposited at a single base level, marginal to an open-basin lacustrine system not bounded within the study area. The $-2,300-\mathrm{m}$ elevation of these features is similar to that of the Jezero delta and outflow channel (Figure 2) and is near the elevation of the various deltas and coastline features making up the proposed coastline of a hemisphere-spanning ocean (Di Achille \& Hynek, 2010). The presence of phyllosilicates in layered scarps of the late sedimentary deposits at NE Syrtis (Figure 21) suggests that these deposits contain detrital material similar to that in the Jezero delta (Ehlmann et al., 2008b; Goudge et al., 2015).

The final resolvable phase of lacustrine activity in the area built a series of lakes in interconnected topographic lows within North Basin. The outlet channel leading eastward from North Basin shows that a lake filled this basin to $-2,400 \mathrm{~m}$ and drained to the east. That this outlet channel does not exit the basin at its current lowest-elevation location $(-2,550 \mathrm{~m}$ in $\mathrm{nf} 1)$ is consistent with a prior blockage of this exit or later erosion of the outlet (Skok \& Mustard, 2014). We propose that the current lowest exit in nf1 was blocked by layered sulfates prior to Amazonian wind-driven erosion of the layered sulfates.

Outflow features continuous with those mapped across the Syrtis Major lava plains to the south of the study area by Mangold et al. (2008a) suggest episodic, powerfully erosive flows across the Syrtis Major lava plains. Flow across the lava plains may have also caused episodic inundation of the Erosional Window in the southwest part of the study area, driving the intense and localized acid-sulfate alteration seen solely in this basin (Figure 15).

\section{Summary, Conclusions, and Future Work}

The layered sulfates at NE Syrtis Major form a thick (up to $600 \mathrm{~m}$ ) sedimentary package unconformable with the underlying Noachian basement and olivine-carbonate units. The polyhydrated-sulfate enriched, basaltic-composition sedimentary rock contains parallel, meter-scale beds that dip up to $7-10^{\circ}$ with no preferred direction. The unit thins against and embays basement highs, to a maximum elevation of $-1,600 \mathrm{~m}$. Boxwork polygonal ridges in the layered sulfates at hundreds of meters scale record fracture-generating volume loss during diagenesis, followed by the precipitation of jarosite-bearing material from fluids circulating through the fractures. Subsequent erosion of the surrounding material exposed the mineralized fractures as raised ridges.

Overall, the upper stratigraphy at NE Syrtis Major was built by a multistage history of water-related processes, likely spanning much of the Hesperian and perhaps into the Amazonian (Figure 24): The sulfates record (1) deposition atop the olivine-carbonate and $\mathrm{Fe} / \mathrm{Mg}$ phyllosilicate Noachian plains units, likely in a deepwater, subaqueous setting; (2) diagenetic dewatering, volume loss, and fracturing; (3) partial erosion to form paleotopography; and (4) mineralization of fractures and capping of partially eroded sulfates with the smooth capping surface. The extended history of these deposits then includes later (5) paleovalley incision, (6) capping and embayment by Hesperian Syrtis Major lavas, (7) differential erosion of sulfates and lavas to 
uncover adjacent deep basins, and (8) the construction of small fluvial-deltaic and lacustrine sedimentary deposits in these basins.

There is no evidence of either local topographic confinement of the sulfates or the existence of higher-elevation sulfates on the adjacent Nili Fossae Plains. Their meter-scale layered character lacking internal unconformities, fine grained nature, and thinning while onlapping topgraphic highs favors detrital sedimentation. If correct, this implies a deepwater setting in a lake system confined by an Isidis Basin-filling ice sheet or deposition at the margin of northern hemisphere ocean with a shoreline at a level much deeper than previously proposed. Neither explanation is fully satisfying, yet the specific characteristics of the deposit and its later fracturing are even less consistent with other lacustrine or aeolian mechanisms, airfall deposition (e.g., from ash) or deposition from ices emplaced by obliquity cycling.

Regardless of the depositional setting, volume-loss fracturing involves water-saturated or very hydrated deposits. Subsequent fracture mineralization requires abundant sulfate-bearing groundwater over hundreds of meters of depth. Both dewatering and jarosite mineralization occurred during the Noachian-Hesperian transition, well after clay and carbonate formation in the Noachian highlands. Later extensive erosion of the layered sulfates and superposed fluvial features on the Hesperian Syrtis Major lavas demonstrate that surface water was at least episodically present and shaped the landscape into the Late Hesperian and Early Amazonian. The pattern seen at NE Syrtis, of aggradation of thick layered deposits during the Noachian-Hesperian transition, followed by significant erosion and superposed fluviodeltaic deposits from the Late Hesperian to Early Amazonian, is thus the result of a Martian surface water cycle at least episodically active for much of the planet's history.

This study uses the maximum available resolution imagery across a wide area and integrated new techniques for DEM creation, error analysis and visualization; the level of detail presented here will be difficult to surpass using orbital data. The key unsolved questions of this study are most productively assessed at rover scale. Outcrop observation of sedimentary bedforms and grainsize within the layered sulfates would decisively confirm or refute our deep-basin sedimentation hypothesis. This result will inform future work on other layered sedimentary deposits globally. If deepwater sedimentation is confirmed, the variation in sedimentary textures within the sequence could indicate the size of the basin (ice sheet confined vs. open ocean). If airfall or ice-enriched sedimentation is confirmed, the sequence could indicate the timing of volcanic processes or climate cycles, respectively. Detailed chemical analysis of the filled volume loss fractures can distinguish between a top-down weathering and upwelling groundwater source of fracture-filling fluids and place firm bounds on the type and scale of groundwater interaction within the layered sulfates. Sufficient potassium might be present to place K-Ar dates to constrain absolute timing of alteration by isotopic analysis of the jarosite-filled fractures.

Acknowledgments

We would like to thank NASA for the Earth and Space Science Fellowship (NNX14AO61H, to D.P. Quinn) that funded this work, as well as a gift to Caltech by F. Stanback that supported early efforts in large 3-D data set creation and visualization. We also thank Nicholas Mangold and Paul Niles for their thoughtful reviews of this manuscript. A supporting information Table S1 containing the highest-quality layer orientation measurements is available with this publication. HiRISE elevation data sets created for this study are archived in the Planetary Data System, and the regional CTX elevation model is archived at CaltechData (https://doi. org/10.22002/D1.1087).

High-resolution, projected versions of Figures 2 and 3 are archived at

CaltechData (https://doi.org/10.22002/

D1.1085), along with a PostGIS

database containing all vector data, including all measured bedding traces, layer orientation fit data, structural control points, and geologic map data (https://doi.org/10.22002/D1.1086).
Additionally, detailed examination of relationships between the units described in this study would substantially clarify the sequence of geologic events affecting NE Syrtis and the surrounding region including the Jezero crater watershed. The origin of the smooth capping surface that unconformably overlies the layered sulfates is unknown, and the contact between the draping valley fill and the Syrtis Major lavas in Valley A may record the interaction of lavas with water-lain sedimentary deposits. Investigation of both of these features would clarify the timing and interplay of sulfate erosion, lava embayment, and the late fluvial-lacustrine history of the region (including a potential Late Hesperian or Early Amazonian inundation). These key features of the layered sulfates and their context can be evaluated in situ, within a $5 \mathrm{~km}$ wide area in $\mathrm{nf}$, near the point in the layered sulfates closest to the NE Syrtis Mars 2020 landing ellipse (as of early 2018). Along the way, the rover would investigate the Hesperian-Amazonian fluviodelatic basin floor deposits near $n f 3$ and $n f 5$. These deposits are significant because they are at a nearly identical base level to those found in Jezero crater. Such a $25-$ to $30-\mathrm{km}$ traverse with observation and sampling campaign has the potential to greatly illuminate the multistage history of aqueous activity captured in the upper stratigraphy of northern Syrtis Major and provide new insights into the Mars surface environment, its climate, and its habitability over a period spanning the Noachian to Amazonian.

\section{References}

Al-Masrahy, M. A., \& Mountney, N. P. (2015). A classification scheme for fluvial-aeolian system interaction in desert-margin settings. Aeolian Research, 17, 67-88. https://doi.org/10.1016/j.aeolia.2015.01.010

Andrews-Hanna, J. C., \& Lewis, K. W. (2011). Early Mars hydrology: 2. Hydrological evolution in the Noachian and Hesperian epochs. Journal of Geophysical Research, 116, E02007. https://doi.org/10.1029/2010JE003709 
Andrews-Hanna, J. C., Phillips, R. J., \& Zuber, M. T. (2007). Meridiani Planum and the global hydrology of Mars. Nature, 446(7132), 163-166. https://doi.org/10.1038/nature05594

Andrews-Hanna, J. C., Zuber, M. T., Arvidson, R. E., \& Wiseman, S. M. (2010). Early Mars hydrology: Meridiani playa deposits and the sedimentary record of Arabia Terra. Journal of Geophysical Research, 115, E06002. https://doi.org/10.1029/2009JE003485

Baratoux, D., Pinet, P., Gendrin, A., Kanner, L., Mustard, J., Daydou, Y., et al. (2007). Mineralogical structure of the subsurface of Syrtis Major from OMEGA observations of lobate ejecta blankets. Journal of Geophysical Research, 112, E08S05. https://doi.org/10. 1029/2007JE002890

Baratoux, D., Toplis, M. J., Monnereau, M., \& Sautter, V. (2013). The petrological expression of early Mars volcanism. Journal of Geophysical Research: Planets, 118, 59-64. https://doi.org/10.1029/2012JE004234

Bibring, J.-P., Langevin, Y., Mustard, J. F., Poulet, F., Arvidson, R., Gendrin, A., et al. (2006). Global mineralogical and aqueous Mars history derived from OMEGA/Mars Express data. Science, 312(5772), 400-404. https://doi.org/10.1126/science.1122659

Bishop, J. L., Tirsch, D., Tornabene, L. L., Jaumann, R., McEwen, A. S., McGuire, P. C., et al. (2013). Mineralogy and morphology of geologic units at Libya Montes, Mars: Ancient aqueously derived outcrops, mafic flows, fluvial features, and impacts. Journal of Geophysical Research: Planets, 118, 487-513. https://doi.org/10.1029/2012JE004151

Bondre, N. R., Duraiswami, R. a., \& Dole, G. (2004). A brief comparison of lava flows from the Deccan Volcanic Province and the Columbia-Oregon Plateau Flood Basalts: Implications for models of flood basalt emplacement. Journal of Earth System Science, 113(4), 809-817. https://doi.org/10.1007/BF02704039

Broz, P., \& Hauber, E. (2012). A unique volcanic field in Tharsis, Mars: Pyroclastic cones as evidence for explosive eruptions. Icarus, 218(1), 88-99. https://doi.org/10.1016/j.icarus.2011.11.030

Bramble, M. S., Mustard, J. F., \& Salvatore, M. R. (2017). The geological history of Northeast Syrtis Major, Mars. Icarus, 293, 66-93. https:// doi.org/10.1016/j.icarus.2017.03.030

Bridges, N. T., \& Muhs, D. R. (2012). Duststones on Mars: Source, transport, deposition, and erosion. In J. P.Grotzinger \& R. E.Milliken (Eds.), Sedimentary geology of Mars (Vol. 102, pp. 169-182). Tulsa, OK: SEPM. https://doi.org/10.2110/pec.12.102.0169

Cartwright, J. (2011). Diagenetically induced shear failure of fine-grained sediments and the development of polygonal fault systems. Marine and Petroleum Geology, 28(9), 1593-1610. https://doi.org/10.1016/j.marpetgeo.2011.06.004

Cartwright, J. A., \& Lonergan, L. (1996). Volumetric contraction during the compaction of mudrocks: A mechanism for the development of regional-scale polygonal fault systems. Basin Research, 8(2), 183-193. https://doi.org/10.1046/j.1365-2117.1996.01536.x

Caumon, G., Collon-Drouaillet, P., Le Carlier De Veslud, C., Viseur, S., \& Sausse, J. (2009). Surface-based 3D modeling of geological structures. Mathematical Geosciences, 41(8), 927-945. https://doi.org/10.1007/s11004-009-9244-2

Clenet, H., Pinet, P., Georges, C., Daydou, Y., Heuripeau, F., Christine, R., et al. (2013). A systematic mapping procedure based on the Modified Gaussian Model to characterize magmatic units from olivine/pyroxenes mixtures: Application to the Syrtis Major volcanic shield on Mars. Journal of Geophysical Research: Planets, 118, 1632-1655. https://doi.org/10.1002/jgre.20112

Di Achille, G., \& Hynek, B. M. (2010). Ancient ocean on Mars supported by global distribution of deltas and valleys. Nature Geoscience, 3(7), 459-463. https://doi.org/10.1038/ngeo891

DiBiase, R. A., Limaye, A. B., Scheingross, J. S., Fischer, W. W., \& Lamb, M. P. (2013). Deltaic deposits at Aeolis Dorsa: Sedimentary evidence for a standing body of water on the northern plains of Mars. Journal of Geophysical Research: Planets, 118, 1285-1302. https://doi.org/10.1002/jgre.20100

Dowdeswell, J. A., \& Siegert, M. J. (1999). Ice-sheet numerical modeling and marine geophysical measurements of glacier-derived sedimentation on the Eurasian Arctic continental margins. Geological Society of America Bulletin, 111(7), 1080-1097. https://doi.org/10.1130/0016-7606(1999)111<1080:ISNMAM>2.3.CO;2

Dromart, G., Quantin, C., \& Olivier, B. (2007). Stratigraphic architectures spotted in southern Melas Chasma, Valles Marineris, Mars. Geology, 35(4), 363-366. https://doi.org/10.1130/G23350A.1

Ehlmann, B. L., \& Edwards, C. S. (2014). Mineralogy of the Martian surface. Annual Review of Earth and Planetary Sciences, 42, 291-315. https://doi.org/10.1146/annurev-earth-060313-055024

Ehlmann, B. L., \& Mustard, J. F. (2012). An in-situ record of major environmental transitions on early Mars at Northeast Syrtis Major. Geophysical Research Letters, 39, L11202. https://doi.org/10.1029/2012GL051594

Ehlmann, B. L., Mustard, J. F., Fassett, C. I., Schon, S. C., Head, J. W. III, Des Marais, D. J., et al. (2008b). Clay minerals in delta deposits and organic preservation potential on Mars. Nature Geoscience, 1(6), 355-358. https://doi.org/10.1038/ngeo207

Ehlmann, B., Mustard, J., \& Murchie, S. (2008a). Orbital identification of carbonate-bearing rocks on Mars. Science, $322,1828-1832$.

Ehlmann, B. L., Mustard, J. F., Murchie, S. L., Bibring, J.-P., Meunier, A., Fraeman, A. A., \& Langevin, Y. (2011). Subsurface water and clay mineral formation during the early history of Mars. Nature, 479(7371), 53-60. https://doi.org/10.1038/nature10582

Ehlmann, B. L., Mustard, J. F., Swayze, G. A., Clark, R. N., Bishop, J. L., Poulet, F., et al. (2009). Identification of hydrated silicate minerals on Mars using MRO-CRISM: Geologic context near Nili Fossae and implications for aqueous alteration. Journal of Geophysical Research, 114, E00D08. https://doi.org/10.1029/2009JE003339

El-Maarry, M. R., Markiewicz, W. J., Mellon, M. T., Goetz, W., Dohm, J. M., \& Pack, A. (2010). Crater floor polygons: Desiccation patterns of ancient lakes on Mars?Journal of Geophysical Research, 115, E10006. https://doi.org/10.1029/2010JE003609

Fassett, C. I., \& Head, J. W. (2005). Fluvial sedimentary deposits on Mars: Ancient deltas in a crater lake in the Nili Fossae region. Geophysical Research Letters, 32, L14201. https://doi.org/10.1029/2005GL023456

Fassett, C. I., \& Head, J. W. (2007). Layered mantling deposits in northeast Arabia Terra, Mars: Noachian-Hesperian sedimentation, erosion, and terrain inversion. Journal of Geophysical Research, 112, E08002. https://doi.org/10.1029/2006JE002875

Fassett, C. I., \& Head, J. W. (2008). The timing of martian valley network activity: Constraints from buffered crater counting. Icarus, 195(1), 61-89. https://doi.org/10.1016/j.icarus.2007.12.009

Fawdon, P., Skok, J. R., Balme, M. R., Vye-Brown, C. L., Rothery, D. A., \& Jordan, C. J. (2015). The geological history of Nili Patera. Mars, 120(5), 951-977. https://doi.org/10.1002/2015JE004795

Fergason, R. L., Christensen, P. R., \& Kieffer, H. H. (2006). High-resolution thermal inertia derived from the Thermal Emission Imaging System (THEMIS): Thermal model and applications: THEMIS THERMAL INERTIA. Journal of Geophysical Research, 111, E12004. https://doi.org/10.1029/2006JE002735

Flahaut, J., Quantin, C., Allemand, P., Thomas, P., \& Le Deit, L. (2010). Identification, distribution and possible origins of sulfates in Capri Chasma (Mars), inferred from CRISM data. Journal of Geophysical Research, 115, E11007. https://doi.org/10.1029/2009JE003566

Frey, H. (2008). Ages of very large impact basins on Mars: Implications for the late heavy bombardment in the inner solar system. Geophysical Research Letters, 35, L13203. https://doi.org/10.1029/2008GL033515 
Fueten, F., Flahaut, J., Le Deit, L., Stesky, R., Hauber, E., \& Gwinner, K. (2011). Interior layered deposits within a perched basin, southern Coprates Chasma, Mars: Evidence for their formation, alteration, and erosion. Journal of Geophysical Research, 116, E02003. https://doi. org/10.1029/2010JE003695

Gay, A., Lopez, M., Cochonat, P., \& Sermondadaz, G. (2004). Polygonal faults-furrows system related to early stages of compaction-Upper Miocene to recent sediments of the Lower Congo Basin. Basin Research, 16(1), 101-116.

Gendrin, A., Mangold, N., Bibring, J.-P., Langevin, Y., Gondet, B., Poulet, F., et al. (2005). Sulfates in Martian layered terrains: The OMEGA/Mars Express view. Science (New York N.Y.), 307(5715), 1587-91. https://doi.org/10.1126/science.1109087

Ghatan, G. J., \& Zimbelman, J. R. (2006). Paucity of candidate coastal constructional landforms along proposed shorelines on Mars: Implications for a northern lowlands-filling ocean. Icarus, 185(1), 171-196. https://doi.org/10.1016/j.icarus.2006.06.007

Ghent, R. R., Anderson, S. W., \& Pithawala, T. M. (2012). The formation of small cones in Isidis Planitia, Mars through mobilization of pyroclastic surge deposits. Icarus, 217(1), 169-183. https://doi.org/10.1016/j.icarus.2011.10.018

Goehring, L., Conroy, R., Akhter, A., Clegg, W. J., \& Routh, A. F. (2010). Evolution of mud-crack patterns during repeated drying cycles. Soft Matter, 6(15), 3562-3567. https://doi.org/10.1039/B922206E

Goudge, T. A., Milliken, R. E., Head, J. W., Mustard, J. F., \& Fassett, C. I. (2017). Sedimentological evidence for a deltaic origin of the western fan deposit in Jezero crater, Mars and implications for future exploration. Earth and Planetary Science Letters, 458, 357-365. https://doi. org/10.1016/j.epsl.2016.10.056

Goudge, T. A., Mustard, J. F., Head, J. W., Fassett, C. I., \& Wiseman, S. M. (2015). Assessing the mineralogy of the watershed and fan deposits of the Jezero crater paleolake system, Mars. Journal of Geophysical Research: Planets, 102, 775-808. https://doi.org/10. 1002/2014JE004782

Goulty, N. R. (2008). Geomechanics of polygonal fault systems: A review. Petroleum Geoscience, 14(4), 389-397. https://doi.org/10. 1144/1354-079308-781

Grotzinger, J. P., Arvidson, R. E., Bell, J. F., Calvin, W., Clark, B. C., Fike, D. A., et al. (2005). Stratigraphy and sedimentology of a dry to wet eolian depositional system, Burns formation, Meridiani Planum, Mars. Earth and Planetary Science Letters, 240(1), 11-72. https:// doi.org/10.1016/j.epsl.2005.09.039

Grotzinger, J. P., Crisp, J., Vasavada, A. R., Anderson, R. C., Baker, C. J., Barry, R., et al. (2012). Mars science laboratory mission and science investigation. Space Science Reviews, 170, 5-56. https://doi.org/10.1007/s11214-012-9892-2

Grotzinger, J. P., Gupta, S., Malin, M. C., Rubin, D. M., Schieber, J., Siebach, K., et al. (2015). Deposition, exhumation, and paleoclimate of an ancient lake deposit, Gale crater, Mars. Science, 350(6257), aac7575-aac7575. https://doi.org/10.1126/science.aac7575

Grotzinger, J. P., \& Milliken, R. E. (2012). Sedimentary Geology of Mars.

Grotzinger, J. P., Sumner, D. Y., Kah, L. C., Stack, K., Gupta, S., Edgar, L., et al. (2013). A habitable fluvio-lacustrine environment at Yellowknife Bay, Gale Crater, Mars. Science, $342,6169$.

Haltigin, T., Pollard, W., Dutilleul, P., Osinski, G., \& Koponen, L. (2014). Co-evolution of polygonal and scalloped terrains, southwestern Utopia Planitia, Mars. Earth and Planetary Science Letters, 387, 44-54. https://doi.org/10.1016/j.epsl.2013.11.005

Hamilton, V. E., \& Christensen, P. R. (2005). Evidence for extensive, olivine-rich bedrock on Mars. Geology, 33(6), 433. https://doi.org/10. $1130 / \mathrm{G} 21258.1$

Harvey, R. P., \& Griswold, J. (2010). Burial, exhumation, metamorphism and other dastardly deeds exposed at the Hesperian/Noachian boundary in the southern Nili Fossae region. Lunar and Planetary Science Conference, 41, 2045.

Hayes, A. G., Grotzinger, J. P., Edgar, L. A., Squyres, S. W., Watters, W. A., \& Sohl-Dickstein, J. (2011). Reconstruction of eolian bed forms and paleocurrents from cross-bedded strata at Victoria Crater, Meridiani Planum, Mars. Journal of Geophysical Research, 116, E00F21. https://doi.org/10.1029/2010JE003688

Hiesinger, H., \& Head, J. W. (2004). The Syrtis Major volcanic province, Mars: Synthesis from Mars Global Surveyor data. Journal of Geophysical Research, 109, E01004. https://doi.org/10.1029/2003JE002143

Hoefen, T. M., Clark, R. N., Bandfield, J. L., Smith, M. D., Pearl, J. C., \& Christensen, P. R. (2003). Discovery of olivine in the Nili Fossae region of Mars. Science (New York N.Y.), 302(5645), 627-30. https://doi.org/10.1126/science.1089647

Howard, A. D., Moore, J. M., \& Irwin, R. P. (2005). An intense terminal epoch of widespread fluvial activity on early Mars: 1. Valley network incision and associated deposits. Journal of Geophysical Research, 110, E12S14. https://doi.org/10.1029/2005JE002459

Hurowitz, J. A., Fischer, W. W., Tosca, N. J., \& Milliken, R. E. (2010). Origin of acidic surface waters and the evolution of atmospheric chemistry on early Mars. Nature Geoscience, 3(5), 323-326. https://doi.org/10.1038/ngeo831

Hynek, B. M., \& Phillips, R. J. (2008). The stratigraphy of Meridiani Planum, Mars, and implications for the layered deposits' origin. Earth and Planetary Science Letters, 274, 214-220. https://doi.org/10.1016/j.epsl.2008.07.025

Irwin, R. P., Howard, A. D., Craddock, R. A., \& Moore, J. M. (2005). An intense terminal epoch of widespread fluvial activity on early Mars: 2. Increased runoff and paleolake development. Journal of Geophysical Research, 110, E12S15. https://doi.org/10.1029/2005JE002460

Ivanov, M. A., \& Head, J. (2003). Syrtis Major and Isidis Basin contact: Morphological and topographic characteristics of Syrtis Major lava flows and material of the Vastitas Borealis Formation. Journal of Geophysical Research, 108(E6), 5063. https://doi.org/10.1029/ 2002JE001994

Ivanov, M. A., Hiesinger, H., Erkeling, G., Hielscher, F. J., \& Reiss, D. (2012). Major episodes of geologic history of Isidis Planitia on Mars. Icarus, 218(1), 24-46. https://doi.org/10.1016/j.icarus.2011.11.029

Kaasalainen, H., \& Stefánsson, A. (2011). Sulfur speciation in natural hydrothermal waters, Iceland. Geochimica et Cosmochimica Acta, 75(10), 2777-2791. https://doi.org/10.1016/j.gca.2011.02.036

Kerber, L., Dickson, J. L., Head, J. W., \& Grosfils, E. B. (2017). Polygonal ridge networks on Mars: Diversity of morphologies and the special case of the Eastern Medusae Fossae Formation. Icarus, 281, 200-219. https://doi.org/10.1016/j.icarus.2016.08.020

Kerber, L., Head, J. W., Madeleine, J. B., Forget, F., \& Wilson, L. (2011). The dispersal of pyroclasts from Apollinaris Patera, Mars: Implications for the origin of the Medusae Fossae Formation. Icarus, 216(1), 212-220. https://doi.org/10.1016/j.icarus.2011.07.035

Kerber, L., Head, J. W., Madeleine, J.-B., Forget, F., \& Wilson, L. (2012). The dispersal of pyroclasts from ancient explosive volcanoes on Mars: Implications for the friable layered deposits. Icarus, 219(1), 358-381. https://doi.org/10.1016/j.icarus.2012.03.016

Kirk, R. L., Howington-Kraus, E., Redding, B., Galuszka, D., Hare, T. M., Archinal, B. A., et al. (2003). High-resolution topomapping of candidate MER landing sites with Mars Orbiter Camera narrow-angle images. Journal of Geophysical Research, 108, 8088. https://doi. org/10.1029/2003je002131

Kirk, R. L., Howington-Kraus, E., Rosiek, M. R., Anderson, J. A., Archinal, B. A., Becker, K. J., et al. (2008). Ultrahigh resolution topographic mapping of Mars with MRO HiRISE stereo images: Meter-scale slopes of candidate Phoenix landing sites. Journal of Geophysical Research, 113, E00A24. https://doi.org/10.1029/2007JE003000

Kite, E. S., Howard, A. D., Lucas, A. S., Armstrong, J. C., Aharonson, O., \& Lamb, M. P. (2015). Stratigraphy of Aeolis Dorsa, Mars: Stratigraphic context of the great river deposits. Icarus, 253, 223-242. https://doi.org/10.1016/j.icarus.2015.03.007 
Kocurek, G. (1981). Significance of interdune deposits and bounding surfaces in aeolian dune sands. Sedimentology, 28(6), 753-780. https:// doi.org/10.1111/j.1365-3091.1981.tb01941.x

Kocurek, G., \& Hunter, R. E. (1986). Origin of polygonal fractures in sand, uppermost Navajo and Page sandstones, Page, Arizona. Journal of Sedimentary Research, 56(6). https://doi.org/10.1306/212F8A7B-2B24-11D7-8648000102C1865D

Koeppen, W. C., \& Hamilton, V. E. (2008). Global distribution, composition, and abundance of olivine on the surface of Mars from thermal infrared data. Journal of Geophysical Research, 113, E05001. https://doi.org/10.1029/2007JE002984

Lewis, K. W., \& Aharonson, O. (2006). Stratigraphic analysis of the distributary fan in Eberswalde crater using stereo imagery. Journal of Geophysical Research, 111, E06001. https://doi.org/10.1029/2005JE002558

Lewis, K. W., \& Aharonson, O. (2014). Occurrence and origin of rhythmic sedimentary rocks on Mars. Journal of Geophysical Research: Planets, 119, 1432-1457. https://doi.org/10.1002/2013JE004404

Lewis, K. W., Aharonson, O., \& Grotzinger, J. (2008). Quasi-periodic bedding in the sedimentary rock record of Mars. Science, 1532(2008). https://doi.org/10.1126/science.1161870

Lichtenberg, K. A., Arvidson, R. E., Morris, R. V., Murchie, S. L., Bishop, J. L., Fernandez Remolar, D., et al. (2010). Stratigraphy of hydrated sulfates in the sedimentary deposits of Aram Chaos, Mars. Journal of Geophysical Research, 115, E00D17. https://doi.org/10. 1029/2009JE003353

Lucchitta, B. K., Isbell, N. K., \& Howington-Kraus, A. (1994). Topography of Valles Marineris: Implications for erosional and structural history. Journal of Geophysical Research, 99(E2), 3783-3798. https://doi.org/10.1029/93JE03095

Malin, M. C., \& Edgett, K. S. (2000). Sedimentary rocks of early Mars. Science, 290(5498), 1927-1937. https://doi.org/10.1126/science.290. 5498.1927

Mangold, N., Ansan, V., Baratoux, D., Costard, F., Dupeyrat, L., Hiesinger, H., et al. (2008a). Identification of a new outflow channel on Mars in Syrtis Major Planum using HRSC/MEx data. Planetary and Space Science, 56(7), 1030-1042. https://doi.org/10.1016/j.pss.2008. 01.011

Mangold, N., Gendrin, A., Gondet, B., LeMouelic, S., Quantin, C., Ansan, V., et al. (2008b). Spectral and geological study of the sulfate-rich region of West Candor Chasma, Mars. Icarus, 194(2), 519-543. https://doi.org/10.1016/j.icarus.2007.10.021

Mangold, N., Poulet, F., Mustard, J. F., Bibring, J.-P., Gondet, B., Langevin, Y., et al. (2007). Mineralogy of the Nili Fossae region with OMEGA/Mars Express data: 2. Aqueous alteration of the crust. Journal of Geophysical Research, 112, E08S04. https://doi.org/10. 1029/2006JE002835

McCollom, T. M., Robbins, M., Moskowitz, B., Berquó, T. S., Jöns, N., \& Hynek, B. M. (2013). Experimental study of acid-sulfate alteration of basalt and implications for sulfate deposits on Mars. Journal of Geophysical Research: Planets, 118, 577-614. https://doi.org/10.1002/ jgre.20044

McEwen, A. S., Eliason, E. M., Bergstrom, J. W., Bridges, N. T., Hansen, C. J., Delamere, W. A., et al. (2007). Mars reconnaissance orbiter's high resolution imaging science experiment (HiRISE). Journal of Geophysical Research, 112, E05S02. https://doi.org/10. 1029/2005JE002605

McLennan, S., Bell, J., Calvin, W., Christensen, P., Clark, B., de Souza, P., et al. (2005). Provenance and diagenesis of the evaporite-bearing Burns formation, Meridiani Planum, Mars. Earth and Planetary Science Letters, 240(1), 95-121. https://doi.org/10.1016/j.epsl.2005.09. 041

Metz, J., Grotzinger, J., Okubo, C., \& Milliken, R. (2010). Thin-skinned deformation of sedimentary rocks in Valles Marineris, Mars. Journal of Geophysical Research, 115, E11004. https://doi.org/10.1029/2010JE003593

Michalski, J., \& Niles, P. B. (2012). Atmospheric origin of Martian interior layered deposits: Links to climate change and the global sulfur cycle. Geology, 40(5), 419-422. https://doi.org/10.1130/G32971.1

Michalski, J. R., Niles, P., Cuadros, J., \& Baldridge, A. (2013). Multiple working hypotheses for the formation of compositional stratigraphy on Mars: Insights from the Mawrth Vallis region. Icarus, 226(1), 816-840. https://doi.org/10.1016/j.icarus.2013.05.024

Michalski, J., Poulet, F., Bibring, J. P., \& Mangold, N. (2010). Analysis of phyllosilicate deposits in the Nili Fossae region of Mars: Comparison of TES and OMEGA data. Icarus, 206(1), 269-289. https://doi.org/10.1016/j.icarus.2009.09.006

Milliken, R. E., Ewing, R. C., Fischer, W. W., \& Hurowitz, J. A. (2014). Wind-blown sandstones cemented by sulfate and clay minerals in Gale Crater, Mars. Geophysical Research Letters, 41, 1149-1154. https://doi.org/10.1002/2014GL060535

Milliken, R. E., Grotzinger, J. P., \& Thomson, B. J. (2010). Paleoclimate of Mars as captured by the stratigraphic record in Gale Crater. Geophysical Research Letters, 37, L04201. https://doi.org/10.1029/2009GL041870

Mitchum, R. M., Vail, P. R., \& Thompson, S. (1977). Seismic stratigraphy and global changes of sea level, Part 2: The depositional sequence as a basic unit for stratigraphic analysis: Section 2. Application of seismic reflection configuration to stratigraphic interpretation. Seismic Stratigraphy: Applications to Hydrocarbon Exploration AAPG Memoir, 26, 53-62.

Murchie, S., Arvidson, R., Bedini, P., Beisser, K., Bibring, J.-P., Bishop, J., et al. (2007). Compact Reconnaissance Imaging Spectrometer for Mars (CRISM) on Mars Reconnaissance Orbiter (MRO). Journal of Geophysical Research, 112, E05S03. https://doi.org/10. 1029/2006JE002682

Murchie, S. L., Mustard, J. F., Ehlmann, B. L., Milliken, R. E., Bishop, J. L., McKeown, N. K., et al. (2009). A synthesis of Martian aqueous mineralogy after 1 Mars year of observations from the Mars Reconnaissance Orbiter. Journal of Geophysical Research, 114, E00D06. https://doi.org/10.1029/2009JE003342

Mustard, J. F., Ehlmann, B. L., Murchie, S. L., Poulet, F., Mangold, N., Head, J. W., et al. (2009). Composition, morphology, and stratigraphy of Noachian crust around the Isidis Basin. Journal of Geophysical Research, 114, E00D12. https://doi.org/10.1029/2009JE003349

Mustard, J. F., Poulet, F., Gendrin, A., Bibring, J. P., Langevin, Y., Gondet, B., et al. (2005). Olivine and pyroxene diversity in the crust of Mars. Science, 307(5715), 1594-1597. https://doi.org/10.1126/science.1109098

Mustard, J. F., Poulet, F., Head, J. W., Mangold, N., Bibring, J.-P., Pelkey, S. M., et al. (2007). Mineralogy of the Nili Fossae region with OMEGA/Mars Express data: 1. Ancient impact melt in the Isidis Basin and implications for the transition from the Noachian to Hesperian. Journal of Geophysical Research, 112, E08S03. https://doi.org/10.1029/2006JE002834

Nelson, E. P., Kullman, A. J., Gardner, M. H., \& Batzle, M. (1999). Fault-fracture networks and related fluid flow and sealing, brushy Canyon Formation, West Texas. In W. C. Haneberg, P. S. Mozley, J. C. Moore, \& L. B. Goodwin (Eds.), Faults and subsurface fluid flow in the shallow crust (Vol. 113, pp. 69-81). Washington, DC: American Geophysical Union.

Niles, P. B., \& Michalski, J. (2009). Meridiani Planum sediments on Mars formed through weathering in massive ice deposits. Nature Geoscience, 2(3), 215-220. https://doi.org/10.1038/ngeo438

Oehler, D. Z., \& Allen, C. C. (2012). Giant polygons and mounds in the lowlands of Mars: Signatures of an ancient ocean?Astrobiology, 12(6), 601-15. https://doi.org/10.1089/ast.2011.0803

Okubo, C. H., Lewis, K. W., McEwen, A. S., \& Kirk, R. L. (2008). Relative age of interior layered deposits in southwest Candor Chasma based on high-resolution structural mapping. Journal of Geophysical Research, 113, E12002. https://doi.org/10.1029/2008JE003181 
Okubo, C. H., \& McEwen, A. S. (2007). Fracture-controlled paleo-fluid flow in Candor Chasma, Mars. Science, 315(5814), 983-985. https:// doi.org/10.1126/science.1136855

Oliver, M. A., \& Webster, R. (1990). Kriging: A method of interpolation for geographical information systems. International Journal of Geographical Information Systems, 4(3), 313-332. https://doi.org/10.1080/02693799008941549

Papike, J., Karner, J., \& Shearer, C. (2006). Comparative planetary mineralogy: Implications of martian and terrestrial jarosite. A crystal chemical perspective. Geochimica et Cosmochimica Acta, 70(5), 1309-1321. https://doi.org/10.1016/j.gca.2005.11.004

Perron, J. T., Mitrovica, J. X., Manga, M., Matsuyama, I., \& Richards, M. A. (2007). Evidence for an ancient martian ocean in the topography of deformed shorelines. Nature, 447(7146), 840-843. https://doi.org/10.1038/nature05873

Quantin, C., Allemand, P., Mangold, N., Dromart, G., \& Delacourt, C. (2005). Fluvial and lacustrine activity on layered deposits in Melas Chasma, Valles Marineris, Mars. Journal of Geophysical Research, 110, E12S19. https://doi.org/10.1029/2005JE002440

Quinn, D. P., \& Ehlmann, B. L. (2019). A PCA-based framework for determining remotely-sensed geological surface orientations and their statistical quality. Earth and Space Sciences. https://doi.org/10.1029/2018EA000416

Ritzer, J. A., \& Hauck, S. A. (2009). Lithospheric structure and tectonics at Isidis Planitia, Mars. Icarus, 201(2), 528-539. https://doi.org/10. 1016/j.icarus.2009.01.025

Roach, L. H., Mustard, J. F., Murchie, S. L., Bibring, J. P., Forget, F., Lewis, K. W., et al. (2009). Testing evidence of recent hydration state change in sulfates on Mars. Journal of Geophysical Research, 114, E00D02. https://doi.org/10.1029/2008JE003245

Sadler, P. M. (1981). Sediment accumulation rates and the completeness of stratigraphic sections. The Journal of Geology, 89(5), 569-584. https://doi.org/10.1086/628623

Saper, L., \& Mustard, J. F. (2013). Extensive linear ridge networks in Nili Fossae and Nilosyrtis, Mars: Implications for fluid flow in the ancient crust. Geophysical Research Letters, 40, 245-249. https://doi.org/10.1002/grl.50106

Schon, S. C., Head, J. W., \& Fassett, C. I. (2012). An overfilled lacustrine system and progradational delta in Jezero crater, Mars: Implications for Noachian climate. Planetary and Space Science, 67(1), 28-45. https://doi.org/10.1016/j.pss.2012.02.003

Shorlin, K. A., De Bruyn, J. R., Graham, M., \& Morris, S. W. (2000). Development and geometry of isotropic and directional shrinkage-crack patterns, Physical Review E-Statistical Physics, Plasmas. Fluids, and Related Interdisciplinary Topics, 61(6 B), 6950-6957. https://doi.org/ 10.1103/PhysRevE.61.6950

Siebach, K. L., \& Grotzinger, J. P. (2014). Volumetric estimates of ancient water on Mount Sharp based on boxwork deposits, Gale Crater Mars. Journal of Geophysical Research: Planets, 119, 189-198. https://doi.org/10.1002/2013JE004482

Siebach, K. L., Grotzinger, J. P., Kah, L. C., Stack, K. M., Malin, M., Léveillé, R., \& Sumner, D. Y. (2014). Subaqueous shrinkage cracks in the Sheepbed mudstone: Implications for early fluid diagenesis, Gale crater, Mars. Journal of Geophysical Research: Planets, 119, 1597-1613. https://doi.org/10.1002/2014JE004623

Skok, J., \& Mustard, J. (2014). Glaciation and volcanic interaction to form the modern Northeast Syrtis region of Mars. Lunar and Planetary Science Conference, 45, 1924. https://doi.org/10.1002/jgre.20118

Skok, J., Mustard, J., \& Ehlmann, B. (2010). Silica deposits in the Nili Patera caldera on the Syrtis Major volcanic complex on Mars. Nature Geoscience, 3, 838-841.

Smalley, I. J. (1966). The properties of glacial loess and the formation of loess deposits. Journal of Sedimentary Research, 36(3), 669-676.

Soare, R. J., Conway, S. J., Gallagher, C., \& Dohm, J. M. (2017). Ice-rich (periglacial) vs icy (glacial) depressions in the Argyre region, Mars: A proposed cold-climate dichotomy of landforms. Icarus, 282, 70-83. https://doi.org/10.1016/j.icarus.2016.09.009

Soucek, O., Bourgeois, O., Pochat, S., \& Guidat, T. (2015). A 3 Ga old polythermal ice sheet in Isidis Planitia, Mars: Dynamics and thermal regime inferred from numerical modeling. Earth and Planetary Science Letters, 426, 176-190. https://doi.org/10.1016/j.epsl.2015.06.038

Squyres, S. W., Grotzinger, J. P., Arvidson, R. E., Bell, J. F., Calvin, W., Christensen, P. R., et al. (2004). In situ evidence for an ancient aqueous environment at Meridiani Planum, Mars. Science (New York N.Y.), 306(5702), 1709-14. https://doi.org/10.1126/science.1104559

Stow, D. A. V., \& Piper, D. J. W. (1984). Deep-water fine-grained sediments: Facies models. Geological Society, London Special Publications, 15(1), 611-646. https://doi.org/10.1144/GSL.SP.1984.015.01.38

Stuart, C. J., \& Caughey, C. A. (1977). Seismic facies and sedimentology of terrigenous Pleistocene deposits in northwest and central Gulf of Mexico. AAPG Memoir, 26, 249-275.

Tewksbury, B. J., Hogan, J. P., Kattenhorn, S. A., Mehrtens, C. J., \& Tarabees, E. A. (2014). Polygonal faults in chalk: Insights from extensive exposures of the Khoman Formation, Western Desert, Egypt. Geology, 42, 479-483. https://doi.org/10.1130/G35362.1

Viviano-Beck, C. E., Seelos, F. P., Murchie, S. L., Kahn, E. G., Seelos, K. D., Taylor, H. W., et al. (2014). Revised CRISM spectral parameters and summary products based on the currently detected mineral diversity on Mars. Journal of Geophysical Research: Planets, 119 , 1403-1431. https://doi.org/10.1002/2014JE004627

Warner, N. H., Sowe, M., Gupta, S., Dumke, A., \& Goddard, K. (2013). Fill and spill of giant lakes in the eastern Valles Marineris region of Mars. Geology, 41(6), 675-678. https://doi.org/10.1130/G34172.1

Weitz, C. M., Milliken, R. E., Grant, J. A., McEwen, A. S., Williams, R. M. E., \& Bishop, J. L. (2008). Light-toned strata and inverted channels adjacent to Juventae and Ganges chasmata, Mars. Geophysical Research Letters, 35, L19202. https://doi.org/10.1029/2008GL035317

Werner, S. C. (2008). The early martian evolution-Constraints from basin formation ages. Icarus, 195(1), 45-60. https://doi.org/10.1016/j. icarus.2007.12.008

Wichman, R., \& Schultz, P. (1989). Sequence and mechanisms of deformation around the Hellas and Isidis impact basins on Mars. Journal of Geophysical Research, 94(B12), 17,133-17,357.

Wiseman, S. M., Arvidson, R. E., Morris, R. V., Poulet, F., Andrews-Hanna, J. C., Bishop, J. L., et al. (2010). Spectral and stratigraphic mapping of hydrated sulfate and phyllosilicate-bearing deposits in northern Sinus Meridiani, Mars. Journal of Geophysical Research, 115 , E00D18. https://doi.org/10.1029/2009JE003354

Zabrusky, K., Andrews-Hanna, J. C., \& Wiseman, S. M. (2012). Reconstructing the distribution and depositional history of the sedimentary deposits of Arabia Terra, Mars. Icarus, 220(2), 311-330. https://doi.org/10.1016/j.icarus.2012.05.007 